\title{
FLI1 and FRA1 transcription factors drive the transcriptional regulatory networks characterizing muscle invasive bladder cancer
}

Perihan Yagmur Guneri-Sozeri ${ }^{1,2}$, Gulden Ozden Yilmaz ${ }^{1}$, Asli Kisim ${ }^{3}$, Aleyna Eray ${ }^{1,2}$, Hamdiye Uzuner ${ }^{1,2}$, Gökhan Karakülah ${ }^{1,2}$, Devrim Pesen Okvur ${ }^{3}$, Serif Senturk ${ }^{1,2}$, Serap Erkek-Ozhan $^{1}$

${ }^{1}$ Izmir Biomedicine and Genome Center, Inciralti 35340, Izmir, Turkey

2 Dokuz Eylül University Izmir International Biomedicine and Genome Institute, Inciralti 35340, Izmir, Turkey

${ }^{3}$ Izmir Institute of Technology, Urla, 35430, Izmir, Turkey

Manuscript correspondence:

Serap Erkek Özhan

Research Group Leader

(Epi)genomics of Cancer Group

Izmir Biomedicine and Genome Center

Dokuz Eylül University Health Campus

Mithatpaşa Caddesi No: 58/5

35330 Balçova, İzmir, Turkey

Phone: +90(232) 2994167

E-mail: serap.erkek@ibg.edu.tr

\section{SUMMARY}

Bladder cancer is mostly present in the form of urothelium carcinoma, causing over 150.000 deaths each year. Its histopathological classification as muscle invasive (MIBC) and nonmuscle invasive (NMIBC) is the most prominent aspect, affecting the prognosis and progression of this disease. In this study, we defined the active regulatory landscape of MIBC and NMIBC cell lines using H3K27ac-seq and used an integrative data approach to combine our findings with existing data. Our analysis revealed FRA1 and FLI1 as the two critical transcription factors differentially regulating MIBC regulatory landscape. Importantly, we show that FRA1 and FLI1 regulate the genes involved in epithelial cell migration and cell junction organization. Knock-down of FRA1 and FLI1 in MIBC revealed the downregulation of several EMT-related genes such as MAP4K4 and FLOT1. Further, ChIP-SICAP performed for FRA1 and FLI1 enabled us to infer chromatin binding partners of these two transcription factors and link this information with their target genes, providing a comprehensive regulatory circuit for the genes implicated in invasive ability of the bladder cancer cells. Finally, for the first time we show that knock-down of FRA1 and FRA1-FLI1 double knock-down results in significant reduction of invasion capacity of MIBC cells towards muscle microenvironment using IC-CHIP assays. Our results collectively highlight the role of these two transcription factors in invasive characteristics of bladder cancer in selection and design of targeted options for treatment of MIBC. 
Keywords: Bladder cancer, enhancer, FRA1, FLI1, transcriptional regulation

\section{INTRODUCTION}

Bladder cancer arising with $90 \%$ frequency from urothelium affected more than 500.000 people in 2020 (Sung et al., 2021). According to its histopathological state, bladder cancer is classified as non-muscle invasive bladder cancer (NMIBC) and muscle invasive bladder cancer (MIBC). NMIBC constitute the great majority of the bladder cancers (80\%) and consist of the tumors with the stages Ta and T1 while the remaining MIBC includes the tumors with the stages T2-T4 (Sanli et al., 2017). TURBT and BCG options are among the first line treatment choices for NMIBC. On the other hand, MIBC cases are required to have radical cystectomy and chemotherapy and radiotherapy (International Collaboration of et al., 2011; Sonpavde et al., 2009). Although NMIBC has a better prognosis compared to MIBC, NMIBC patients need a costly long-term follow-up and can develop into MIBC with $20 \%$ frequency (van den Bosch and Alfred Witjes, 2011). Recent studies mainly driven by the TCGA consortium has characterized the mutational landscape and annotated molecular subgroups of both NMIBC (Hurst et al., 2017; Lindskrog et al., 2021) and MIBC (Cancer Genome Atlas Research, 2014; Kamoun et al., 2020; Robertson et al., 2017). One major finding from these molecular studies was the exceptionally high rate of chromatin modifier mutations both in NMIBC and MIBC. It was identified that almost $80 \%$ of the bladder cancer patients had mutations in the genes involved in chromatin regulation ( $\mathrm{Li}$ et al., 2016). This finding definitely points out to the epigenetic deregulation and defects in regulation of the gene expression in this disease. Thus, a molecular understanding of the chromatin level regulation is essential. During the last decade, mainly the studies driven by ENCODE and Roadmap consortiums revealed the chromatin and regulatory landscapes of diverse normal and cancer cell lines, and normal tissues (Consortium et al., 2020; Grubert et al., 2020; Thurman et al., 2012; Zhang and Mahony, 2019), providing important clues about the regulatory networks characterizing these cell lines and tissues. Identification of the regulatory landscapes of tumorigenic samples has been started to get great attention, given the potential applicability of the knowledge arising with these kind of studies. Especially, characterization of the active enhancer elements in pediatric brain tumors has proven very useful, resulting in identification of the transcription factors and cell of origin differentially involved in molecular subtypes of these tumors (Erkek et al., 2019; Lin et al., 2016).

There are several studies which analyzed the expression pattern of certain genes in NMIBC and MIBC, potentially involved in proliferative and invasive properties of bladder cancer cell lines. STAG2 expression has been identified to be a prognostic marker for NMIBC progression (Lelo et al., 2018). In addition, one study suggested a higher rate of progression of T1 stage NMIBC patients with high CDKN2A expression and low FGFR3 expression (Breyer et al., 2018). Another study implicated the prognostic value of high ERBB2 expression in progression of NMIBC (Breyer et al., 2017). It was also shown that determining the expression pattern of FASN, Her2/neu, and E2F1 might be important for the correct treatment of NMIBC cases (Abdelrahman et al., 2019). High expression of TGFBI has been determined to be involved in proliferative and invasive characteristics of bladder cancer cells (Zou et al., 2019). However, there is not yet a study uncovering the regulatory networks differentially characterizing NMIBC and MIBC, which could explain the global molecular mechanisms involved in muscle invasive status of bladder cancer. In this study, we define the active enhancer landscapes of NMIBC and MIBC using H3K27ac ChIP-seq we generated in two NMIBC cell lines, RT4 and RT112 (Hepburn et al., 2012) and four MIBC cell 
lines, T24, J82, HT1376 and 5637 (Jian et al., 2008; Park et al., 2019; Ramakrishnan et al., 2018). H3K27ac is a definite marker of active regulatory landscapes previously used in many other studies (Creyghton et al., 2010). We determined the differentially regulated enhancers between NMIBC and MIBC, integrated the ChIP-seq data with RNA-seq, known geneenhancer target information and chromatin proteomic assays, and validated our results by functional assays. Our results show that FRA1 and FLI1 are the two transcription factors mainly governing the transcriptional regulatory network of MIBC in interaction with SWI/SNF remodeling complex, and their depletion downregulates the genes involved in epithelial cell migration and decreases the invasion ability of MIBC cell lines.

\section{EXPERIMENTAL MODEL AND SUBJECT DETAILS}

\section{Cell Lines}

T24, J82, HT1376, 5637, RT4 and RT112 bladder cancer cell lines were used in this study. J82 and RT4 cell lines were kindly provided by Şerif Şentürk and T24 cell line was provided by Neşe Atabey. Other cell lines HT1376, RT112 and 5637 were purchased from DSMZ (German Collection of Microorganisms and Cell Lines). T24, J82, RT4 and HT1376 cell lines were grown with Dubacco's Modified Eagle Medium (Gibco) in the presence of $10 \%$ Fetal Bovine Serum and 1\% Penicillin supplements. Other cell lines, RT112 and 5637 were grown in Roswell Park Memorial Institute (RPMI) 1640 Medium (Gibco) supplied with 10\% Fetal Bovine Serum and 1\% Penicillin. C2C12 myoblast cells were kindly provided by Mehmet Öztürk. Muscle differentiation of $\mathrm{C} 2 \mathrm{C} 12$ cells was achieved using $10 \%$ horse serum (Gibco, 26050070) for 5 days.

\section{METHOD DETAILS}

\section{Chromatin Immunoprecipitation (ChIP)}

Chromatin immunoprecipitation (ChIP) experiments were performed with nearly 15 million cells per ChIP. Modified version of the protocol from Weber et al., 2007 (Weber et al., 2007) was followed in all experiments that were performed for each cell line separately. For H3K27ac ChIPs, cells were cross-linked with $1 \%$ formaldehyde for $10 \mathrm{~min}$ at room temperature, followed by $2.5 \mathrm{M}$ Glycine treatment at $+4{ }^{\circ} \mathrm{C}$ for 10 minutes to stop the crosslinking. Then, cells were washed and lysed with Lysis Buffer in the presence of $1 \mathrm{X}$ Protease Inhibitor Cocktail (Roche,11873580001). Chromatin was fragmented into small pieces (200-500 bp) using S220 Covaris Ultrasound Sonicator. After sonication of the chromatin samples, $50 \mu \mathrm{l}$ was taken for input fraction and the rest is used for IP. $4 \mu \mathrm{g}$ H3K27ac antibody (Active Motif, 39133) was coupled to $40 \mu$ l Dynabeads M280 Anti Rabbit Magnetic beads (Thermo Fisher, 11204D) (pre-washed with BSA) via rotating overnight at $+4^{\circ} \mathrm{C}$. Next day, chromatin was bound with pre-washed magnetic beads coupled with H3K27ac antibody for 3 hours. Then, stringent washes were done using a freshly prepared DOC buffer, Lysis buffer and TE. Immunoprecipitated chromatin was eluted by resuspending the beads in a freshly prepared $100 \mu$ l elution buffer by agitating the sample at $1000 \mathrm{rpm}$ at $25{ }^{\circ} \mathrm{C}$ for 15 minutes, centrifuging the sample at $11000 \mathrm{rpm}$ for 2 minutes at room temperature. Elution step was repeated once more. For transcription factor ChIPs, a slightly more stringent protocol was applied. Different from the H3K27ac ChIPs, cells were crosslinked with $1.25 \%$ formaldehyde at RT for 15 minutes and magnetic bead blocking was done using $60 \mu \mathrm{l}$ magnetic beads in the presence of $10 \mu \mathrm{l}$ tRNA $(10 \mathrm{mg} / \mathrm{mL})$ and $10 \mu \mathrm{l} \mathrm{BSA} \mathrm{(10}$ $\mathrm{mg} / \mathrm{mL}$ ), rotating for 2 hours at $+4{ }^{\circ} \mathrm{C}$. Chromatin was precleared by addition of $10 \mu \mathrm{l}$ preblocked magnetic beads and rotating the sample at $+4{ }^{\circ} \mathrm{C}$ for 1 hour. After chromatin preclearing, antibodies targeting transcription factors were added to the chromatin sample in determined concentrations (see Antibodies part of methods) and the sample was rotated 
bioRxiv preprint doi: https://doi.org/10.1101/2021.11.22.468946; this version posted November 23, 2021. The copyright holder for this preprint (which was not certified by peer review) is the author/funder. All rights reserved. No reuse allowed without permission.

overnight at $+4{ }^{\circ} \mathrm{C}$. Following day, antibody-bound chromatin was coupled with $50 \mu \mathrm{l}$ preblocked magnetic beads by rotating at $+4{ }^{\circ} \mathrm{C}$ for 3 hours. All other steps were performed in the same manner as in H3K27ac ChIPs.

For elution of DNA from the input and IP fractions, sample volumes were brought to $200 \mu$ by addition of TE buffer, and $4 \mu \mathrm{l}$ RNAse $(10 \mathrm{mg} / \mathrm{mL})$ was added and the sample was incubated for 30 minutes at $37{ }^{\circ} \mathrm{C}$. Then, $1 \%$ SDS, $100 \mathrm{mM} \mathrm{NaCl}$ and $200 \mu \mathrm{g} / \mathrm{ml}$ Proteinase $\mathrm{K}$ were added at final concentrations and the sample was incubated at $55{ }^{\circ} \mathrm{C}$ for at least 2.5 hours then overnight at $65^{\circ} \mathrm{C}$. Zymo DNA clean-up \& concentrator kit was used to purify the DNA.

\section{ChIP-SICAP}

ChIP-SICAP protocol developed by Rafiee et al., 2016 was utilized (Rafiee et al., 2016). For the ChIP part of the protocol, T24 cell line was cross-linked with $1.5 \%$ final concentration of formaldehyde for $15 \mathrm{~min}$ and followed by addition of $150 \mathrm{mM}$ Glycine for 5 minutes, continuously shaking at RT. After a couple of washing and lysing steps, protein concentrations were measured in the presence of $1 \%$ PBS-SDS. Standard proteins were treated the same except Benzonase addition. Then samples were incubated at $95{ }^{\circ} \mathrm{C}$ for 5 minutes. Then T24 chromatin's DNA and proteins were separated by adding $0.5 \mu \mathrm{l}$ Benzonase (Sigma Aldrich, E8263-5KU) and vortexing. $25 \mu \mathrm{l}$ from prepared samples were added to one well of 96 well plate and Pierce ${ }^{\mathrm{TM}}$ BCA Protein Assay Kit (Thermo Fisher Scientific, 23225) manual was followed to measure the protein content. Overall, for each replicate, chromatin samples corresponding to nearly $2 \mu \mathrm{g}$ protein were used for ChIP assays performed for FRA1 and FLI1 transcription factors. Each chromatin sample was sonicated for 19 cycles, 1 minute on/1 minute off on Covaris S220. Input DNA of each sample was controlled for sonication size. After sonication, the samples were centrifuged for 10 minutes at $12000 \mathrm{~g}$ at $+4{ }^{\circ} \mathrm{C}$. TritonX-100 was added to the supernatants with a final concentration of $1.5 \%$. Then FLI1 (1:50) and FRA1 (1:50) antibodies were added to the samples and antibodies were coupled with chromatin samples overnight at +4 cold room with $800 \mathrm{rpm}$ agitation on Thermomixer. Chromatin samples not bound with antibody were used as negative controls. Next day, the samples were centrifuged at $+4{ }^{\circ} \mathrm{C}$ for 10 minutes at $12000 \mathrm{~g}$. Supernatants were taken and filled up to $1 \mathrm{~mL}$ with IP Buffer (Rafiee et al., 2016). Meanwhile, $50 \mu$ l Dynabeads (M280 Anti Rabbit Magnetic Beads) for each sample were washed with IP Buffer $\left(+4{ }^{\circ} \mathrm{C}\right)$ once. Pre-washed magnetic beads were then added to the samples and coupled at $+4{ }^{\circ} \mathrm{C}$ for 3 hours by rotating. Then samples were washed and resuspended with $200 \mu$ PBS-T (PBS including $0.1 \%$ Tween 20 ) and shipped to Francis Crick Institute for the SICAP part of the protocol. After the chromatin immunoprecipitation, the chromatin fragments were kept bound to the protein $A / G$ beads on dry ice until they were treated using the ChIP-SICAP procedure. ChIP-SICAP was performed as already described in (Rafiee et al., 2016; Rafiee et al., 2020). Briefly, the beads were treated with Klenow 3'exo minus, T4 PNK, and dNTPs (NEB) to make 3'-overhangs and remove 3'-phosphates. Then, the beads were treated with terminal deoxynucleotidyl transferase (TdT) and biotinylated nucleotides (ddUTP and dCTP 1:1). The beads were then washed 6 times with IP buffer (Tris- $\mathrm{HCl}$ pH $7.550 \mathrm{mM}$, Triton X-100 1\%, NP-40 0.5\%, EDTA $5 \mathrm{mM}$ ). The isolated proteins were eluted using elution buffer (SDS 7.5\%, DTT $200 \mathrm{mM}$ ) by incubating at $37{ }^{\circ} \mathrm{C}$ for $15 \mathrm{~min}$. Eluted samples were diluted in IP buffer. Then $100 \mu \mathrm{L}$ of either prS beads were added for the DNA enrichment. Streptavidin beads were washed 3 times with SDS washing buffer (Tris-HCl $10 \mathrm{mM} \mathrm{pH}$ 8, SDS 1\%, NaCl $200 \mathrm{mM}$, EDTA 1mM), once with BW2x buffer (Tris- $\mathrm{HCl} \mathrm{pH} 810 \mathrm{mM}$, Triton X-100 0.1\%, NaCl 2M, EDTA $1 \mathrm{mM}$ ), once with iso-propanol $20 \%$ in water and three times with acetonitrile $40 \%$ in water. The beads were transferred to PCR tubes using acetonitrile $40 \%$. The beads separated on the magnet, and the supernatant was removed. Then the beads were resuspended in $15 \mu \mathrm{l}$ Ambic $50 \mathrm{mM}$ plus DTT $10 \mathrm{mM}$ final concentration. Then the samples were incubated at $50{ }^{\circ} \mathrm{C}$ for $15 \mathrm{~min}$ to reduce the disulphide bonds. The cysteines were then alkylated with IAA $20 \mathrm{mM}$ final concentration for 15 min in dark. IAA was neutralized by adding DTT $10 \mathrm{mM}$ final concentration. To digest the 
proteins, $300 \mathrm{ng}$ LysC (Wako) was added to each sample. After an overnight incubation, the supernatant was transferred to a new PCR tube. Then $200 \mathrm{ng}$ Trypsin was added to each tube. The digestion continued for 6-8 hours. Finally, the peptides were cleaned up using Ziptips with $0.6 \mu \mathrm{C}_{18}$ resin (Merck). The samples were injected to an Orbitrap Fusion Lumos, working on data dependent acquisition mode.

\section{Antibodies}

ChIP experiments were carried out with $5 \mu \mathrm{g} \mathrm{H3K27ac} \mathrm{antibody} \mathrm{(Active} \mathrm{Motif,} \mathrm{\# 39133),} \mathrm{1:100}$ diluted FRA1 antibody (Cell Signaling Technology, \#5281) and 1:100 diluted FLI1 antibody (Abcam, \#ab15289). For ChIP-SICAP, FLI1 and FRA1 antibodies were used with 1:50 dilution. For Western Blotting, FRA1 and FLI1 antibodies were used with 1:1000 dilution. Bactin primary antibody (Cell Signaling Technology, 3700) was used as reference protein with a 1:1000 dilution. Anti-Rabbit Secondary Antibody in 1:30000 dilution and Anti-Mouse Secondary Antibody (Cell Signaling Technology, 5151; Li-Cor, 926-68020, respectively) were used in 1:15000 dilution during Western Blotting experiments.

\section{Western Blotting}

48 hours and 72 hours after knockdown, cells were collected with $200 \mu$ RIPA + PIC (1X) Buffer. Samples were vigorously vortexed in every 10 minutes up to 30 minutes. Then the samples were sonicated for 5 cycles (30 seconds on/ 30 seconds off) to efficiently get the proteins in the nucleus, too. After sonication, the samples centrifuged for 20 minutes at $+4{ }^{\circ} \mathrm{C}$ at full speed. We stored the supernatant of the samples at $-80^{\circ} \mathrm{C}$. Protein amounts were measured according to the Pierce ${ }^{\mathrm{TM}}$ BCA Protein Assay Kit (Thermo Fisher Scientific, 23225)'s protocol. Then, the proteins were diluted with Laemmli Buffer and RIPA Buffer (1X) to equal protein concentrations of the samples and boiled at $95{ }^{\circ} \mathrm{C}$ for 5 minutes. $30 \mu \mathrm{g}$ proteins were loaded into \%8 separating gel. Bio-RAD Western Blot System (1658029) was used to perform Western Blotting. Samples were first run at 90 Volt (V) for 20 minutes until the proteins passed into separating gel and then ran at $120 \mathrm{~V}$ for 1 and a half hours. Samples were then transferred to nitrocellulose membrane at $350 \mathrm{~mA}$ for 1.5 hours. After transferring the proteins to the membrane, membrane was blocked with $5 \%$ milk powder dissolved in TBS-T for 1 hour on a shaker at RT, followed by the antibody binding overnight at $+4{ }^{\circ} \mathrm{C}$ on a shaker. The next day membranes were washed with TBS-T for 10 minutes 3 times on a shaker at RT. Then, secondary antibody was bound to primary antibody on the membrane for 1 hour at RT on a shaker, which was followed by washing with TBS-T three times again. Membranes were imaged using Li-COR ODYSSEY Clx device.

\section{RT-qPCR}

RT-qPCR experiments were performed to analyze the changes in gene expressions after control siRNA, FLI1, FRA1 knockdown or FLI1 and FRA1 knockdown together. 48 hours and 72 hours post-transfection of siRNAs, RNA from the cells were collected using $\mathrm{MN}$ Nucleospin RNA Isolation Kit (740955.50) according to kit's instructions. Elution volume was $40 \mu \mathrm{l}$ for each sample. Collection of RNA was followed by cDNA conversion using $1 \mu \mathrm{g}$ RNA for each reaction with the Maxima First Strand cDNA Synthesis Kit (Thermo Scientific, K1642). Expression of the genes were determined using FastStart Essential DNA Green Master Kit (ROCHE, catalog no: 06402712001). cDNA converted from RNA was used as 1:5 dilution (in ultra-pure water) per reaction. Quantitative PCR reaction was held on Applied Biosystems 7500 Fast Real Time PCR Device according to the manufacturer's instructions. Relative expression of the target genes were calculated using the $2^{\wedge} \Delta \Delta C T$ Method (Livak and Schmittgen, 2001). For each biological replicate, RT-qPCR experiments were done in three technical replicates and mean expression values for the two biological replicates values were plotted. Plots representing relative expression changes were drawn at GRAPHPAD 
version 8.3.0 (Unpaired parametric t test was performed using GraphPad Prism version 8.3.0. for Windows).

\section{Primer Design}

All primers were designed using NCBI Primer Blast Tool (Ye et al., 2012). Sequences of the primers are listed in Table S7.

\section{Knockdown Experiments}

Custom siRNAs targeting 5'-CACCAUGAGUGGCAGUCAG-3' (Vial et al., 2003) for FRA1 and 5'-GUUCACUGCUGGCCUAUAA-3' (Tsai et al., 2017) for FLI1 were ordered from GE Healthcare Dharmacon, Inc. As negative control, MISSION ${ }^{\circledR}$ siRNA Universal Negative Controls SIC001 was used (MERCK). In each knockdown assay, siRNAs were transfected using Thermo Fisher Lipofectamine 3000 Transfection Reagent (Catalog Number: L3000001) according to transfection reagent's protocol. $75 \mathrm{nM}$ siRNA was transfected to T24 cells $(65 \%$ confluent) for FLI1 and FLI1 unique knockdowns and $50 \mathrm{nM}$ siRNAs targeting FLI1 and FRA1 were used for co-knockdown of FLI1 and FRA1. T24 cells were incubated in transfection medium for 24 hours. Then, the transfection medium was removed and transfected cells were passaged further to be collected for RNA and protein isolation.

\section{Invasion assay - IC-Chip Design and Analysis}

We used IC-CHIP (INITIO Cell Biyoteknoloji) to test the muscle invasion capacity of T24 cell line for control siRNA, FLI1 siRNA, FRA1 siRNA and co-knockdown of FLI1 and FRA1. T24 cells in all conditions were marked using cell tracker, CellTracker ${ }^{\mathrm{TM}}$ Green CMFDA (C2925). Differentiated $\mathrm{C} 2 \mathrm{C} 12$ myoblast cell line was used to mimic "muscle microenvironment". C2C12 cell line differentiation condition was set up by supplementing the C2C12 cells with $10 \%$ Horse Serum (Sigma Aldrich, H1138-100ML) rather than FBS for 5 days. One day before setting up the invasion assays, T24 cells were labeled using $5 \mu \mathrm{M}$ Green CellTracker (Thermofisher) according to manufacturer's instructions. Knockdown experiments were done as mentioned above. Growth Factor Reduced Matrigel (Corning, 354230) (1:1 diluted with FBS free medium) was added to the middle channel of the IC-CHIP to set positive and negative controls' middle channel environment and Growth Factor Reduced Matrigel (1:1 diluted with differentiated $\mathrm{C} 2 \mathrm{C} 12$ cells at 1 million cells/ $1 \mathrm{~mL}$ in FBS free medium) was added to the middle channel to monitor "invasion to muscle" (Please see Figure 7A for the setup). Afterwards, IC-CHIPs were incubated at $37^{\circ} \mathrm{C}$ for 30 minutes. Then bottom channels of the IC-CHIPs for positive and negative controls were loaded with FBS(+) medium and FBS(-) medium, respectively. Upper channels were loaded with T24 cells at 1 million/cells in FBS(-) medium for positive and negative control conditions. For the "invasion to muscle" setup, T24 cells for each condition (control siRNA, FRA1 siRNA, FLI1 siRNA, FLI1 + FRA1 siRNA) were loaded to the upper channel of IC-CHIPs in FBS(-) medium after overnight incubation of the IC-chips containing the muscle microenvironment and FBS(-) medium in upper and lower channels. IC-CHIPs were observed for 3 days (day 0, 1 and 2) post-loading of the T24 cells. Images were acquired for each day with a 10X objective using a confocal microscope (Zeiss) and analyzed using Image J.(Schneider et al., 2012) The quantification of images was performed by Python programming and R Studio as previously described (Ilhan et al., 2020). The invasion capacity of the cells was determined through normalization of datasets to day 0 (Firatligil-Yildirir et al., 2021).

\section{Next Generation Sequencing}

ChIP library preparation and sequencing were performed at the GeneCore unit of EMBL. Sequencing libraries were sequenced on the Hiseq2500 platform using single end 50 bp reads for H3K27ac ChIP and input samples. Transcription factor ChIP and input libraries 
(FRA1 and FLI1) were sequenced on NextSeq 500 high output mode using 75 bp single end reads.

\section{QUANTIFICATION AND STATISTICAL ANALYSIS}

\section{Alignment and Processing of NGS Data}

Next generation data was aligned to the GRHg38 version of the human genome using Burrows Wheeler Aligner (BWA) version 0.7.17-r1188 with default parameters (Li and Durbin, 2009). Quality of the alignments was confirmed using Homer NGS Data Quality Control Analysis tool version 4.10.3. (makeTagDirectory command) (Heinz et al., 2010).

\section{Gene Annotation}

GENCODE Comprehensive Gene Annotation v30 is used to annotate the genes (Frankish et al., 2019).

\section{Peak Finding}

Macs2 peak finding algorithm (Zhang et al., 2008) was used with -broad option to call the peaks from H3K27ac ChIP-Seq data. Afterwards, the peaks which are completely located in promoter regions (+/- $1 \mathrm{~kb}$ surrounding transcriptional start sites) of protein coding genes (according to the GENCODE v30 Comprehensive Gene Annotation data, https://www.gencodegenes.org/human/release_30.html) were excluded for any further analysis.

FRA1 and FLI1 transcription factor peak finding was performed using Homer findPeaks command with the - style factor option.

\section{Finding MIBC/NMIBC Specific Enhancer Regions}

DiffBind Bioconductor package with default parameters was used to identify group specific enriched (muscle-invasive bladder cancer specific or non-muscle invasive bladder cancer specific) enhancer (Ross-Innes et al., 2012; Stark and Brown, 2011). 4 cell lines in MIBC and 2 cell lines in NMIBC are used as replicates of each group. Using FDR cut-off $=<0.05$, we identified 295 number NMIBC-specific and 1404 number MIBC-specific enhancers.

\section{Snapshot Visualization of ChIP-seq Signal}

Aligned H3K27ac, FLI1 and FRA1 ChIP-seq reads were RPKM normalized using deepTools' "bamCovarage" function with "normalizeUsing RPKM" parameter (Ramirez et al., 2016). After normalization, we visualized the ChIP-Seq reads using GViz Bioconductor package (Hahne, 2016). We used "horizon" type visualization of the reads by adjusting the horizon scale to 50 in Figure 2 and 25 in Figure 4. GENCODE hg38 Comprehensive Gene Annotation Version 30 data was defined as the "GeneRegionTrack" for the annotation of the genes at the region of interest. Transcripts on those regions were shown in collapsed form using "collapseTranscripts" parameter.

\section{Identification of The Expressed Genes in NMIBC and MIBC Cell Lines}

We downloaded the gene expression data (rpkm values) from Cancer Cell Line Encyclopedia (Barretina et al., 2012) for the NMIBC and MIBC cell lines. To determine a cut-off for the 
gene expression values, we first calculated the average gene expression values in NMIBC or MIBC and then we used the R package Mclust (Scrucca et al., 2016) to set a cut-off for gene expression in NMIBC or MIBC cell lines. We took all the gene expression values for proteincoding genes provided in the CCLE database, and removed the genes with expression values ' 0 ' rpkm. Then using " $G=3$ " option and $p$-value $<0.05$ in Mclust library, we divided the gene expression values (log2(RPKM)) into "expressed" (Group 2 and 3) and "not expressed" (Group 1) (Supplementary Figure 1). Accordingly, RPKM value of expression cut-off for NMIBC is determined as -0.77 while it is 0.98 for MIBC on log2 scale. These processes resulted in identification of 11681 and 10131 numbers of genes being expressed in NMIBC and MIBC cell lines, respectively.

\section{Processing of NMIBC and MIBC Patient Gene Expression Data}

306 Urothelial Carcinoma samples' gene expression data was obtained from GSE32894 Accession Code (Sjodahl et al., 2012). Non-normalized gene expression data was normalized by using "normalizeQuantiles" function in Limma Bioconductor Package (Ritchie et al., 2015). Tumour samples having the stage $<$ T2 are defined as a member of NMIBC group while remaining ones ( $>=$ T2) are defined as in MIBC group. Expression boxplots of each group specific transcription factor were drawn by "ggplot2" package function "ggplot" (Wickham, 2016). To add the significance scores, "ggsignif" package was used by using basic Student's t test for statistical analysis (Ahlmann-Eltze, 2021).

\section{Identification of The Genes Regulated by Group Specific Enhancer Regions}

Group specific enhancer regions (FDR $=<0.05$ ) were given as a query to UCSC (https://genome.ucsc.edu/cgi-bin/hgTables) geneHancer algorithm to get the predictions of the genes regulated by these enhancers (29). GeneHancer Interactions (GH Interactions) table format was chosen as output. Use of the gene-enhancer interaction data provided in GeneHancer database resulted in identification of 3306 and 9269 target genes for NMIBC and MIBC specific enhancers, respectively. However, as all these genes would not be relevant for NMIBC and MIBC cell lines, we filtered out the genes which were not expressed in NMIBC or MIBC and from those kept the protein coding ones. After this filtering step, 456 target genes for NMIBC-specific enhancers and 1752 target genes for MIBC-specific enhancers were identified.

\section{Transcription Factor Motif Binding Analysis On Respective Regions Including Group Specific Peaks}

Tag Directories which were established by using HOMER algorithm's "makeTagDirectory" command were combined for NMIBC and MIBC separately. Then, nucleosome free regions in these combined tag directories were found using HOMER algorithm's findPeaks command with -nfr option. Resulting NMIBC or MIBC specific NFRs were overlapped with the respective group specific enhancers. Afterwards, transcription motif finding was performed on the overlapping NFR regions using findMotifsGenome.pl command of Homer algorithm (Heinz et al., 2010).

\section{Overlap of MIBC-specific and NMIBC-specific Enhancers with TF Peaks}

Overlaps between FLI1 and FRA1 peaks and MIBC or NMIBC-specific enhancers were using -findOverlaps function with -type within parameter using GenomicRanges package (Lawrence et al., 2013). Output results were visualized as barplots (Figure 4A).

Identifying The Target Genes of FRA1 and FLI1 Transcription Factors On MIBCspecific Enhancer Regions 
Group-specific enhancer regions targeting a gene (456 target genes for NMIBC-specific enhancers and 1752 target genes for MIBC-specific enhancers) were overlapped with the FRA1 and FLI1 peaks. In this way FLI1 and FRA1 peaks were linked with the target genes. As a result, 854 genes were found to be regulated by FRA1 on MIBC-specific enhancers yet 201 genes were identified as FLI1 targets. Gephi Software (version 0.9.2) (Bastian, 2009) was used to visualize the transcription factors - target gene networks for the genes involved in epithelial cell migration, cell junction organization and epithelial cell proliferation related terms (Figure 4B).

\section{Pathway Enrichment Analysis}

Pathway enrichment analysis was done using the protein coding ones (according to the GENCODE v30 Comprehensive Gene Annotation data, https://www.gencodegenes.org/human/release_30.html). To analyze the Gene Ontology Terms related with the target genes, they were converted to Entrez gene IDs at first. 1606 genes out of 1752 MIBC target genes and 403 out of 456 NMIBC target genes can be converted to Entrez gene IDs by using mapIDs() function of org.Hs.eg.db package version 3.8.2 (Carlson, 2019). Final set of target genes of NMIBC was analyzed by using clusterProfiler package (version 3.12.10) enrichGO() function, setting maxGSsize (maximum gene ontology set size) parameter to 3000 and selecting $p$ adjust method as FDR (Yu et al., 2012). On the other hand, the finalized set of the target genes of MIBC group was analyzed by using the same package and function by using default maxGSsize which is 500 and with the same $p$ adjust method. We represented the results of the Gene Ontology term analysis by using the dotplot() function in the clusterProfiler package.

\section{Analysis of MAP4K4 Expression Data in Primary Tumors}

Scatter plots showing the correlation between the expression of MAP4K4 and FRA1 and FLI1 (Figure S7A-S7B) were generated using the gene expression data available for TCGA 2017 ( $n=408$ ) cohort at cBioPortal database (Cerami et al., 2012) and the tab 'Plots'. For the metastatic site distribution plots (Figure S7C-S7D), patients with high MAP4K4 expression were determined using the option 'mRNA expression z-scores relative to diploid samples (RNA Seq V2 RSEM)', and resulting clinical data was inspected for the metastatic site distribution. (TCGA 2017 group $(n=408)$ has MAP4K4 mRNA altered group $(n=15)$ and MAP4K4 mRNA unaltered group $(n=393)$. On the other hand, TCGA 2014 group has 131 samples, 5 of them is MAP4K4 mRNA altered and the rest $(n=126)$ is unaltered.)

\section{Analysis of ChIP-SICAP Data}

Peptides were injected into Orbitrap Fusion Lumos LC - MS/MS Device working on data dependent acquisition mode. Mass spectrometry raw data were processed with MaxQuant (1.6.2.6) (Cox and Mann, 2008) using default settings. MSMS spectra were searched against the Uniprot databases (Human Swissprot) combined with a database containing protein sequences of contaminants. Enzyme specificity was set to trypsin/P and LysC, allowing a maximum of two missed cleavages. Cysteine carbamidomethylation was set as fixed modification, and methionine oxidation and protein $\mathrm{N}$-terminal acetylation were used as variable modifications. Global false discovery rate for both protein and peptides were set to $1 \%$. The match-between-runs and re-quantify options were enabled. Intensity-based quantification options (iBAQ) was also calculated. Differentially enriched proteins were enriched using limma package (Ritchie et al., 2015). Proteins with adjusted p-value $<0.05$ and $\log F C>1$ were determined as significantly enriched in the respective transcription factor chromatin bound interactome.

\section{Integration of ChIP-SICAP Data with Existing ChIP-seq and DepMap Data}


We searched for the ChIP-seq data available for the components of SWI/SNF complex, which are identified to interact with FRA1 and/or FLI1 according to ChIP-SICAP results, in the Cistrome database (Liu et al., 2011). For each factor, we inspected the good quality ChIP-seq data available for epithelial cancer cell lines which were not subjected any special treatment before ChIP experiments at UCSC genome browser (Karolchik et al., 2012). (please see Figure S8A for the used data sets). MIBC enhancers regulating MAP4K4 and FLOT1 were checked for SWI/SNF complex component ChIP-seq signal (Figure S8B-8C). Components with localized signal at the respective enhancer are speculated to regulate the target genes. For the integration of ChIP-SICAP data with DepMap data, for a given target gene regulated by MIBC enhancer and occupied by FRA1 and FLI1 (according to ChIP-seq data), we identified the genes on which the respective target gene has been determined to be dependent (Top100 genes identified with either Crispr and/or RNAi screens (Cancer Dependency Map; DepMap ), positively correlated ones).

\section{Examination of the expression of key MIBC genes in different stages of MIBC patients}

We used TCGA 2017 cohort (Robertson et al., 2017) to check MIBC driving genes' mRNA expression difference between different histopathological stages of the tumor samples. We grouped tumors in T2 stage $(n=132)$ representing the "less-aggressive" and T3 and T4 stages together $(n=277)$ representing "more-aggressive" and compared the mRNA expression of FLI1 and MAP4K4 genes between these two different groups using cBioPortal (Cerami et al., 2012) with its "compare" option. Boxplots representing the mRNA expression change between different tumour stages were also obtained from cBioPortal (Cerami et al., 2012).

\section{RESULTS}

\section{Enhancer landscapes differentially characterizing NMIBC and MIBC}

Using the H3K27ac ChIP-seq data we generated for 2 NMIBC and 4 MIBC cell lines, we called the active regulatory elements in NMIBC $(n=31911)$ and MIBC $(n=58226)$ cell lines. Our analysis identified that $37 \%$ of NMIBC regulatory elements overlapped with MIBC regulatory regions (Figure $1 \mathrm{~A}$ ). Performing an unsupervised clustering analysis on the regulatory regions determined for both NMIBC and MIBC was able to separate NMIBC and MIBC cell lines (Figure 1B). Using the appropriate tools, we identified the active regulatory elements differentially regulated between NMIBC and MIBC. This analysis revealed 295 NMIBC-specific and 1404 MIBC-specific regulatory elements (adjusted $p$ value $=<0.05$ ) (Figure 1C). Representative examples of NMIBC-specific and MIBC-specific active regulatory landscapes are shown in Figure 1D-1E. Overall, our differential enhancer analysis resulted in reliable NMIBC and MIBC specific regulatory regions which we used in our subsequent analysis.

\section{Target genes of differentially regulated enhancers}

After finding the differentially regulated enhancers for NMIBC and MIBC, one critical question was to identify the target genes of these enhancers. It has been well established that enhancer-gene regulation is largely distance independent and depends on the 3D organization of the genome and interaction of the enhancers with the promoter regions of the genes (Dupont et al., 2009). To identify the target genes of the enhancers specific for NMIBC and MIBC, we used the data present in GeneHancer database, which combines several features such as capture $\mathrm{Hi}-\mathrm{C}$, correlation of the expression of the genes with enhancer RNAs, expression of quantitative trait loci within the enhancer of interest and provides reliable enhancer-gene interactions (Fishilevich et al., 2017). Using the information available in the GeneHancer database and combining it with the expression status of the genes in NMIBC and MIBC (Figure S1), we linked $70 \%$ of MIBC enhancers and $65 \%$ of NMIBC 
enhancers with their target genes (Table S1-S2). We identified that among the enhancers linked with a gene in our analysis, almost half of MIBC enhancers and NMIBC enhancers regulated a single target gene while almost a quarter regulated 2 genes (Figure 2A-2B).

We identified the target genes of MIBC-specific enhancers to be involved in epithelium migration (adjusted $p$ value $=0.001$ ), regulation of epithelial cell proliferation (adjusted $p$ value $=0.00047$ ). (Figure 2C-2D, Table S3), which includes the genes like TGFB2, HIF1A, and PRKCA highly relevant for epithelial to mesenchymal transition (Llorens et al., 2019; Tam et al., 2020; Xu et al., 2009). On the other hand, our analysis revealed that NMIBCspecific enhancers regulated the genes involved in regulation of transcription by RNA polymerase II ( $\mathrm{p}$ adj. value $=9.1764066279671 \mathrm{e}-05$ ) (Figure 2E-2F), and significantly enriched for transcription factors $(16.45 \%$, Fisher's Exact Test odds ratio $=3.12, \mathrm{p}$ value $=$ 5.192e-07) defined by Lambert et al. (Lambert et al., 2018), consisting of several FOX family and Zinc finger family members (Table S4). Those also include GRHL2, which was previously identified as anti-oncogene in bladder carcinoma by regulating the expression of ZEB1 gene thus preventing EMT both in cell lines and tissue samples (Shen et al., 2020). In addition, KDM5B, which is a H3K4 demethylase (Dey et al., 2008) and regulated by NMIBC specific enhancers, is also implicated in progression of bladder carcinoma (Li et al., 2013). These results suggest that while the NMIBC-specific enhancers mainly regulate the transcription factors implicated in maintenance of a non-invasive character, MIBC-specific enhancers activate the genes involved in cell migration and proliferation such that the cells gain invasive characteristics.

\section{Transcription factors implicated in regulation of NMIBC and MIBC}

Following the identification of the differential regulatory elements characterizing NMIBC and MIBC and their target genes, we tempted to uncover the transcription factors involved in the regulation of these elements. Performing a transcription motif finding revealed FOS family of transcription factors (Milde-Langosch, 2005) to be enriched at MIBC-specific regulatory elements (Figure S2) while the transcription factors including p53/p63/p73 family (Levrero et al., 2000), nuclear receptor family (Weikum et al., 2018) were enriched at NMIBC-specific regulatory elements (Figure S3). To refine our transcription factors list and to determine the ones which would have differential activity in NMIBC and MIBC, we complemented our transcription factor motif analysis with the expression analysis of the respective transcription factors. We analyzed the expression of the top 10 transcription factors enriched at NMIBC and MIBC regulatory elements using the gene expression data available for the cell lines we use (Barretina et al., 2012) or patients classified as NMIBC and MIBC (Sjodahl et al., 2012). We identified that FRA1, a transcription factor belonging to FOS family and implicated in epithelial to mesenchymal transition and metastasis (Desmet et al., 2013; Diesch et al., 2014) to be enriched at MIBC-specific regulatory elements and significantly overexpressed in both MIBC lines and MIBC patients. We also determined FLI1, a transcription factor involved in development and cancer migration and invasion (Li et al., 2015; Scheiber et al., 2014), as the next best candidate enriched for MIBC-specific enhancers though its expression in MIBC cell lines and patients was borderline significant ( $p$-value $=0.1$ for cell lines and $p$-value $=$ 0.07 for tissue.) (Figure 3A-3B, Figure S4A). On the other hand, transcription factors p63, a tumor suppressor with differential variant expression and involved in bladder tumorigenesis (Karni-Schmidt et al., 2011), GRHL2, a transcription factor supporting the expression of epithelial genes and deregulated in various cancers (Ma et al., 2017), and the PPARG, a nuclear receptor highly mutated in bladder cancer and implicated in urothelial differentiation (Liu et al., 2019a) were significantly enriched at NMIBC-specific regulatory elements and significantly overexpressed in NMIBC lines and NMIBC-class patients (Figure 3C-3D, Figure S4B). These results suggest that FRA1 and FLI1 might be the two critical drivers implicated 
in muscle-invasive characteristics of bladder cancer while the proper function and existence of p63, GRHL2 and PPARG are required to preserve non-muscle invasive properties.

\section{FRA1 and FLI1 regulate the genes involved in epithelial cell migration and cell junction organization}

Muscle invasive bladder cancer patients have very bad prognosis compared to non-muscle invasive bladder cancer and have high risk of metastasis (Sanli et al., 2017). Therefore, a thorough understanding of the gene regulation in MIBC is essential. To establish the transcriptional regulatory networks in MIBC, we performed ChIP-seq for FRA1 and FLI1 in T24 MIBC cell line. Our results showed the localization of these two transcription factors at the enhancer regions involved in the regulation of the respective genes. Collectively, FLI1 and FRA1 peaks intersected with MIBC-specific enhancers with $7.8 \%$ and $65.3 \%$ rates, respectively. As a comparison, for NMIBC-specific enhancers, these rates were $0 \%$ and $1.6 \%$, respectively, suggesting the activity of FLI1 and FRA1 mainly at MIBC-specific enhancers (Figure 4A). Overall, we identified lower number peaks for FLI1 ( $n=3834)$ compared to FRA1 ( $n=31918)$. This result might be attributed to the lower expression of FLI1 compared to FRA1 in T24 cell line (FRA1 expression: 7.6 (log2 (RPKM), FLI1 expression: $4.2(\log 2(\mathrm{RPKM}))$ (Barretina et al., 2012). Nevertheless, both known and de novo motif finding analysis identified FRA1 and FLI1 as the best enriched motifs at FRA1 and FLI1 peaks (Figure S5A-S5B), respectively, showing the specificity of FRA1 and FLI1 ChIP-seq data. Next, we linked FRA1 and FLI1 with the target genes of the MIBC enhancers (Figure 4B) involved in 'migration' and 'cell junction organization', and 'epithelial cell proliferation' based on our results (Figure $2 \mathrm{C}$, Table S3). Our results reveal that common target genes of FRA1 and FLI1 are more for cell junction organization.

We knock-down FLI1 and FRA1 alone or in combination in the MIBC cell line T24 to determine whether the expression of the genes within this regulatory network will be changed after manipulation of FRA1 and FLI1. This strategy resulted in a highly efficient knock-down both at the transcript and protein level (Figure 4C-4D). We identified that some key genes implicated in EMT, epithelial cell migration and cell junction organization such as MAP4K4, FLOT1, MYC, CSNK2B, and CD151 (Figure 4E-4F, Figure S6) were significantly downregulated after FRA1 and/or FLI1 knock-down. Expression of TGFB2 gene was significantly downregulated after FLI1 knockdown while it was significantly upregulated with knockdown of FRA1 (Figure S6D), implying the regulation of TGFB2 in two modes in bladder cancer. TGFB2 has been determined to be upregulated after FRA1 knockdown in breast cancer as well (Bejjani et al., 2021), in accordance with our findings. Among the downregulated genes in both FRA1 and FLI1 knockdowns, MAP4K4 attracts special attention. We discovered that MAP4K4 expression significantly correlates with FRA1 and FLI1 expression in primary MIBC (Figure S7A-S7B). Further, primary MIBC patients expressing higher levels of MAP4K4 had significantly higher metastatic potential compared to the ones expressing MAP4K4 at lower levels (Figure S7C-S7D) in two cohorts of the TCGA bladder cancer studies (Cancer Genome Atlas Research, 2014; Robertson et al., 2017), making MAP4K4 is a prominent FRA1 and FLI1 regulated gene critical for metastasis of bladder cancer.

\section{FRA1 and FLI1 interact with the chromatin remodeler complexes, mediating the regulation of EMT related genes}

Having identified the role of FRA1 and FLI1 in regulation of the genes implicated in MIBC, we employed the ChIP-SICAP assay (Rafiee et al., 2016), which enables identification of the factors chromatin bound together with the transcription factor for which ChIP experiment has been performed. Our results showed that protein partners significantly enriched $(\log F C>1$, 
adjusted $p$ value $<0.05)$ for FRA1 and FLI1 interaction were mainly located in chromosome and nucleus (Figure 5A). FRA1 interacting chromatin proteins $(n=1424$, adjusted $p$ value < 0.05 , logFC > 1) included several components of SWI/SNF complex, chromodomain and bromodomain containing modifiers, high mobility group proteins (Figure 5B, Table S5). FLI1 interacting regulators $(n=103$, adjusted $p$ value $<0.05, \log F C>1$ ) included also components of chromatin remodeler complexes such as SMARCC2, RBBP5, several transcription factors such as JUN, ENY2 and kinases such as AURKB (Figure 5C, Table S6). In both FRA1 and FLI1 ChIP-SICAP assays, we were able to locate FRA1 and FLI1 in the respective interactomes (Figure 5B-5C)

ChIP-SICAP assay provided the information for the interacting partners of FRA1 and FLI1. To associate these identified interaction partners with the transcriptional regulatory networks we determined (Figure 4), we made use of the available ChIP-seq data generated for the components of SWI/SNF remodeling complex (Liu et al., 2011) across different epithelial cancer cell lines, and the information available in depMap portal (Cancer Dependency Map; DepMap ) (Figure 6A). Using this strategy, we were able to constitute the regulatory hubs for the regulation of MAP4K4 and FLOT1 (Figure 6B-6E). We identified the components of SWI/SNF remodeler, SMARCA4, SMARCE1, SMARCC1 and SMARCB1, interacting with FRA1 (ChIP-SICAP data), to localize the enhancer region regulating MAP4K4 (Figure S8). Among the genes MAP4K4 show dependency (based on the data on depMap portal), we identified IQGAP1, FHL2, and PARP2 to be present in the chromatin associated interacting partners of FRA1 (Figure 6B). Given the previous literature which shows nuclear localization and functions of these proteins (Chen et al., 2018; Gil-Kulik et al., 2020; Nakazawa et al., 2016; Smith et al., 2015), we suggest that these interacting partners also collaborate with FRA1 for regulation of MAP4K4. Extending these predictions, we determined that interacting partners of IQGAP1 (String database (Szklarczyk et al., 2021; von Mering et al., 2003)) include many proteins which are also identified in FRA1 ChIP-SICAP (Figure 6C). Within the regulatory hub of FLOT1, we also determined components of SWI/SNF complex to localize to the enhancer region regulating FLOT1 (Figure S8) and identified REXO4, CLIC1, GNL1, and FAM50A, which FLOT1 is determined to be dependent on (depMap) in FRA1 chromatinbound interactome data (Figure 6D). Similar to the regulation of MAP4K4, we were able to extend the regulatory scheme for FLOT1 using protein-protein interaction data from STRING database (von Mering et al., 2003) (Figure 6E). Collectively, our integrative approach constitutes valuable hypothetical regulatory models for the genes which are potentially implicated in muscle invasion of bladder cancer.

\section{FRA1 and FLI1 knockdown reduces invasive power of muscle invasive bladder cancer cells}

After seeing the implications of FRA1 and FLI1 knock-down on transcriptional level in T24 cells (Figure 4), we investigated the effect of knock-down in invasive characteristics of this MIBC cell line. To test the invasion capability of T24 cells for the knock-downs, we used ICCHIP assay, which enables the detection of invasion ability through matrigel across different microenvironment (Firatligil-Yildirir et al., 2021; Ilhan et al., 2020; Onal et al., 2021) in three conditions: Positive control (10\% FBS), negative control ( $0 \%$ FBS) and muscle microenvironment (Figure 7A). Similar to the knockdown experiments for gene expression analysis (Figure 4), knockdown experiments were quite efficient (Figure S9). To create 'muscle microenvironment', we used myoblast $\mathrm{C} 2 \mathrm{C} 12$ cells differentiated into muscle with horse serum (Figure S10A). Quantification of invasive capacity of T24 cells showed that as expected, cells invaded towards the FBS-medium but not the FBS-free medium (Figure $\mathrm{S} 10 \mathrm{~B})$. Presence of muscle cells in matrigel resulted in collective cell migration in contrast to the single cell migration into cell-free matrigel, reflected as shorter mean distances from the 
startline (Figure 7B, 7C), in agreement with prior studies which showed metastasis to muscle is rare (Surov et al., 2010) and the migration of bladder cancer cells into the muscle occurs in a collective invasion mode (Beunk et al., 2019; Cheng et al., 2009; Imanishi et al., 2014).

Overall, knockdown of FLI1 was not as effective as knockdown of FRA1 in reducing invasion. Upon comparing the $10 \%$ FBS microenvironment across different conditions, compared to control siRNA, we identified significantly less invasion for FRA1 single and FRA1-FLI1 double knock-down conditions. Invasion for FRA1 single knockdown was also lower than that for FLI1 single knockdown. Invasion for control and FLI1 siRNA conditions were similar to each other. (Figure 7B). Double knockdown reduced invasion suggesting FRA1 was dominant over FLI1, in agreement with the lower rate of FLI1 peak intersection with MIBC enhancers compared to FRA1 peaks (Figure 4A) and lower number of FLI1 target genes compared to FRA1 (Figure 4B). Next, comparison of the invasion capacity towards muscle microenvironment demonstrated the role of FRA1 in invasion in the presence of muscle cells as well. Both FRA1 and FRA1-FLI1 double knock-down resulted in significantly less invasion compared to control siRNA in the presence of the muscle microenvironment (Figure 7C). Together, these results show the involvement of the FRA1 transcription factor in invasive capacity of bladder cancer cell lines with differential behavior in cell-free and muscle microenvironments.

MIBC cases show gradual muscle invasion status, starting from T2 and reaching T4 for the maximum invasion (Sanli et al., 2017). In accordance with our findings we obtained from ICCHIP assay, we determined significantly higher expression of MAP4K4, target of FRA1 and FLI1, in patients belonging to T3 and T4 groups compared to the ones which are in T2 group (Figure S11A). Additionally, we identified the expression of FLI1 and FRA1 to be increased in T3-T4 stage patients as well (Figure S11B-S11C). Collectively our results highly suggest for the role of FRA1 and FLI1 in muscle invasive capability of bladder cancer.

\section{DISCUSSION}

In this study, we defined the active regulatory landscape of the NMIBC and MIBC cell lines using the information we gathered from H3K27ac ChIP-seq. Our in depth analysis revealed differentially regulated enhancers between NMIBC and MIBC, linked those enhancers with their target genes and identified the unique transcriptional regulatory networks implicated in NMIBC and MIBC. We further extended these analyses with transcription factor ChIP-seq and ChIP-SICAP assays, which enabled identification of the chromatin factors associated with the transcription factors involved in regulation of MIBC. Additionally, our functional studies we performed using knock-down and invasion assays proved the functionality of the transcription factors which we determined to be differentially regulated between NMIBC and MIBC.

We identified target genes of MIBC enhancers to be implicated in epithelial cell migration and cell-cell junction organization. For the NMIBC enhancers, the major target genes were related to transcriptional machinery, consisting of transcription factors, which might be critical for epithelial characteristics. In this regulatory scheme, epithelial transcription factors GRHL2, TP63 and PPARG are the main drivers constituting NMIBC regulatory network while FRA1 and FLI1, two transcription factors previously implicated in EMT in several cancers (Desmet et al., 2013; Diesch et al., 2014; Sayan et al., 2012; Scheiber et al., 2014; Zhang et al., 2016), establish the transcriptional circuitry of MIBC.

FRA1 transcription factor has been shown as motility regulator of bladder cancer cell lines RT4 and J82 (Sayan et al., 2012). Its overexpression enhanced the mobility of RT4 cell line 
and its downregulation decreased the migration of J82 cell line. Moreover, FRA1 has also been shown as an important factor regulating the metastasis of squamous cell carcinoma (Zhang et al., 2016), colorectal cancer cells (Diesch et al., 2014). Overexpression of FLI1 has been mainly implicated in hematological malignancies ( $\mathrm{Li}$ et al., 2015). It has been shown to have a role in invasion and migration of breast cancer (Scheiber et al., 2014) and EWS-FLI1 fusion transcript has been detected in some primitive neuroectodermal tumors (Johnson et al., 2010). Based on existing literature and our analysis, we hypothesized that FRA1 and FLI1 transcription factors can be the drivers of invasion to muscularis propria in bladder cancer. Thus, we investigated the role of FRA1 and FLI1 in MIBC regulation in more detail. Our FRA1 and FLI1 ChIP-seq results showed the localization of these two factors at MIBC enhancers, emphasizing the role of FRA1 and FLI1 in shaping MIBC regulatory landscape. Further knock-down of FRA1 and FLI1 resulted in significantly lower expression of genes involved in epithelial cell migration. One of those genes MAP4K4, a kinase implicated in cancer development (Gao et al., 2016), has been also shown to have a role in invasiveness of bladder cancer cell lines (Ma, 2014). In addition, MAP4K4 was one of the significantly upregulated genes in a carcinogen-induced mouse bladder cancer (Yao et al., 2004). It has been also shown to promote invasion in medulloblastoma cells (Tripolitsioti et al., 2018). FLOT1, a member of integral membrane with a prominent role in cell morphogenesis (Bodin et al., 2014), was another gene significantly downregulated after both FRA1 and FLI1 knockdown. This gene was identified to affect EMT transition in lung cancer (Zhang et al., 2019), knock-down of FLOT1 in breast cancer cells resulted in decreased rates of proliferation (Lin et al., 2011). Further, FLOT1 was determined to be overexpressed in bladder cancer and its expression correlated with migration and invasion characteristics of the cells (Guan et al., 2014).

Integration of ChIP-seq results with existing data and ChIP-SICAP suggested some previously unknown regulatory interactions, which might be critical for invasive characteristics of muscle invasive bladder cancer. Among the interaction partners of FRA1, we determined IQGAP1, FHL2 and CAB39 genes which MAP4K4 shows dependency. IQGAP1 functions in both nucleus and cytoplasm with many different roles and complex interactions, implicated in cell motility (Smith et al., 2015). Further, it is determined to affect cell proliferation in multiple myeloma (Ma et al., 2013), regulates centrosome function in breast cancer (Osman et al., 2020), and is involved in EMT regulation in gastric cancer (Liu et al., 2019b). We identified CD44 and RAC1, which are identified in FRA1 chromatin-bound interactome as interacter partners of IQGAP1, further strengthening the link between FRA1 and IQGAP1. FHL2 has been previously identified to regulate the expression of p21 (Nakazawa et al., 2016). PARP2 is involved in DNA repair (Chen et al., 2018) with high expression levels in acute myeloid leukemia (Gil-Kulik et al., 2020). Regarding the regulatory hub of FLOT1, localization of CLIC1 has been detected in cytoplasm, nucleus and membrane of the cells and CLIC1 has been implicated in invasion and progression of cancer (Gurski et al., 2015; Li et al., 2018). FAM50A has been also shown to localize in nucleus during ameloblast differentiation (Kim et al., 2018). REXO4 has been shown to be implicated in drug sensitivity (Krishnamurthy et al., 2015) and to regulate the expression of QR gene (Krishnamurthy et al., 2015) in breast cancer. Lastly, GNL1 functions as a nucleolar GTPase and has been identified to be overexpressed in bladder cancer (Fang et al., 2013). Our results showed that many interacting partners of GNL1 (Szklarczyk et al., 2021) can be also identified among the proteins identified in FRA1 interactome, suggesting the putative role of GNL1 complex in association with FRA1 in regulation of FLOT1 gene.

We strengthened the association of FRA1 and FLI1 in bladder cancer cell's invasion ability via employing IC-CHIP assay in different microenvironments and different knock-down conditions. By mimicking the in vivo tumor microenvironment in vitro, we were able to 
determine invasive power of cancer cells. Interestingly, the effect of knockdowns on invasion was influenced by the presence of muscle cells in the microenvironment, suggesting that invasion assessment should involve presence of stromal cells. What is more, with FRA1 and FRA1 and FLI1 co-knockdowns, cells showed collective rather than single cell migration, in agreement with the known role of FRA1 in cell junctions (Zhang et al., 2016) and our findings, which showed the regulation of many genes involved in cell junction organization by FRA1 and FLI1 (Figure 4B). Previously, FRA1 has been shown to involved in motility of bladder cancer cells using transwell migration assays (Sayan et al., 2012). Here, our results complement this finding via showing its role in invasion through matrigel towards serum and muscle environment, in agreement with our molecular findings. Although FLI1 knock-down has been identified to decrease migration and invasion of hepatocellular carcinoma cell lines (Wang et al., 2018), the role of FLI1 in invasive characteristics of bladder cancer cells has not been shown in any other study. Additionally, considering the higher expression of FRA1 and FLI1 and their targets (Figure S11) in bladder cancer with stages > T2, we propose that these two transcription factors can be critical players in the regulation of muscle invasive bladder cancer cell lines. Further long term invasion experiments including different cell lines and more focused inter-molecular interaction investigations can be carried out in future research; however, this is beyond the scope of this work.

Collectively, our results show the multi-faceted role of FRA1 and FLI1 transcription factors in regulation of the invasive characteristics of MIBC. We believe these results have profound implications for the specific diagnosis and treatment of bladder cancer. MAP4K4 is regarded as a novel target for several cancers (Gao et al., 2016), also considering that many MAP4K4 inhibitors are available, which are shown to be effective for survival of cardiomyocytes (Fiedler et al., 2019), prevention of thrombosis (Nam et al., 2021) and reduction of the invasion capacity of glioblastoma (Prolo et al., 2019) and medulloblastoma (Tripolitsioti et al., 2018), targeting MAP4K4 in bladder cancer might be a valuable strategy as well. Additionally, there are many studies investigating the effect of small molecules and inhibitors on targeting of FLI1, especially within the context of EWS-FLI1 fusion (Li et al., 2015). In this regard, stratification of MIBC patients according to FLI1 expression and subsequent treatment with FLI1 inhibitors might be highly beneficial treatment strategy for MIBC patients showing high expression of FLI1. Further, a study showed the dependency of EWS/FLI1 transcription factors on bromodomain-containing proteins for the proper transcriptional regulation and treatment with JQ1, an inhibitor for bromodomain-containing proteins (Gollavilli et al., 2018). In our analysis, we identified BRD3 as one of the chromatin-bound interacting partners of FLI1 (Figure 5C). Thus, we suggest that FLI1 expression level might be a determining factor for treatment of bladder cancer patients with JQ1, which is shown to be quite effective for bladder cancer (Li et al., 2019).

\section{ACKNOWLEDGEMENTS}

This study was funded by Scientific and Technological Research Council of Turkey (TUBITAK) grant (number 118Z166), EMBO Installation Grant (number 4148), Science Academy's Young Scientist Awards Program (BAGEP) and L'Oreal-UNESCO National for Women in Science Fellowship and L'Oreal-UNESCO International Rising Talent Program. We thank IBG's Bioinformatics Platform, Alirıza Arıbaş and Nazmiye Arslan for the assistance on the bioinformatic analysis and data upload, and Melek Üçüncü from IBG's Optical Imaging facility for the help on the acquisition of Confocal images. We thank Neşe Atabey for providing us with T24 cell line and Mehmet Öztürk for the supply of C2C12 cells.

\section{AUTHOR CONTRIBUTIONS}


P.Y.G.S., G.Ö.Y. S.S. and S.E.O. designed the study. P.Y.G.S, G.Ö.Y, A.K. performed the experiments. P.Y.G.S, G.Ö.Y, A.K., A.E., H.U., G.K., D.P.O. analyzed the data. D.P.O., S.S., S.E.O. supervised the study. P.Y.G.S., G.Ö.Y., D.P.O. and S.E.O. wrote the manuscript.

\section{CONTACT FOR REAGENT AND RESOURCE SHARING}

Requests on reagents and resources can be directed to Serap Erkek Ozhan (serap.erkek@ibg.edu.tr).

\section{CONFLICT OF INTEREST}

D. Pesen-Okvur is CTO of INITIO Cell Biyoteknoloji.

\section{FIGURE LEGENDS}

Figure 1. Differentially regulated enhancers between NMIBC and MIBC cell lines. $(A)$ Venn diagram showing the overlap between H3K27ac peaks called in NMIBC and MIBC. (B) Heatmap displaying the correlation among the cell lines according to the signals present at consensus H3K27ac peaks (unsupervised). (C) Volcano plot showing the differentially regulated enhancers (FDR $=<0.05)$ between MIBC and NMIBC $(n=1699)$. (D-E) Snapshots visualize H3K27ac signal at exemplary NMIBC (D) and MIBC (E) specific enhancers.

Figure 2. Target genes of MIBC enhancers are involved in regulation of epithelial cell migration. (A-B) Barplots show the relationship between percent of the enhancers and the number of their target genes, (A) MIBC specific enhancers, (B) NMIBC specific enhancers. $(C, E)$ ClusterProfiler outputs displaying the enriched GO terms for the target genes of MIBC enhancers $(C)$ and NMIBC enhancers $(E)$. (D, F) Snapshots showing H3K37ac signal at MIBC enhancer regulating TGFB2 (D) and NMIBC enhancer regulating FGFR3 (F). Enhancer regions are shown in pink rectangles.

Figure 3. Transcription factors enriched at MIBC and NMIBC enhancers. (A, C) Top transcription factor motifs enriched at $\operatorname{MIBC}(A)$ and NMIBC $(C)$ enhancers. $(B, D)$ Boxplots showing the expression of FRA1 and FLI1 across the NMIBC $(\mathrm{n}=2)$ and MIBC cell lines $(\mathrm{n}=4)$ (B) and the expression of TP63, GRHL2 and PPARG (D). * $\mathrm{p}$ value $<0.05$

Figure 4. Knockdown of FRA1 and FLI1 downregulates the expression of genes involved in epithelial cell migration. (A) Barplots show the overlap rates of MIBC and NMIBC enhancers with FRA1 and FLI1 peaks. (B) Regulatory network denoting the transcription factors, FRA1 and FLI1 and their target genes involved in epithelium migration, cell junction organization and regulation of epithelial cell proliferation. For simplicity similar terms were left out of the visualized image (please see Table S3, 'epithelium migration' and 'cell junction organization', and 'regulation of epithelial cell proliferation' related terms are highlighted in yellow). (C-D) Plots showing the downregulation of FRA1 (C) and FLI1 (D) at mRNA and protein level. Top panels display the relative mRNA levels, bottom panels show the Western blot images. (E-F) Barplots display the relative mRNA levels of FLOT1 (E) and MAP4K4 (F) (top panels). Snapshots showing H3K27ac, FRA1 and FLI1 signals at the MIBC enhancers regulating FLOT1 and MAP4K4 genes (bottom panels). Error bars show the standard deviation of two biological replicates. Each biological replicate is analyzed in three technical replicates. ${ }^{*} p$ value $<0.05,{ }^{* *} p$ value $<0.01$

Figure 5. Chromatin factors interacting with FRA1 and FLI1 in MIBC. (A) Barplots show the cellular compartments FLI1 and FRA1 chromatin-bound interactors are localized. (B-C) Scatter plots visualizing the correlation between ChIP-SICAP replicates for FRA1 (B) and FLI1 (C). IBAQ values are normalized to no antibody control values. 
Figure 6. Regulatory hubs implicated in regulation of EMT-related genes. (A) Schematic showing the workflow for the constitution of the regulatory hubs. (B, D) Regulatory hubs for the regulation of MAP4K4 (B) and FLOT1 $(\mathrm{D})$. (C, E) String protein-protein interaction networks for IQGAP1 (C) and REXO4 (E). Proteins which can be also identified in FRA1 chromatin-bound interactome (Supplementary Table 5) are shown in red.

Figure 7. FRA1 and FLI1 knockdown results in reduction of the invasion capacity in MIBC cells. (A) Diagram showing the experimental design using IC-CHIPs. (B-C) Comparison of the invasive capacity of T24 cells into cell-free matrigel in the presence of FBS (B) and into the muscle microenvironment (C). Left panels show the representative Zstack projection images for different conditions. Scale bar: $100 \mu \mathrm{m}$. Boxplots display the distribution of the distance from the start line (right upper panel). Line graphs show the mean distance values with the error bars $(n=2-6)$ from day 0 to day 2 . The data is normalized to day 0 (right lower panel). Student's t-test (two-tailed) was used for the statistics.

\section{REFERENCES}

Abdelrahman, A.E., Rashed, H.E., Elkady, E., Elsebai, E.A., El-Azony, A., and Matar, I. (2019). Fatty acid synthase, Her2/neu, and E2F1 as prognostic markers of progression in non-muscle invasive bladder cancer. Ann Diagn Pathol 39, 42-52. 10.1016/j.anndiagpath.2019.01.002.

Ahlmann-Eltze, C., Patil I. (2021). Ggsignif: R Package for Displaying Significance Brackets for 'ggplot2'. 10.31234/osf.io/7awm6.

Barretina, J., Caponigro, G., Stransky, N., Venkatesan, K., Margolin, A.A., Kim, S., Wilson, C.J., Lehar, J., Kryukov, G.V., Sonkin, D., et al. (2012). The Cancer Cell Line Encyclopedia enables predictive modelling of anticancer drug sensitivity. Nature 483, 603-607. 10.1038/nature11003.

Bastian, M., Heymann S., Jacomy M. (2009). Gephi: An Open Source Software for Exploring and Manipulating Networks. Proceedings of the International AAAI Conference on Web and Social Media.

Bejjani, F., Tolza, C., Boulanger, M., Downes, D., Romero, R., Maqbool, M.A., Zine El Aabidine, A., Andrau, J.C., Lebre, S., Brehelin, L., et al. (2021). Fra-1 regulates its target genes via binding to remote enhancers without exerting major control on chromatin architecture in triple negative breast cancers. Nucleic Acids Res 49, 2488-2508. 10.1093/nar/gkab053.

Beunk, L., Brown, K., Nagtegaal, I., Friedl, P., and Wolf, K. (2019). Cancer invasion into musculature: Mechanics, molecules and implications. Semin Cell Dev Biol 93, 36-45. 10.1016/j.semcdb.2018.07.014.

Bodin, S., Planchon, D., Rios Morris, E., Comunale, F., and Gauthier-Rouviere, C. (2014). Flotillins in intercellular adhesion - from cellular physiology to human diseases. J Cell Sci 127, 5139-5147. 10.1242/jcs. 159764.

Breyer, J., Otto, W., Wirtz, R.M., Wullich, B., Keck, B., Erben, P., Kriegmair, M.C., Stoehr, R., Eckstein, M., Laible, M., et al. (2017). ERBB2 Expression as Potential Risk-Stratification for Early Cystectomy in Patients with pT1 Bladder Cancer and Concomitant Carcinoma in situ. Urol Int 98, 282-289. 10.1159/000453670.

Breyer, J., Wirtz, R.M., Erben, P., Worst, T.S., Stoehr, R., Eckstein, M., Bertz, S., Sikic, D., Denzinger, S., Burger, M., et al. (2018). High CDKN2A/p16 and Low FGFR3 Expression Predict Progressive Potential of Stage pT1 Urothelial Bladder Carcinoma. Clin Genitourin Cancer 16, 248-256 e242. 10.1016/j.clgc.2018.01.009.

Cancer Dependency Map; DepMap

Cancer Genome Atlas Research, N. (2014). Comprehensive molecular characterization of urothelial bladder carcinoma. Nature 507, 315-322. 10.1038/nature12965. 
Carlson, M. (2019). org.Hs.eg.db: Genome wide annotation for Human.

Cerami, E., Gao, J., Dogrusoz, U., Gross, B.E., Sumer, S.O., Aksoy, B.A., Jacobsen, A., Byrne, C.J., Heuer, M.L., Larsson, E., et al. (2012). The cBio cancer genomics portal: an open platform for exploring multidimensional cancer genomics data. Cancer Discov 2, 401 404. 10.1158/2159-8290.CD-12-0095.

Chen, Q., Kassab, M.A., Dantzer, F., and Yu, X. (2018). PARP2 mediates branched poly ADP-ribosylation in response to DNA damage. Nat Commun 9, 3233. 10.1038/s41467-01805588-5.

Cheng, L., Montironi, R., Davidson, D.D., and Lopez-Beltran, A. (2009). Staging and reporting of urothelial carcinoma of the urinary bladder. Mod Pathol 22 Suppl 2, S70-95. 10.1038/modpathol.2009.1.

Consortium, E.P., Moore, J.E., Purcaro, M.J., Pratt, H.E., Epstein, C.B., Shoresh, N., Adrian, J., Kawli, T., Davis, C.A., Dobin, A., et al. (2020). Expanded encyclopaedias of DNA elements in the human and mouse genomes. Nature 583, 699-710. 10.1038/s41586-0202493-4.

Cox, J., and Mann, M. (2008). MaxQuant enables high peptide identification rates, individualized p.p.b.-range mass accuracies and proteome-wide protein quantification. Nat Biotechnol 26, 1367-1372. 10.1038/nbt.1511.

Creyghton, M.P., Cheng, A.W., Welstead, G.G., Kooistra, T., Carey, B.W., Steine, E.J., Hanna, J., Lodato, M.A., Frampton, G.M., Sharp, P.A., et al. (2010). Histone H3K27ac separates active from poised enhancers and predicts developmental state. Proc Natl Acad Sci U S A 107, 21931-21936. 10.1073/pnas.1016071107.

Desmet, C.J., Gallenne, T., Prieur, A., Reyal, F., Visser, N.L., Wittner, B.S., Smit, M.A., Geiger, T.R., Laoukili, J., Iskit, S., et al. (2013). Identification of a pharmacologically tractable Fra-1/ADORA2B axis promoting breast cancer metastasis. Proc Natl Acad Sci U S A 110, 5139-5144. 10.1073/pnas.1222085110.

Dey, B.K., Stalker, L., Schnerch, A., Bhatia, M., Taylor-Papidimitriou, J., and Wynder, C. (2008). The histone demethylase KDM5b/JARID1b plays a role in cell fate decisions by blocking terminal differentiation. Mol Cell Biol 28, 5312-5327. 10.1128/MCB.00128-08.

Diesch, J., Sanij, E., Gilan, O., Love, C., Tran, H., Fleming, N.I., Ellul, J., Amalia, M., Haviv, I., Pearson, R.B., et al. (2014). Widespread FRA1-dependent control of mesenchymal transdifferentiation programs in colorectal cancer cells. PLoS One 9, e88950. 10.1371/journal.pone.0088950.

Dupont, C., Armant, D.R., and Brenner, C.A. (2009). Epigenetics: definition, mechanisms and clinical perspective. Semin Reprod Med 27, 351-357. 10.1055/s-0029-1237423.

Erkek, S., Johann, P.D., Finetti, M.A., Drosos, Y., Chou, H.C., Zapatka, M., Sturm, D., Jones, D.T.W., Korshunov, A., Rhyzova, M., et al. (2019). Comprehensive Analysis of Chromatin States in Atypical Teratoid/Rhabdoid Tumor Identifies Diverging Roles for SWI/SNF and Polycomb in Gene Regulation. Cancer Cell 35, 95-110 e118. 10.1016/j.ccell.2018.11.014.

Fang, Z.Q., Zang, W.D., Chen, R., Ye, B.W., Wang, X.W., Yi, S.H., Chen, W., He, F., and Ye, G. (2013). Gene expression profile and enrichment pathways in different stages of bladder cancer. Genet Mol Res 12, 1479-1489. 10.4238/2013.May.6.1.

Fiedler, L.R., Chapman, K., Xie, M., Maifoshie, E., Jenkins, M., Golforoush, P.A., Bellahcene, M., Noseda, M., Faust, D., Jarvis, A., et al. (2019). MAP4K4 Inhibition Promotes Survival of Human Stem Cell-Derived Cardiomyocytes and Reduces Infarct Size In Vivo. Cell Stem Cell 24, 579-591 e512. 10.1016/j.stem.2019.01.013.

Firatligil-Yildirir, B., Bati-Ayaz, G., Tahmaz, I., Bilgen, M., Pesen-Okvur, D., and YalcinOzuysal, O. (2021). On-chip determination of tissue-specific metastatic potential of breast cancer cells. Biotechnol Bioeng 118, 3799-3810. 10.1002/bit.27855.

Fishilevich, S., Nudel, R., Rappaport, N., Hadar, R., Plaschkes, I., Iny Stein, T., Rosen, N., Kohn, A., Twik, M., Safran, M., et al. (2017). GeneHancer: genome-wide integration of enhancers and target genes in GeneCards. Database (Oxford) 2017. 10.1093/database/bax028. 
Frankish, A., Diekhans, M., Ferreira, A.M., Johnson, R., Jungreis, I., Loveland, J., Mudge, J.M., Sisu, C., Wright, J., Armstrong, J., et al. (2019). GENCODE reference annotation for the human and mouse genomes. Nucleic Acids Res 47, D766-D773. 10.1093/nar/gky955.

Gao, X., Gao, C., Liu, G., and Hu, J. (2016). MAP4K4: an emerging therapeutic target in cancer. Cell Biosci 6, 56. 10.1186/s13578-016-0121-7.

Gil-Kulik, P., Dudzinska, E., Radzikowska-Buchner, E., Wawer, J., Jojczuk, M., Nogalski, A., Wawer, G.A., Feldo, M., Kocki, W., Cioch, M., et al. (2020). Different regulation of PARP1, PARP2, PARP3 and TRPM2 genes expression in acute myeloid leukemia cells. BMC Cancer 20, 435. 10.1186/s12885-020-06903-4.

Gollavilli, P.N., Pawar, A., Wilder-Romans, K., Natesan, R., Engelke, C.G., Dommeti, V.L., Krishnamurthy, P.M., Nallasivam, A., Apel, I.J., Xu, T., et al. (2018). EWS/ETS-Driven Ewing Sarcoma Requires BET Bromodomain Proteins. Cancer Res 78, 4760-4773. 10.1158/00085472.CAN-18-0484.

Grubert, F., Srivas, R., Spacek, D.V., Kasowski, M., Ruiz-Velasco, M., Sinnott-Armstrong, N., Greenside, P., Narasimha, A., Liu, Q., Geller, B., et al. (2020). Landscape of cohesinmediated chromatin loops in the human genome. Nature 583, 737-743. 10.1038/s41586-0202151-x.

Guan, Y., Song, H., Zhang, G., and Ai, X. (2014). Overexpression of flotillin-1 is involved in proliferation and recurrence of bladder transitional cell carcinoma. Oncol Rep 32, 748-754. 10.3892/or.2014.3221.

Gurski, L.A., Knowles, L.M., Basse, P.H., Maranchie, J.K., Watkins, S.C., and Pilch, J. (2015). Relocation of CLIC1 promotes tumor cell invasion and colonization of fibrin. Mol Cancer Res 13, 273-280. 10.1158/1541-7786.MCR-14-0249.

Hahne, F., Ivanek R. (2016). Visualizing Genomic Data Using Gviz and Bioconductor. In Statistical Genomics: Methods and Protocols, D.S. In Mathé E, ed. (Springer New York), pp. 335-351. 10.1007/978-1-4939-3578-9_16.

Heinz, S., Benner, C., Spann, N., Bertolino, E., Lin, Y.C., Laslo, P., Cheng, J.X., Murre, C., Singh, H., and Glass, C.K. (2010). Simple combinations of lineage-determining transcription factors prime cis-regulatory elements required for macrophage and $B$ cell identities. Mol Cell 38, 576-589. 10.1016/j.molcel.2010.05.004.

Hepburn, A.C., Veeratterapillay, R., Williamson, S.C., El-Sherif, A., Sahay, N., Thomas, H.D., Mantilla, A., Pickard, R.S., Robson, C.N., and Heer, R. (2012). Side population in human non-muscle invasive bladder cancer enriches for cancer stem cells that are maintained by MAPK signalling. PLoS One 7, e50690. 10.1371/journal.pone.0050690.

Hurst, C.D., Alder, O., Platt, F.M., Droop, A., Stead, L.F., Burns, J.E., Burghel, G.J., Jain, S., Klimczak, L.J., Lindsay, H., et al. (2017). Genomic Subtypes of Non-invasive Bladder Cancer with Distinct Metabolic Profile and Female Gender Bias in KDM6A Mutation Frequency. Cancer Cell 32, 701-715 e707. 10.1016/j.ccell.2017.08.005.

Ilhan, M., Kucukkose, C., Efe, E., Gunyuz, Z.E., Firatligil, B., Dogan, H., Ozuysal, M., and Yalcin-Ozuysal, O. (2020). Pro-metastatic functions of Notch signaling is mediated by CYR61 in breast cells. Eur J Cell Biol 99, 151070. 10.1016/j.ejcb.2020.151070.

Imanishi, K., Yoneyama, M.S., Hatakeyama, S., Yamamoto, H., Koie, T., Saitoh, H., Yamaya, K., Funyu, T., Nakamura, T., Ohyama, C., and Tsuboi, S. (2014). Invadopodia are essential in transurothelial invasion during the muscle invasion of bladder cancer cells. Mol Med Rep 9, 2159-2165. 10.3892/mmr.2014.2113.

International Collaboration of, T., Medical Research Council Advanced Bladder Cancer Working, P., European Organisation for, R., Treatment of Cancer Genito-Urinary Tract Cancer, G., Australian Bladder Cancer Study, G., National Cancer Institute of Canada Clinical Trials, G., Finnbladder, Norwegian Bladder Cancer Study, G., Club Urologico Espanol de Tratamiento Oncologico, G., Griffiths, G., et al. (2011). International phase III trial assessing neoadjuvant cisplatin, methotrexate, and vinblastine chemotherapy for muscleinvasive bladder cancer: long-term results of the BA06 30894 trial. J Clin Oncol 29, 21712177. 10.1200/JCO.2010.32.3139. 
Jian, W., Yamashita, H., Cardenas, D., Sonpavde, G., and Lerner, S. (2008). Comparison of the 5637 human urothelial cancer cell line with a second-generation 5637 cell line for cancer therapy. Cancer Research 68, 2711-2711.

Johnson, A.D., Pambuccian, S.E., Andrade, R.S., Dolan, M.M., and Aslan, D.L. (2010). Ewing sarcoma and primitive neuroectodermal tumor of the esophagus: report of a case and review of literature. Int J Surg Pathol 18, 388-393. 10.1177/1066896908316903.

Kamoun, A., de Reynies, A., Allory, Y., Sjodahl, G., Robertson, A.G., Seiler, R., Hoadley, K.A., Groeneveld, C.S., Al-Ahmadie, H., Choi, W., et al. (2020). A Consensus Molecular Classification of Muscle-invasive Bladder Cancer. Eur Urol 77, 420-433. 10.1016/j.eururo.2019.09.006.

Karni-Schmidt, O., Castillo-Martin, M., Shen, T.H., Gladoun, N., Domingo-Domenech, J., Sanchez-Carbayo, M., Li, Y., Lowe, S., Prives, C., and Cordon-Cardo, C. (2011). Distinct expression profiles of p63 variants during urothelial development and bladder cancer progression. Am J Pathol 178, 1350-1360. 10.1016/j.ajpath.2010.11.061.

Karolchik, D., Hinrichs, A.S., and Kent, W.J. (2012). The UCSC Genome Browser. Curr Protoc Bioinformatics Chapter 1, Unit1 4. 10.1002/0471250953.bi0104s40.

Kim, Y., Hur, S.W., Jeong, B.C., Oh, S.H., Hwang, Y.C., Kim, S.H., and Koh, J.T. (2018). The Fam50a positively regulates ameloblast differentiation via interacting with Runx2. J Cell Physiol 233, 1512-1522. 10.1002/jcp.26038.

Krishnamurthy, N., Liu, L., Xiong, X., Zhang, J., and Montano, M.M. (2015). Downregulation of hPMC2 imparts chemotherapeutic sensitivity to alkylating agents in breast cancer cells. Cancer Biol Ther 16, 518-527. 10.1080/15384047.2015.1016661.

Lambert, S.A., Jolma, A., Campitelli, L.F., Das, P.K., Yin, Y., Albu, M., Chen, X., Taipale, J., Hughes, T.R., and Weirauch, M.T. (2018). The Human Transcription Factors. Cell 175, 598599. 10.1016/j.cell.2018.09.045.

Lawrence, M., Huber, W., Pages, H., Aboyoun, P., Carlson, M., Gentleman, R., Morgan, M.T., and Carey, V.J. (2013). Software for computing and annotating genomic ranges. PLoS Comput Biol 9, e1003118. 10.1371/journal.pcbi.1003118.

Lelo, A., Prip, F., Harris, B.T., Solomon, D., Berry, D.L., Chaldekas, K., Kumar, A., Simko, J., Jensen, J.B., Bhattacharyya, P., et al. (2018). STAG2 Is a Biomarker for Prediction of Recurrence and Progression in Papillary Non-Muscle-Invasive Bladder Cancer. Clin Cancer Res 24, 4145-4153. 10.1158/1078-0432.CCR-17-3244.

Levrero, M., De Laurenzi, V., Costanzo, A., Gong, J., Wang, J.Y., and Melino, G. (2000). The p53/p63/p73 family of transcription factors: overlapping and distinct functions. J Cell Sci 113 ( Pt 10), 1661-1670.

Li, B.P., Mao, Y.T., Wang, Z., Chen, Y.Y., Wang, Y., Zhai, C.Y., Shi, B., Liu, S.Y., Liu, J.L., and Chen, J.Q. (2018). CLIC1 Promotes the Progression of Gastric Cancer by Regulating the MAPK/AKT Pathways. Cell Physiol Biochem 46, 907-924. 10.1159/000488822.

Li, F., Yang, C., Zhang, H.B., Ma, J., Jia, J., Tang, X., Zeng, J., Chong, T., Wang, X., He, D., and Guo, P. (2019). BET inhibitor JQ1 suppresses cell proliferation via inducing autophagy and activating LKB1/AMPK in bladder cancer cells. Cancer Med 8, 4792-4805. 10.1002/cam4.2385.

Li, H., and Durbin, R. (2009). Fast and accurate short read alignment with Burrows-Wheeler transform. Bioinformatics 25, 1754-1760. 10.1093/bioinformatics/btp324.

Li, H.T., Duymich, C.E., Weisenberger, D.J., and Liang, G. (2016). Genetic and Epigenetic Alterations in Bladder Cancer. Int Neurourol J 20, S84-94. 10.5213/inj.1632752.376.

Li, X., Su, Y., Pan, J., Zhou, Z., Song, B., Xiong, E., and Chen, Z. (2013). Connexin 26 is down-regulated by KDM5B in the progression of bladder cancer. Int J Mol Sci 14, 7866-7879. 10.3390/ijms14047866.

Li, Y., Luo, H., Liu, T., Zacksenhaus, E., and Ben-David, Y. (2015). The ets transcription factor Fli-1 in development, cancer and disease. Oncogene 34, 2022-2031. 10.1038/onc.2014.162.

Lin, C., Wu, Z., Lin, X., Yu, C., Shi, T., Zeng, Y., Wang, X., Li, J., and Song, L. (2011). Knockdown of FLOT1 impairs cell proliferation and tumorigenicity in breast cancer through 
upregulation of FOXO3a. Clin Cancer Res 17, 3089-3099. 10.1158/1078-0432.CCR-103068.

Lin, C.Y., Erkek, S., Tong, Y., Yin, L., Federation, A.J., Zapatka, M., Haldipur, P., Kawauchi, D., Risch, T., Warnatz, H.J., et al. (2016). Active medulloblastoma enhancers reveal subgroup-specific cellular origins. Nature 530, 57-62. 10.1038/nature16546.

Lindskrog, S.V., Prip, F., Lamy, P., Taber, A., Groeneveld, C.S., Birkenkamp-Demtroder, K., Jensen, J.B., Strandgaard, T., Nordentoft, I., Christensen, E., et al. (2021). An integrated multi-omics analysis identifies prognostic molecular subtypes of non-muscle-invasive bladder cancer. Nat Commun 12, 2301. 10.1038/s41467-021-22465-w.

Liu, C., Tate, T., Batourina, E., Truschel, S.T., Potter, S., Adam, M., Xiang, T., Picard, M., Reiley, M., Schneider, K., et al. (2019a). Pparg promotes differentiation and regulates mitochondrial gene expression in bladder epithelial cells. Nat Commun 10, 4589. 10.1038/s41467-019-12332-0.

Liu, J., Ni, X., Li, Y., Chen, M., Chen, W., Wu, Y., Chen, B., Wu, Y., and Xu, M. (2019b). Downregulation of IQGAP1 inhibits epithelial-mesenchymal transition via the HIF1alpha/VEGF-A signaling pathway in gastric cancer. J Cell Biochem 120, 15790-15799. 10.1002/jcb.28849.

Liu, T., Ortiz, J.A., Taing, L., Meyer, C.A., Lee, B., Zhang, Y., Shin, H., Wong, S.S., Ma, J., Lei, Y., et al. (2011). Cistrome: an integrative platform for transcriptional regulation studies. Genome Biol 12, R83. 10.1186/gb-2011-12-8-r83.

Livak, K.J., and Schmittgen, T.D. (2001). Analysis of relative gene expression data using real-time quantitative PCR and the 2(-Delta Delta C(T)) Method. Methods 25, 402-408. 10.1006/meth.2001.1262.

Llorens, M.C., Rossi, F.A., Garcia, I.A., Cooke, M., Abba, M.C., Lopez-Haber, C., BarrioReal, L., Vaglienti, M.V., Rossi, M., Bocco, J.L., et al. (2019). PKCalpha Modulates Epithelialto-Mesenchymal Transition and Invasiveness of Breast Cancer Cells Through ZEB1. Front Oncol 9, 1323. 10.3389/fonc.2019.01323.

Ma, B., Li H., Zhang C., Cai Q., Li G., Xu Y. (2014). Expression of MAP4K4 in bladder cancer and its biological effect on human bladder cancer T24 cells. Chinese Journal of Urology, 469472.

Ma, L., Yan, H., Zhao, H., and Sun, J. (2017). Grainyhead-like 2 in development and cancer. Tumour Biol 39, 1010428317698375. 10.1177/1010428317698375.

Ma, Y., Jin, Z., Huang, J., Zhou, S., Ye, H., Jiang, S., and Yu, K. (2013). IQGAP1 plays an important role in the cell proliferation of multiple myeloma via the MAP kinase (ERK) pathway. Oncol Rep 30, 3032-3038. 10.3892/or.2013.2785.

Milde-Langosch, K. (2005). The Fos family of transcription factors and their role in tumourigenesis. Eur J Cancer 41, 2449-2461. 10.1016/j.ejca.2005.08.008.

Nakazawa, N., Sathe, A.R., Shivashankar, G.V., and Sheetz, M.P. (2016). Matrix mechanics controls FHL2 movement to the nucleus to activate p21 expression. Proc Natl Acad Sci U S A 113, E6813-E6822. 10.1073/pnas.1608210113.

Nam, G.S., Kim, S., Kwon, Y.S., Kim, M.K., and Nam, K.S. (2021). A new function for MAP4K4 inhibitors during platelet aggregation and platelet-mediated clot retraction. Biochem Pharmacol 188, 114519. 10.1016/j.bcp.2021.114519.

Onal, S., Turker-Burhan, M., Bati-Ayaz, G., Yanik, H., and Pesen-Okvur, D. (2021). Breast cancer cells and macrophages in a paracrine-juxtacrine loop. Biomaterials 267, 120412. 10.1016/j.biomaterials.2020.120412.

Osman, M.A., Antonisamy, W.J., and Yakirevich, E. (2020). IQGAP1 control of centrosome function defines distinct variants of triple negative breast cancer. Oncotarget 11, 2493-2511. 10.18632/oncotarget.27623.

Park, H.S., Lee, S., Lee, J., Shin, H.B., Yoo, S.M., Lee, M.S., and Park, J. (2019). Suppression of CD81 promotes bladder cancer cell invasion through increased matrix metalloproteinase expression via extracellular signal-regulated kinase phosphorylation. Investig Clin Urol 60, 396-404. 10.4111/icu.2019.60.5.396.

Prolo, L.M., Li, A., Owen, S.F., Parker, J.J., Foshay, K., Nitta, R.T., Morgens, D.W., Bolin, S., Wilson, C.M., Vega, L.J., et al. (2019). Targeted genomic CRISPR-Cas9 screen identifies 
MAP4K4 as essential for glioblastoma invasion. Sci Rep 9, 14020. 10.1038/s41598-01950160-w.

Rafiee, M.R., Girardot, C., Sigismondo, G., and Krijgsveld, J. (2016). Expanding the Circuitry of Pluripotency by Selective Isolation of Chromatin-Associated Proteins. Mol Cell 64, 624635. 10.1016/j.molcel.2016.09.019.

Rafiee, M.R., Sigismondo, G., Kalxdorf, M., Forster, L., Brugger, B., Bethune, J., and Krijgsveld, J. (2020). Protease-resistant streptavidin for interaction proteomics. Mol Syst Biol 16, e9370. 10.15252/msb.20199370.

Ramakrishnan, S., Huss, W., Foster, B., Ohm, J., Wang, J., Azabdaftari, G., Eng, K.H., and Woloszynska-Read, A. (2018). Transcriptional changes associated with in vivo growth of muscle-invasive bladder cancer cell lines in nude mice. Am J Clin Exp Urol 6, 138-148.

Ramirez, F., Ryan, D.P., Gruning, B., Bhardwaj, V., Kilpert, F., Richter, A.S., Heyne, S., Dundar, F., and Manke, T. (2016). deepTools2: a next generation web server for deepsequencing data analysis. Nucleic Acids Res 44, W160-165. 10.1093/nar/gkw257.

Ritchie, M.E., Phipson, B., Wu, D., Hu, Y., Law, C.W., Shi, W., and Smyth, G.K. (2015). limma powers differential expression analyses for RNA-sequencing and microarray studies. Nucleic Acids Res 43, e47. 10.1093/nar/gkv007.

Robertson, A.G., Kim, J., Al-Ahmadie, H., Bellmunt, J., Guo, G., Cherniack, A.D., Hinoue, T., Laird, P.W., Hoadley, K.A., Akbani, R., et al. (2017). Comprehensive Molecular Characterization of Muscle-Invasive Bladder Cancer. Cell 171, 540-556 e525. 10.1016/j.cell.2017.09.007.

Ross-Innes, C.S., Stark, R., Teschendorff, A.E., Holmes, K.A., Ali, H.R., Dunning, M.J., Brown, G.D., Gojis, O., Ellis, I.O., Green, A.R., et al. (2012). Differential oestrogen receptor binding is associated with clinical outcome in breast cancer. Nature 481, 389-393. 10.1038/nature10730.

Sanli, O., Dobruch, J., Knowles, M.A., Burger, M., Alemozaffar, M., Nielsen, M.E., and Lotan, Y. (2017). Bladder cancer. Nat Rev Dis Primers 3, 17022. 10.1038/nrdp.2017.22.

Sayan, A.E., Stanford, R., Vickery, R., Grigorenko, E., Diesch, J., Kulbicki, K., Edwards, R., Pal, R., Greaves, P., Jariel-Encontre, I., et al. (2012). Fra-1 controls motility of bladder cancer cells via transcriptional upregulation of the receptor tyrosine kinase AXL. Oncogene 31, 1493-1503. 10.1038/onc.2011.336.

Scheiber, M.N., Watson, P.M., Rumboldt, T., Stanley, C., Wilson, R.C., Findlay, V.J., Anderson, P.E., and Watson, D.K. (2014). FLI1 expression is correlated with breast cancer cellular growth, migration, and invasion and altered gene expression. Neoplasia 16, 801-813. 10.1016/j.neo.2014.08.007.

Schneider, C.A., Rasband, W.S., and Eliceiri, K.W. (2012). NIH Image to ImageJ: 25 years of image analysis. Nat Methods 9, 671-675. 10.1038/nmeth.2089.

Scrucca, L., Fop, M., Murphy, T.B., and Raftery, A.E. (2016). mclust 5: Clustering, Classification and Density Estimation Using Gaussian Finite Mixture Models. R J 8, 289-317.

Shen, J., Lv, X., and Zhang, L. (2020). GRHL2 Acts as an Anti-Oncogene in Bladder Cancer by Regulating ZEB1 in Epithelial-Mesenchymal Transition (EMT) Process. Onco Targets Ther 13, 2511-2522. 10.2147/OTT.S239120.

Sjodahl, G., Lauss, M., Lovgren, K., Chebil, G., Gudjonsson, S., Veerla, S., Patschan, O., Aine, M., Ferno, M., Ringner, M., et al. (2012). A molecular taxonomy for urothelial carcinoma. Clin Cancer Res 18, 3377-3386. 10.1158/1078-0432.CCR-12-0077-T.

Smith, J.M., Hedman, A.C., and Sacks, D.B. (2015). IQGAPs choreograph cellular signaling from the membrane to the nucleus. Trends Cell Biol 25, 171-184. 10.1016/j.tcb.2014.12.005. Sonpavde, G., Goldman, B.H., Speights, V.O., Lerner, S.P., Wood, D.P., Vogelzang, N.J., Trump, D.L., Natale, R.B., Grossman, H.B., and Crawford, E.D. (2009). Quality of pathologic response and surgery correlate with survival for patients with completely resected bladder cancer after neoadjuvant chemotherapy. Cancer 115, 4104-4109. 10.1002/cncr.24466.

Stark, R., and Brown, G.D. (2011). DiffBind: differential binding analysis of ChIP-seq peak data. (Bioconductor).

Sung, H., Ferlay, J., Siegel, R.L., Laversanne, M., Soerjomataram, I., Jemal, A., and Bray, F. (2021). Global Cancer Statistics 2020: GLOBOCAN Estimates of Incidence and Mortality 
Worldwide for 36 Cancers in 185 Countries. CA Cancer J Clin 71, 209-249. 10.3322/caac.21660.

Surov, A., Hainz, M., Holzhausen, H.J., Arnold, D., Katzer, M., Schmidt, J., Spielmann, R.P., and Behrmann, C. (2010). Skeletal muscle metastases: primary tumours, prevalence, and radiological features. Eur Radiol 20, 649-658. 10.1007/s00330-009-1577-1.

Szklarczyk, D., Gable, A.L., Nastou, K.C., Lyon, D., Kirsch, R., Pyysalo, S., Doncheva, N.T., Legeay, M., Fang, T., Bork, P., et al. (2021). The STRING database in 2021: customizable protein-protein networks, and functional characterization of user-uploaded gene/measurement sets. Nucleic Acids Res 49, D605-D612. 10.1093/nar/gkaa1074.

Tam, S.Y., Wu, V.W.C., and Law, H.K.W. (2020). Hypoxia-Induced Epithelial-Mesenchymal Transition in Cancers: HIF-1alpha and Beyond. Front Oncol 10, 486. 10.3389/fonc.2020.00486.

Thurman, R.E., Rynes, E., Humbert, R., Vierstra, J., Maurano, M.T., Haugen, E., Sheffield, N.C., Stergachis, A.B., Wang, H., Vernot, B., et al. (2012). The accessible chromatin landscape of the human genome. Nature 489, 75-82. 10.1038/nature11232.

Tripolitsioti, D., Kumar, K.S., Neve, A., Migliavacca, J., Capdeville, C., Rushing, E.J., Ma, M., Kijima, N., Sharma, A., Pruschy, M., et al. (2018). MAP4K4 controlled integrin beta1 activation and c-Met endocytosis are associated with invasive behavior of medulloblastoma cells. Oncotarget 9, 23220-23236. 10.18632/oncotarget.25294.

Tsai, H.P., Tsai, T.H., Hsieh, Y.J., Chen, Y.T., Lee, C.L., Tsai, Y.C., She, T.C., Lin, C.L., Chai, C.Y., and Kwan, A.L. (2017). Overexpression of Fli-1 in astrocytoma is associated with poor prognosis. Oncotarget 8, 29174-29186. 10.18632/oncotarget.16303.

Unpaired parametric t test was performed using GraphPad Prism version 8.3.0. for Windows (GraphPad Software).

van den Bosch, S., and Alfred Witjes, J. (2011). Long-term cancer-specific survival in patients with high-risk, non-muscle-invasive bladder cancer and tumour progression: a systematic review. Eur Urol 60, 493-500. 10.1016/j.eururo.2011.05.045.

Vial, E., Sahai, E., and Marshall, C.J. (2003). ERK-MAPK signaling coordinately regulates activity of Rac1 and RhoA for tumor cell motility. Cancer Cell 4, 67-79. 10.1016/s15356108(03)00162-4.

von Mering, C., Huynen, M., Jaeggi, D., Schmidt, S., Bork, P., and Snel, B. (2003). STRING: a database of predicted functional associations between proteins. Nucleic Acids Res 31 , 258-261. 10.1093/nar/gkg034.

Wang, H., Ou, Y., Ou, J., and Jian, Z. (2018). Fli1 promotes metastasis by regulating MMP2 signaling in hepatocellular carcinoma. Mol Med Rep 17, 1986-1992. 10.3892/mmr.2017.8047.

Weber, M., Hellmann, I., Stadler, M.B., Ramos, L., Paabo, S., Rebhan, M., and Schubeler, D. (2007). Distribution, silencing potential and evolutionary impact of promoter DNA methylation in the human genome. Nat Genet 39, 457-466. 10.1038/ng1990.

Weikum, E.R., Liu, X., and Ortlund, E.A. (2018). The nuclear receptor superfamily: A structural perspective. Protein Sci 27, 1876-1892. 10.1002/pro.3496.

Wickham, H. (2016). ggplot2: Elegant Graphics for Data Analysis (Springer-Verlag).

Xu, J., Lamouille, S., and Derynck, R. (2009). TGF-beta-induced epithelial to mesenchymal transition. Cell Res 19, 156-172. 10.1038/cr.2009.5.

Yao, R., Lemon, W.J., Wang, Y., Grubbs, C.J., Lubet, R.A., and You, M. (2004). Altered gene expression profile in mouse bladder cancers induced by hydroxybutyl(butyl)nitrosamine. Neoplasia 6, 569-577. 10.1593/neo.04223.

Ye, J., Coulouris, G., Zaretskaya, I., Cutcutache, I., Rozen, S., and Madden, T.L. (2012). Primer-BLAST: a tool to design target-specific primers for polymerase chain reaction. BMC Bioinformatics 13, 134. 10.1186/1471-2105-13-134.

Yu, G., Wang, L.G., Han, Y., and He, Q.Y. (2012). clusterProfiler: an R package for comparing biological themes among gene clusters. OMICS 16, 284-287. 10.1089/omi.2011.0118.

Zhang, L., Mao, Y., Mao, Q., Fan, W., Xu, L., Chen, Y., Xu, L., and Wang, J. (2019). FLOT1 promotes tumor development, induces epithelial-mesenchymal transition, and modulates the 
cell cycle by regulating the Erk/Akt signaling pathway in lung adenocarcinoma. Thorac Cancer 10, 909-917. 10.1111/1759-7714.13027.

Zhang, X., Wu, J., Luo, S., Lechler, T., and Zhang, J.Y. (2016). FRA1 promotes squamous cell carcinoma growth and metastasis through distinct AKT and c-Jun dependent mechanisms. Oncotarget 7, 34371-34383. 10.18632/oncotarget.9110.

Zhang, Y., Liu, T., Meyer, C.A., Eeckhoute, J., Johnson, D.S., Bernstein, B.E., Nusbaum, C., Myers, R.M., Brown, M., Li, W., and Liu, X.S. (2008). Model-based analysis of ChIP-Seq (MACS). Genome Biol 9, R137. 10.1186/gb-2008-9-9-r137.

Zhang, Y., and Mahony, S. (2019). Direct prediction of regulatory elements from partial data without imputation. PLoS Comput Biol 15, e1007399. 10.1371/journal.pcbi.1007399.

Zou, J., Huang, R., Li, H., Wang, B., Chen, Y., Chen, S., Ou, K., and Wang, X. (2019). Secreted TGF-beta-induced protein promotes aggressive progression in bladder cancer cells. Cancer Manag Res 11, 6995-7006. 10.2147/CMAR.S208984. 
Figure 1

A

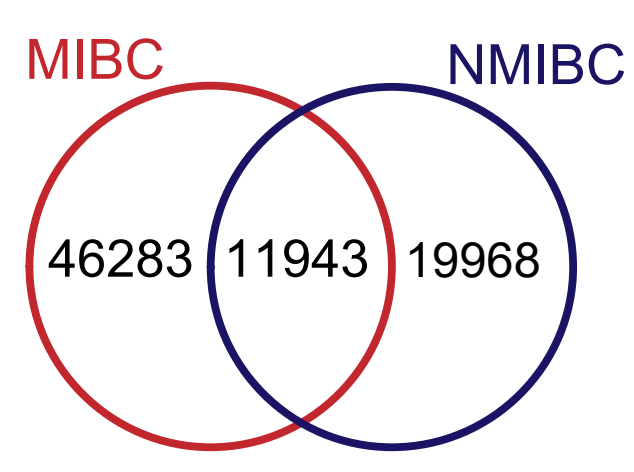

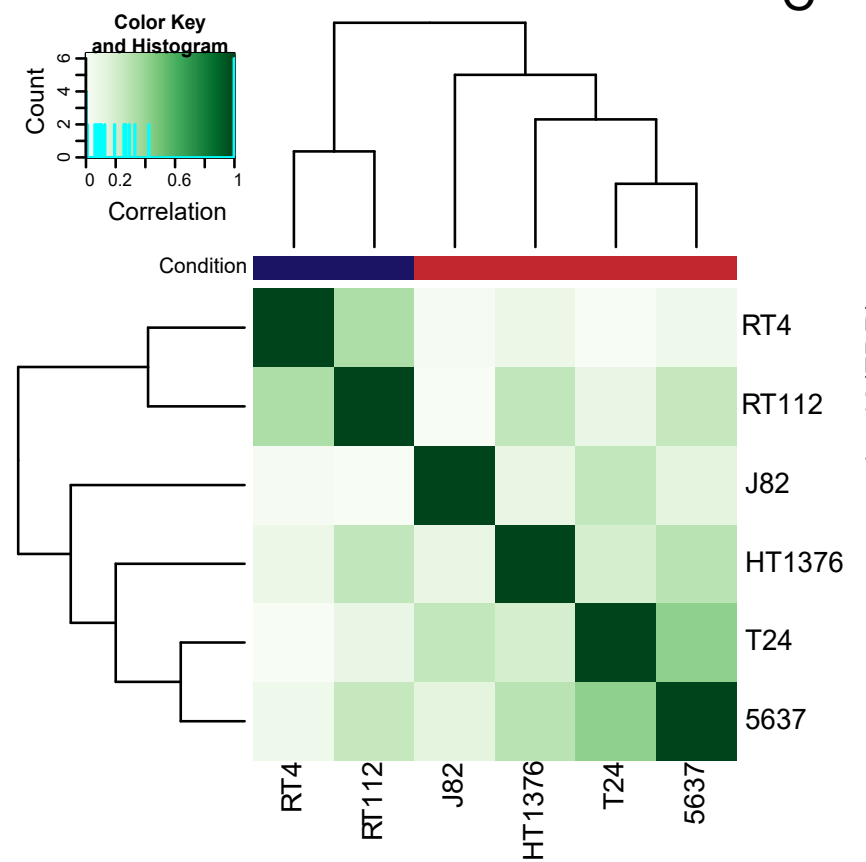

C

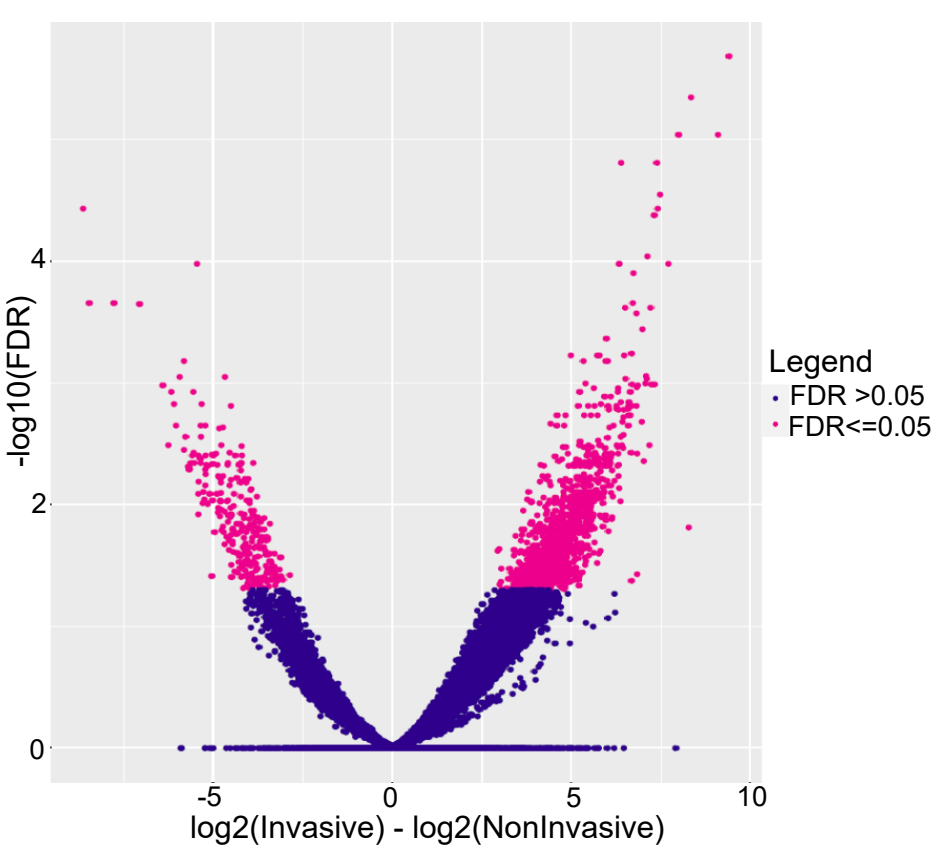

D

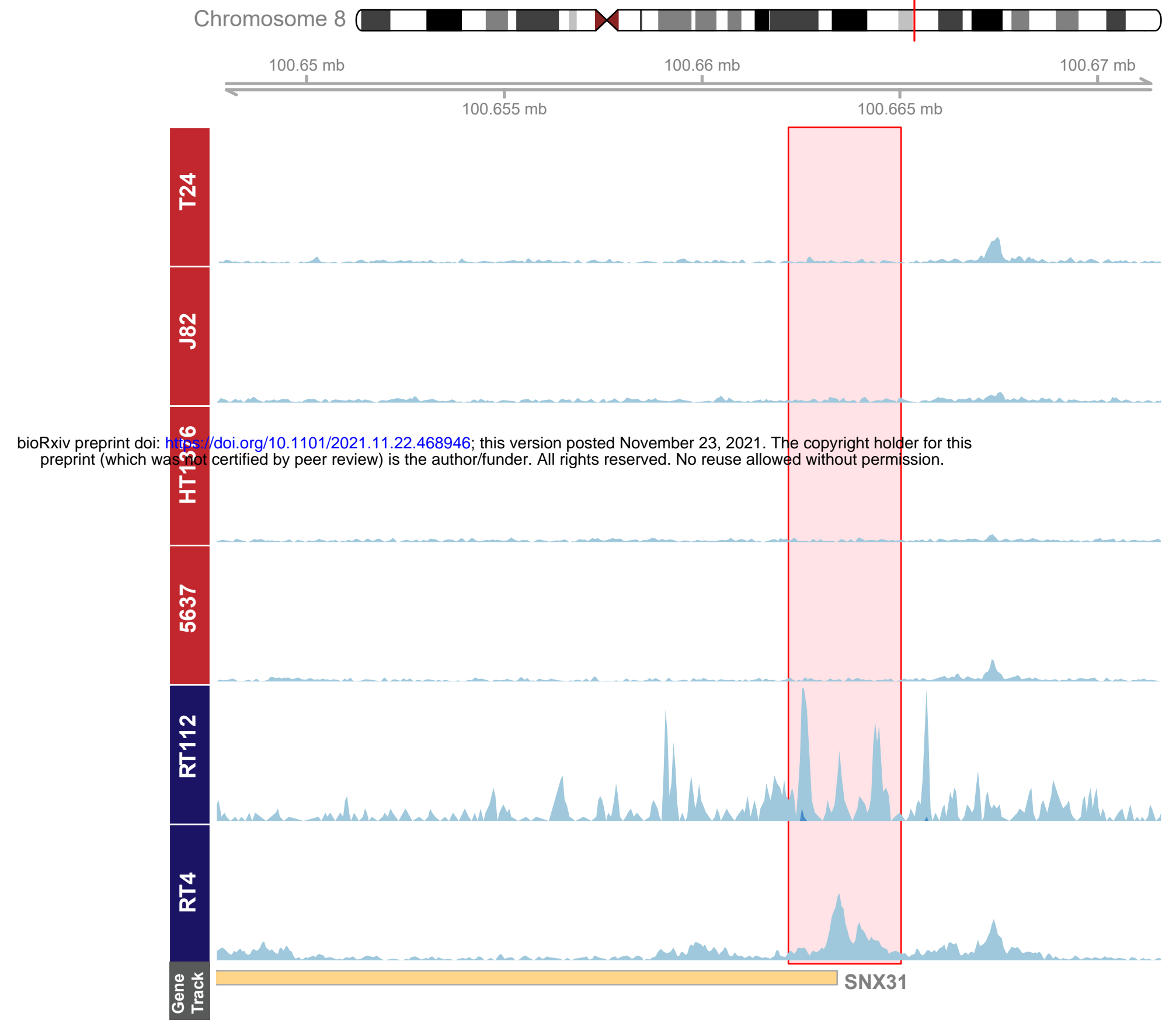

E

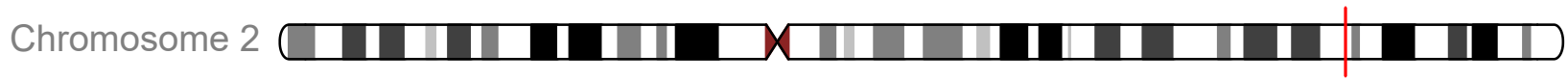

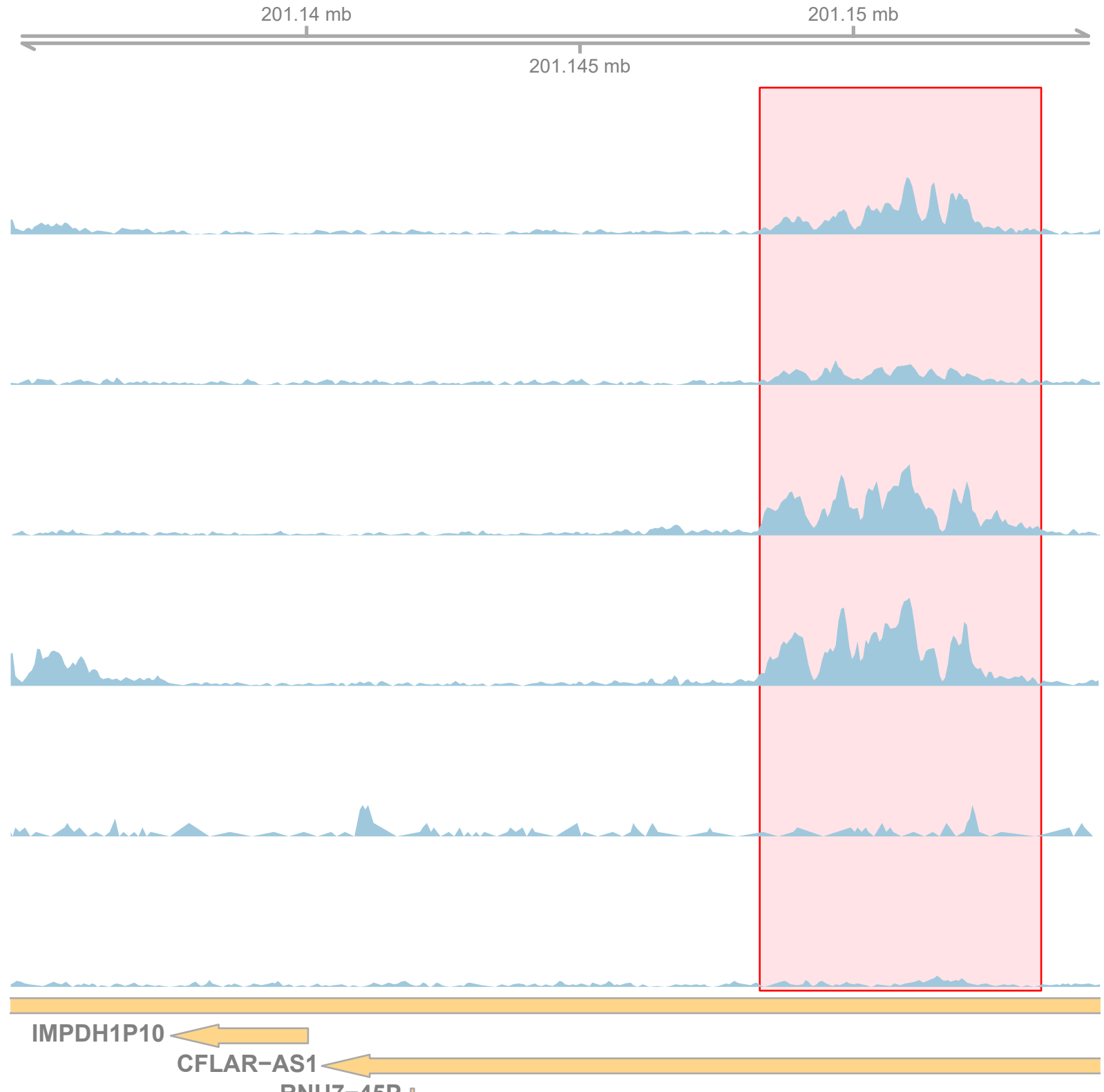

RNU7-45P 


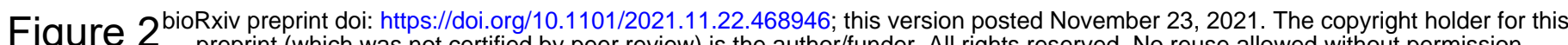
gure 2 preprint (which was not certified by peer review) is the authorffunder. All rights reserved. No reuse allowed without permission.

A

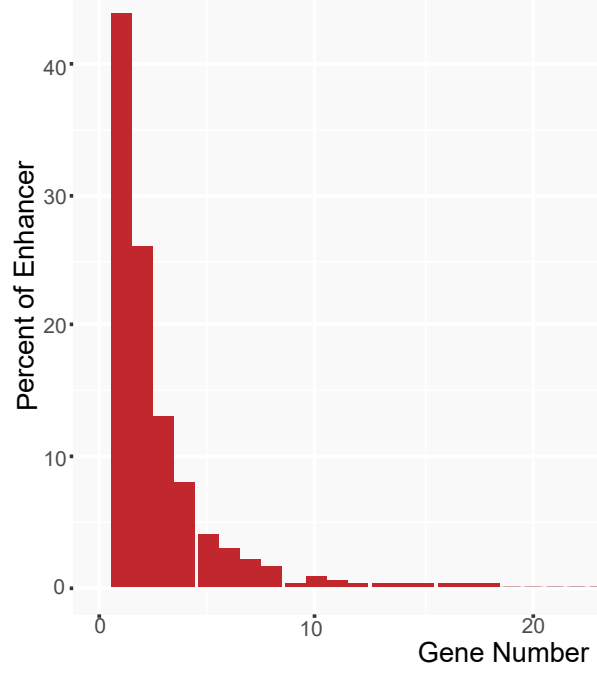

C

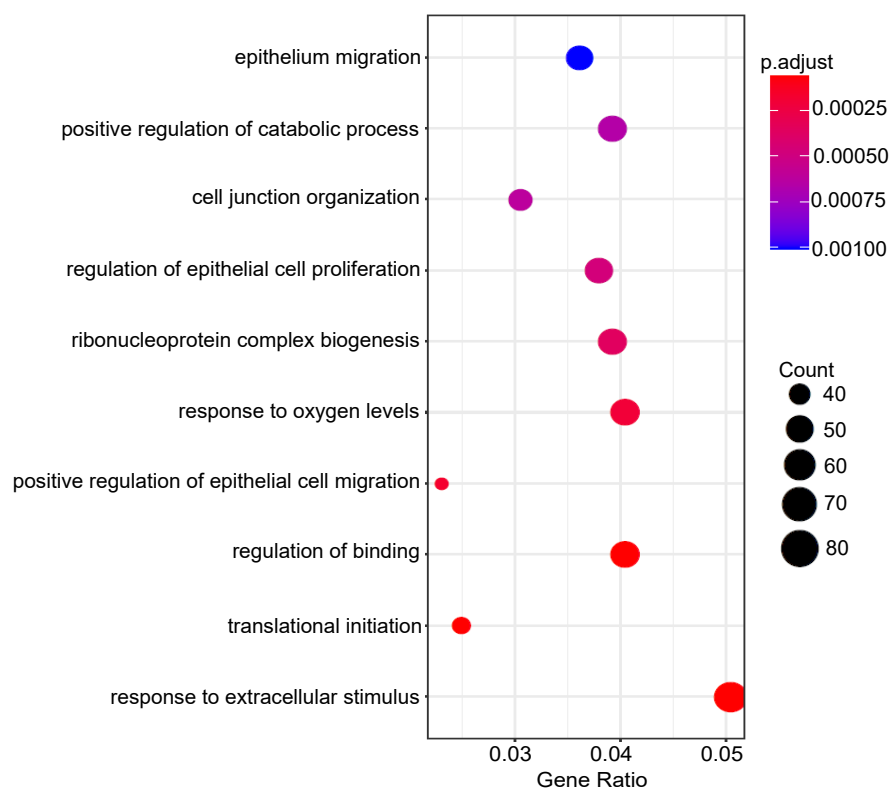

$\mathrm{E}$

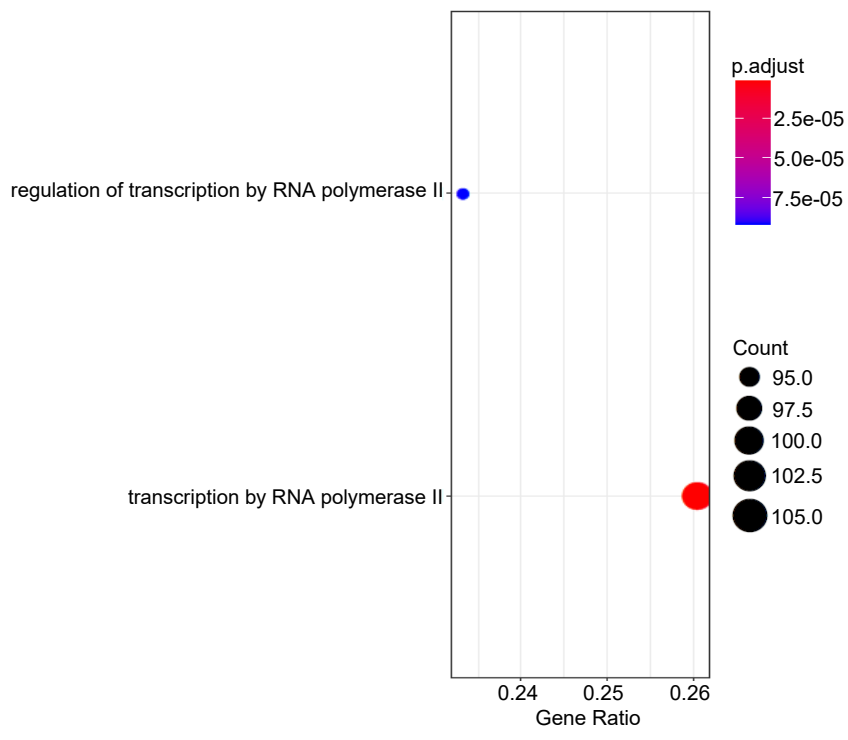

B

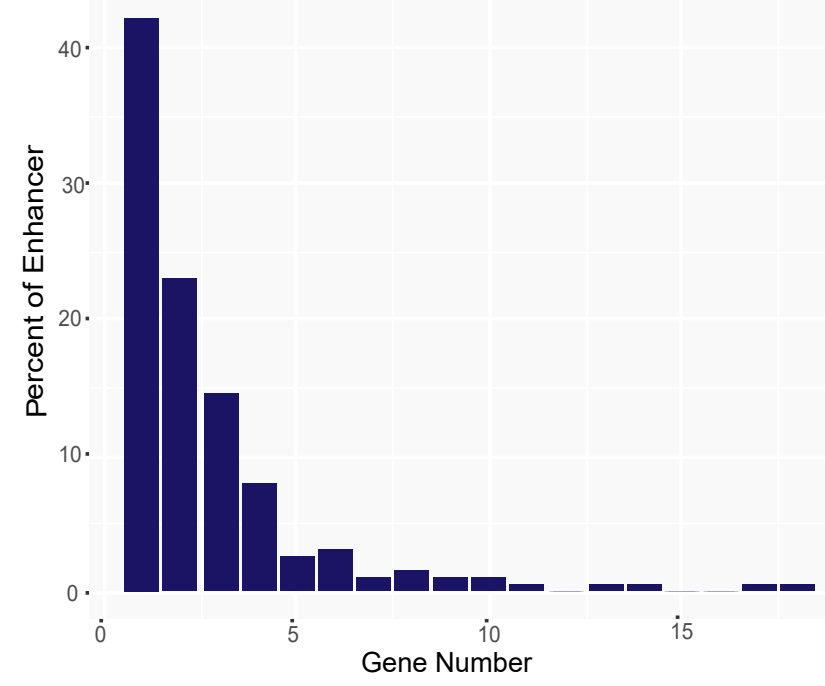

$\mathrm{D}$

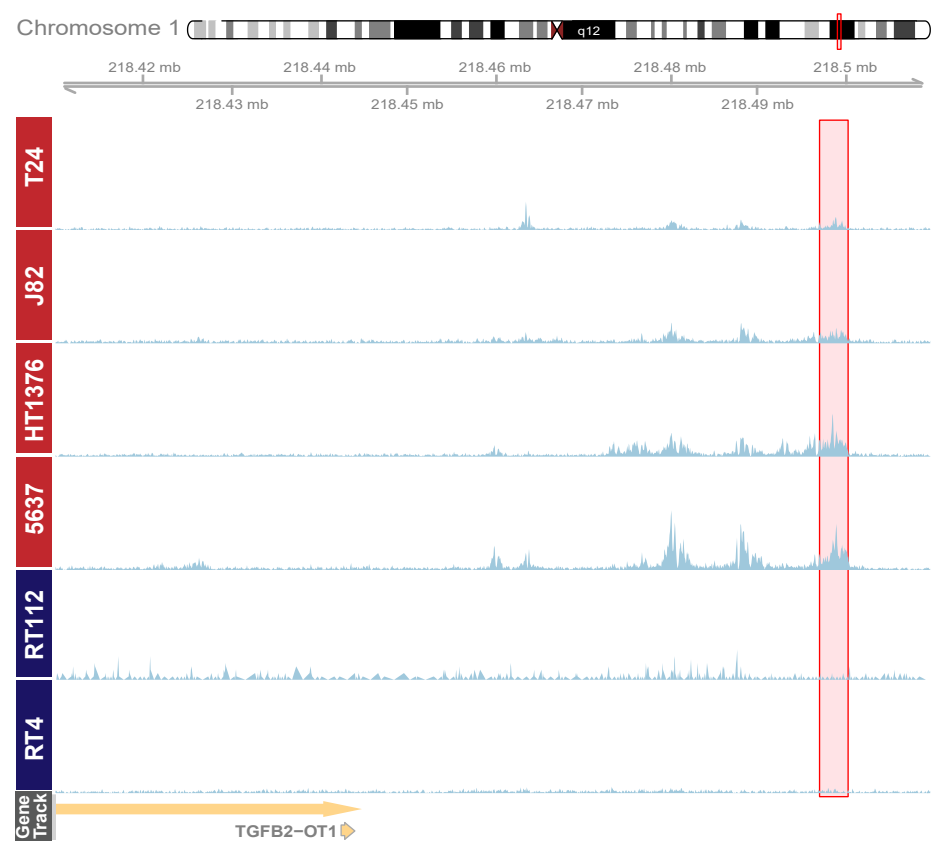

$\mathrm{F}$
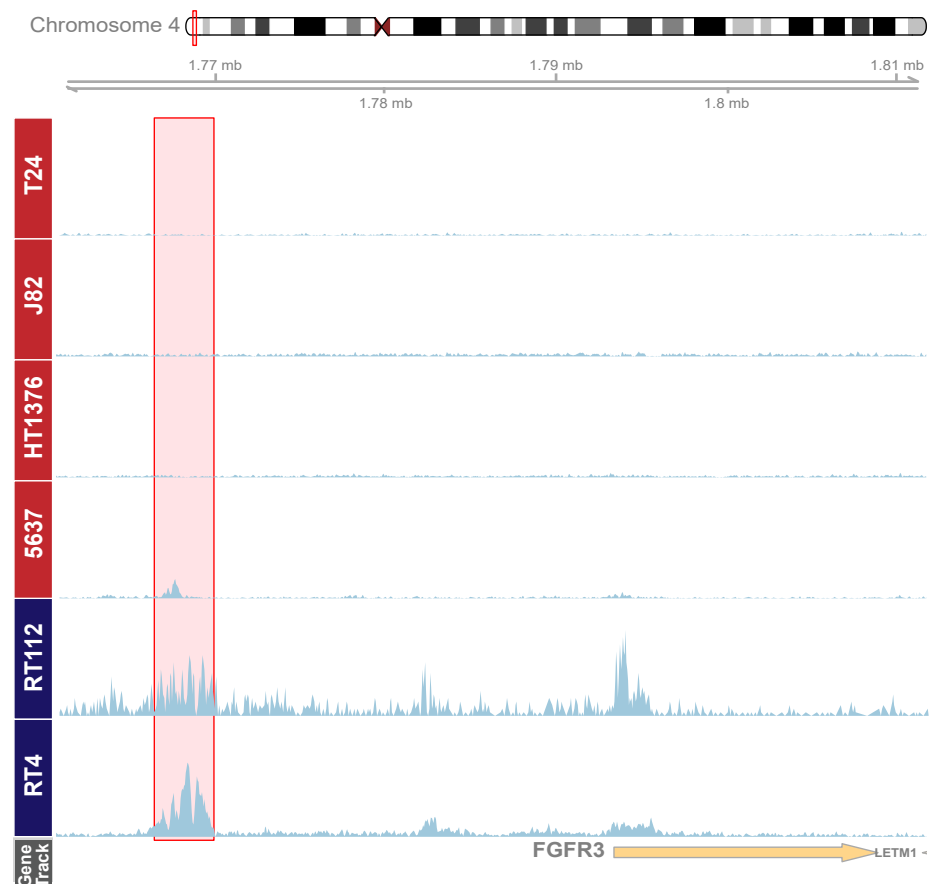
Fiqure 3 bioRxiv preprint doi: https://doi.org/10.1101/2021.11.22.468946; this version posted November 23, 2021. The copyright holder for this preprint (which was not certified by peer review) is the author/funder. All rights reserved. No reuse allowed without permission.

A

Known Motif

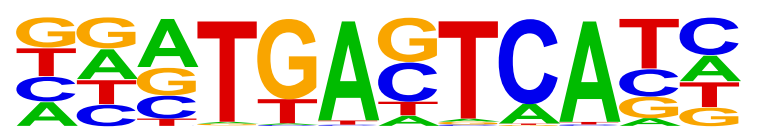

Transcription Factor (Best Enrichment)

FRA1

FLI1

1e-38

Transcription Factor

(Best Enrichment)

p63

1e-12

GRHL2

AAACCG TTRAACACTITE

IGACCTITGCCCCA
PPARG

1e-4
B
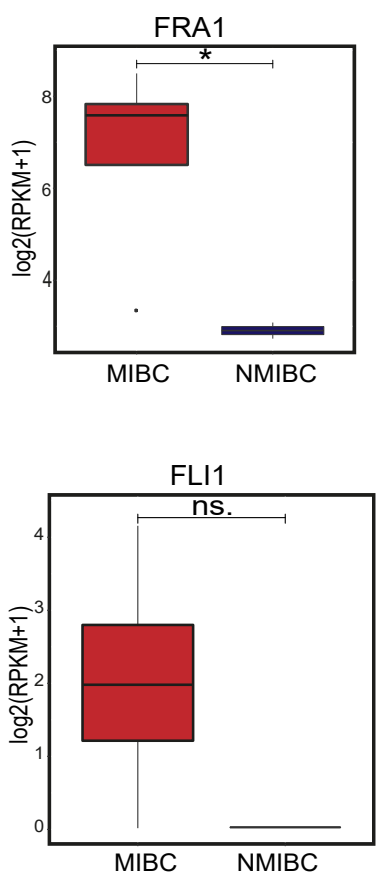

D
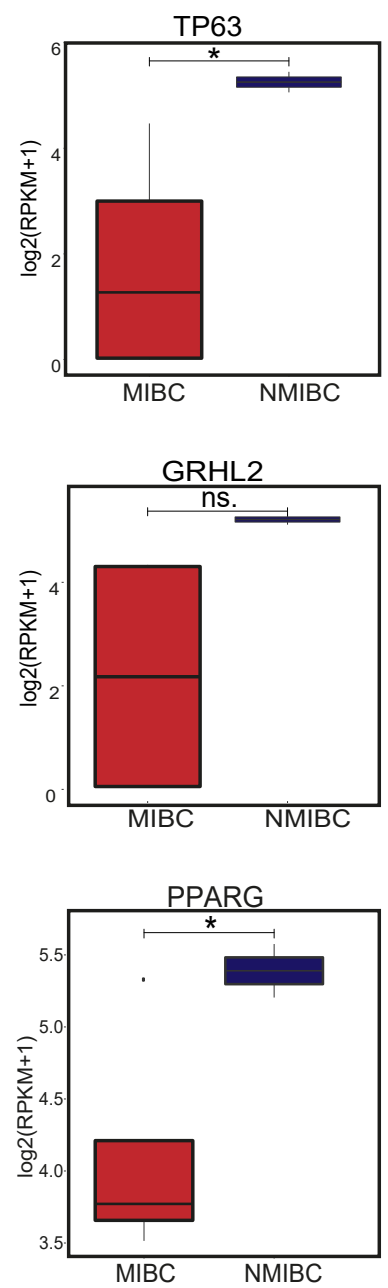


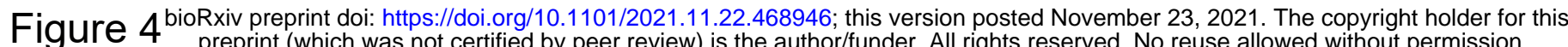
A

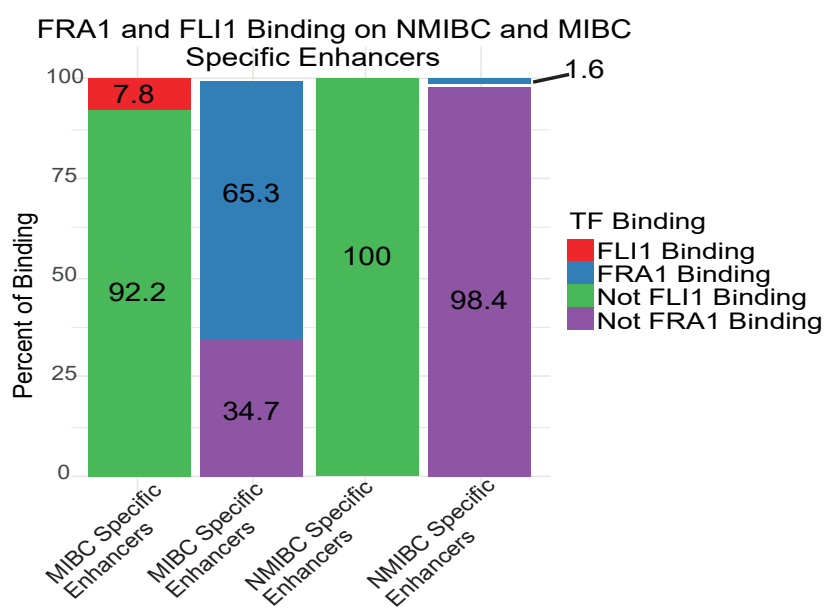

C

FRA1 Relative Expression
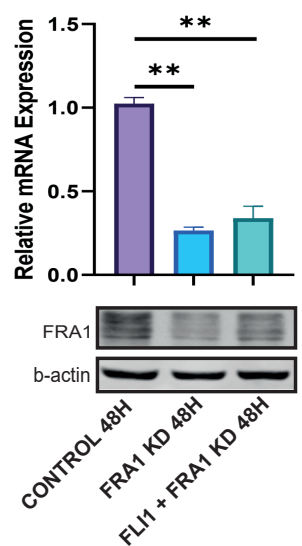

E

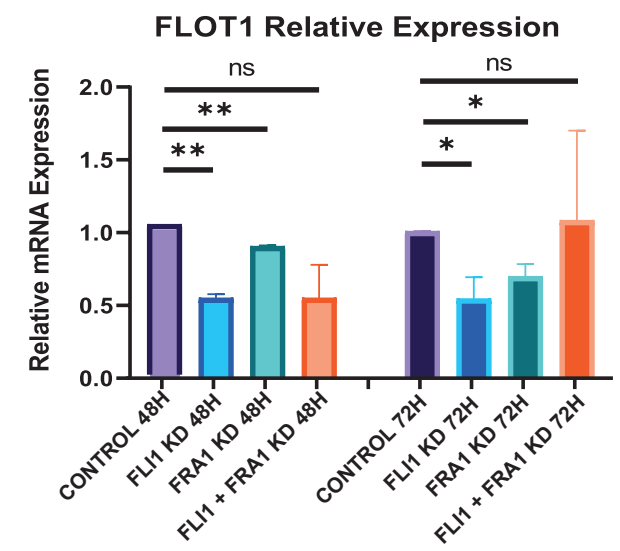

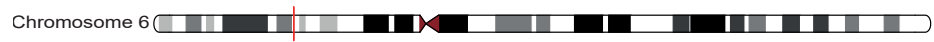

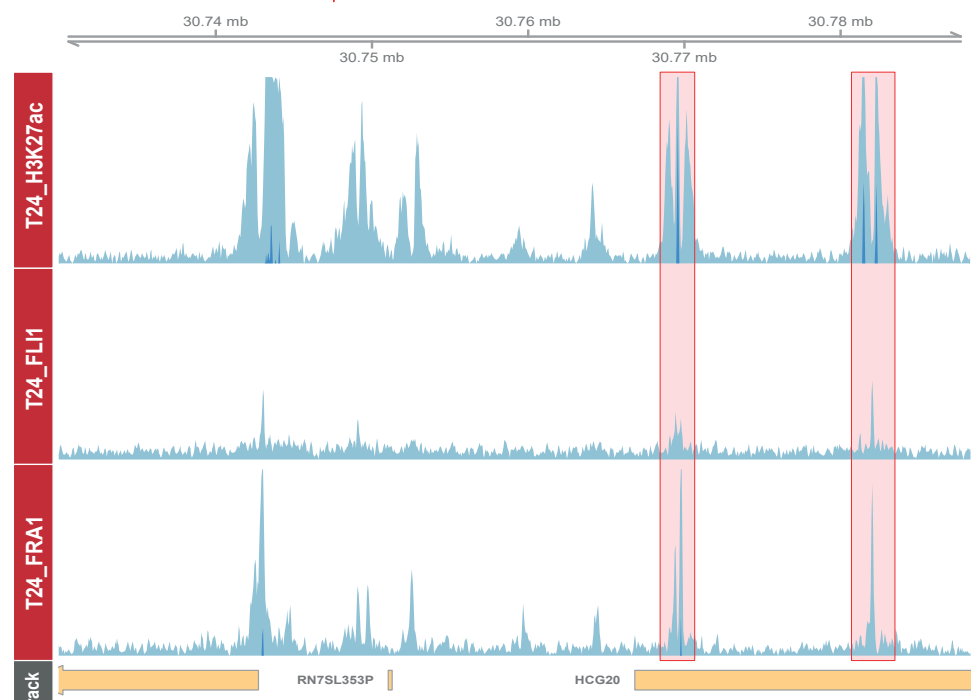
$\mathrm{B}$

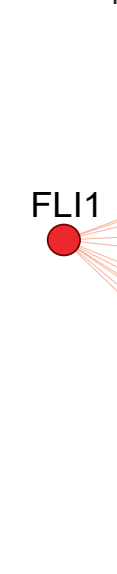

D
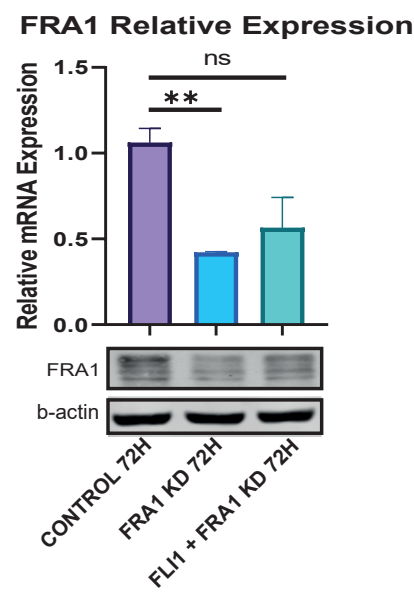

$\mathrm{F}$

FLI1
Regulation of epithelial cell proliferation

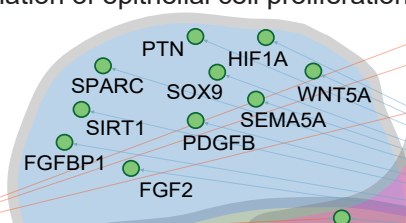

CSNK2B

OLOXL2 OANXA3

CORO1B

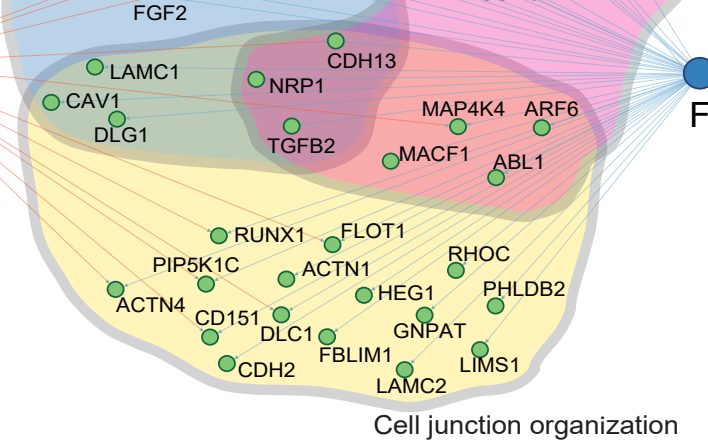

FLI1 Relative Expression
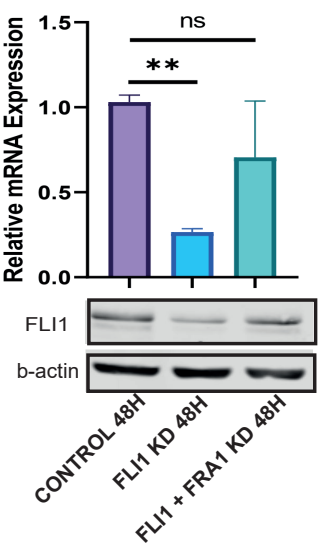

MAP4K4 Relative Expression

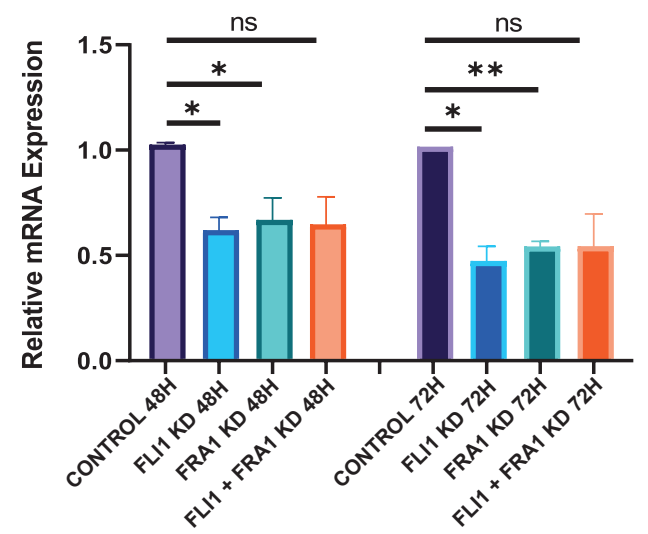

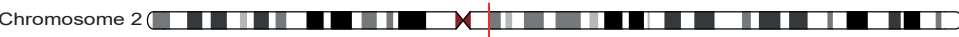

FLI1 Relative Expression

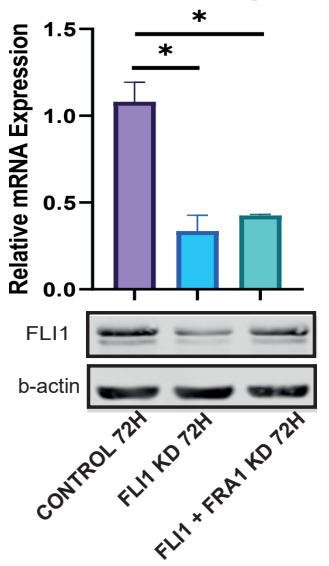

CAPN7 OSPRED1

STC1 PLK2

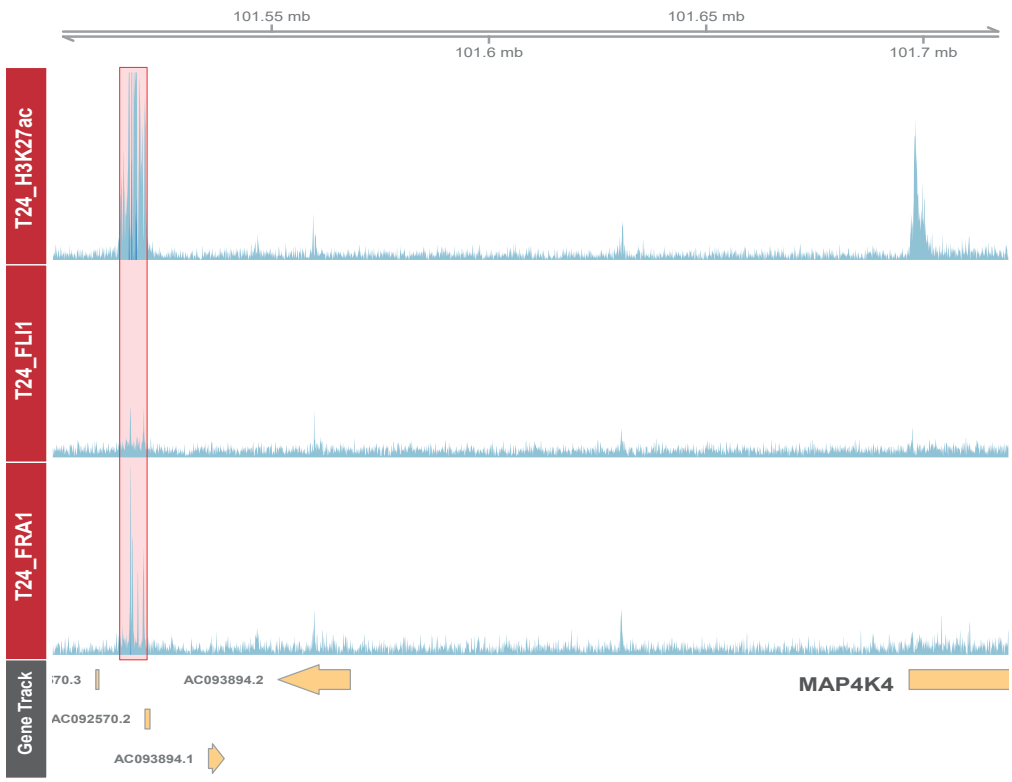




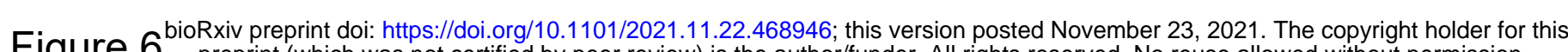
igure 6 preprint (which was not certified by peer review) is the author/funder. All rights reserved. No reuse allowed without permission.

A

(1) TF ChIP-seq \& GeneHancer Regulation

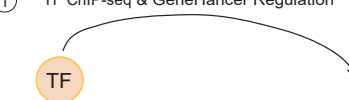

Enhancer Promoter

TF ChIP-SICAP \& Chromatin Factor ChIP-seq

(2)

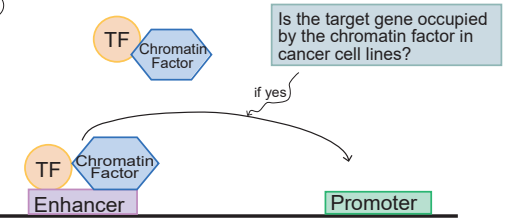

(3) TF ChIP-SICAP \& depMap $\begin{array}{ll}\text { Other } & \rightarrow \quad \begin{array}{l}\text { Is the other factor neccecary } \\ \text { for the target gene? }\end{array}\end{array}$

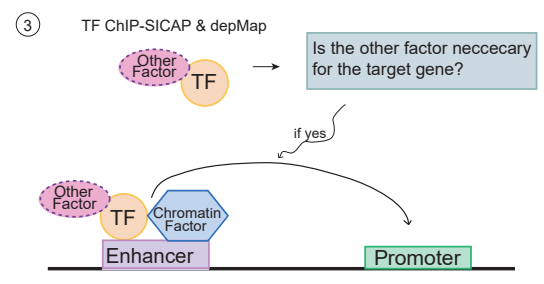

Enhancer
B

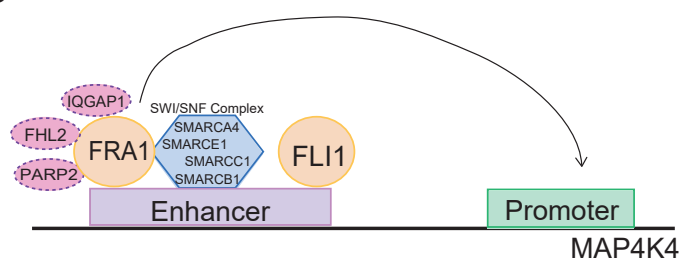

D

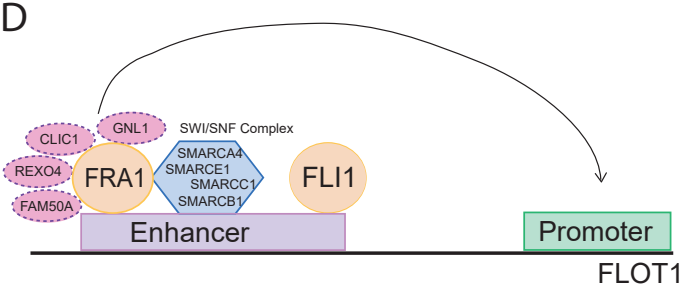

C

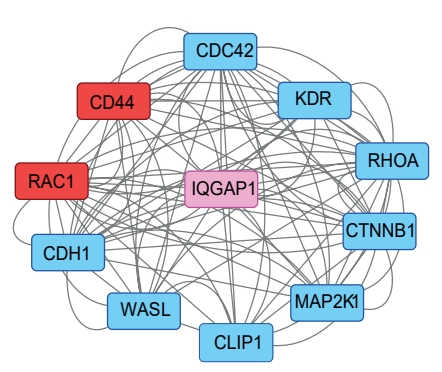

E
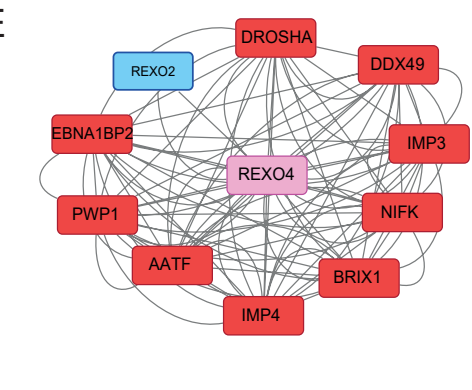
Figure 7 bioRxiv preprint doi: https://doi.org/10.1101/2021.11.22.468946; this version posted November 23, 2021. The copyright holder for this preprint (which was not certified by peer review) is the author/funder. All rights reserved. No reuse allowed without permission.

A

IC-CHIP Positive Control

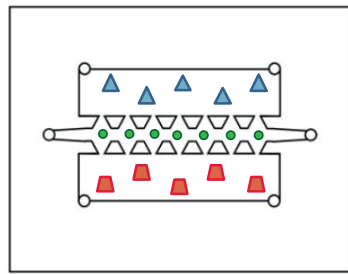

$\triangle$ Knockdowned Cells

- 1:1 Matrigel : FBS free medium

- $10 \%$ FBS containing medium
IC-CHIP Negative Control

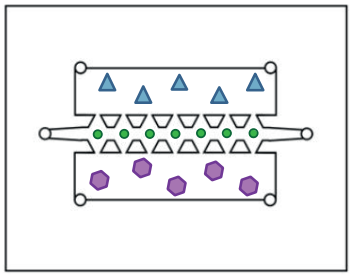

$\triangle$ Knockdowned Cells

1:1 Matrigel : FBS free medium

- FBS free medium
IC-CHIP Muscle Microenvironment

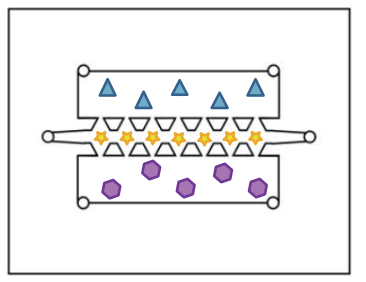

$\triangle$ Knockdowned Cells

1:1 Matrigel : C2C12 cells in FBS free medium FBS free medium

B

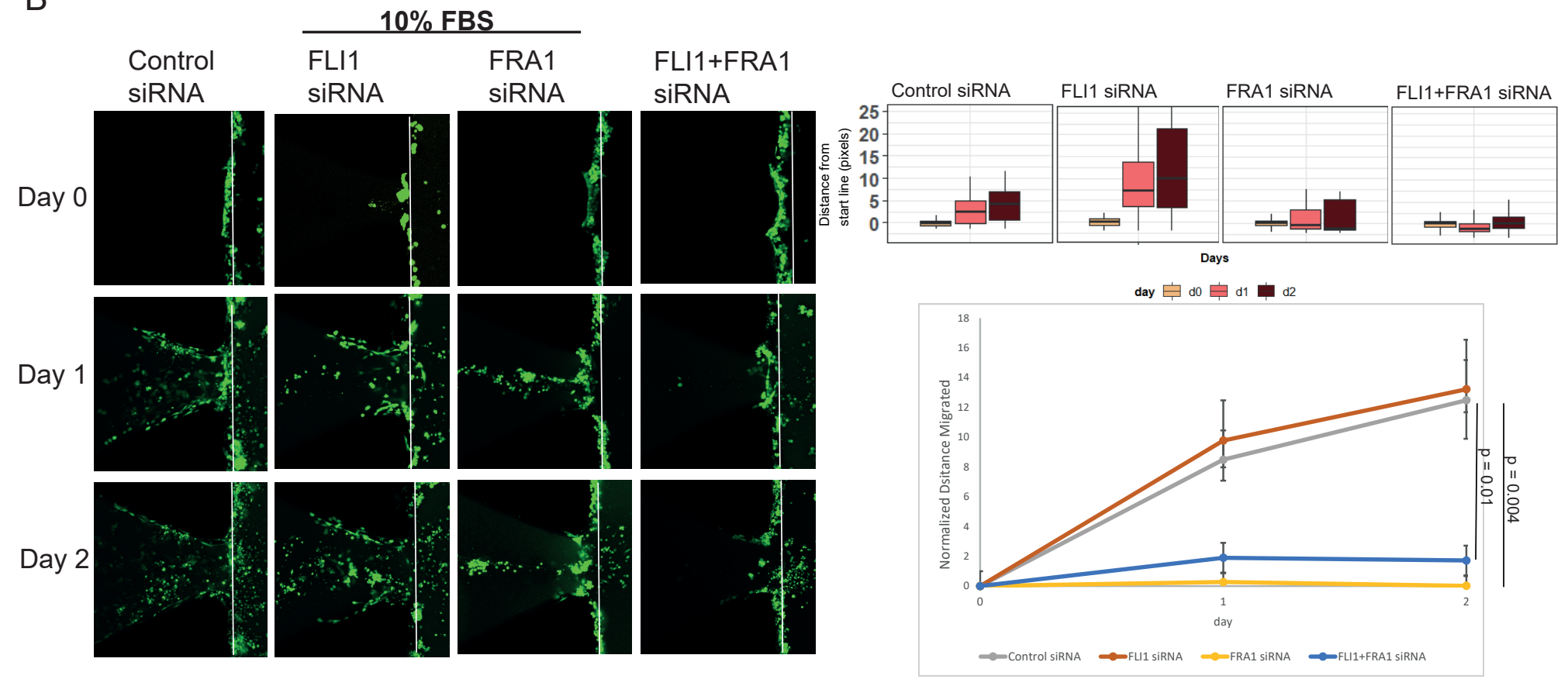

C

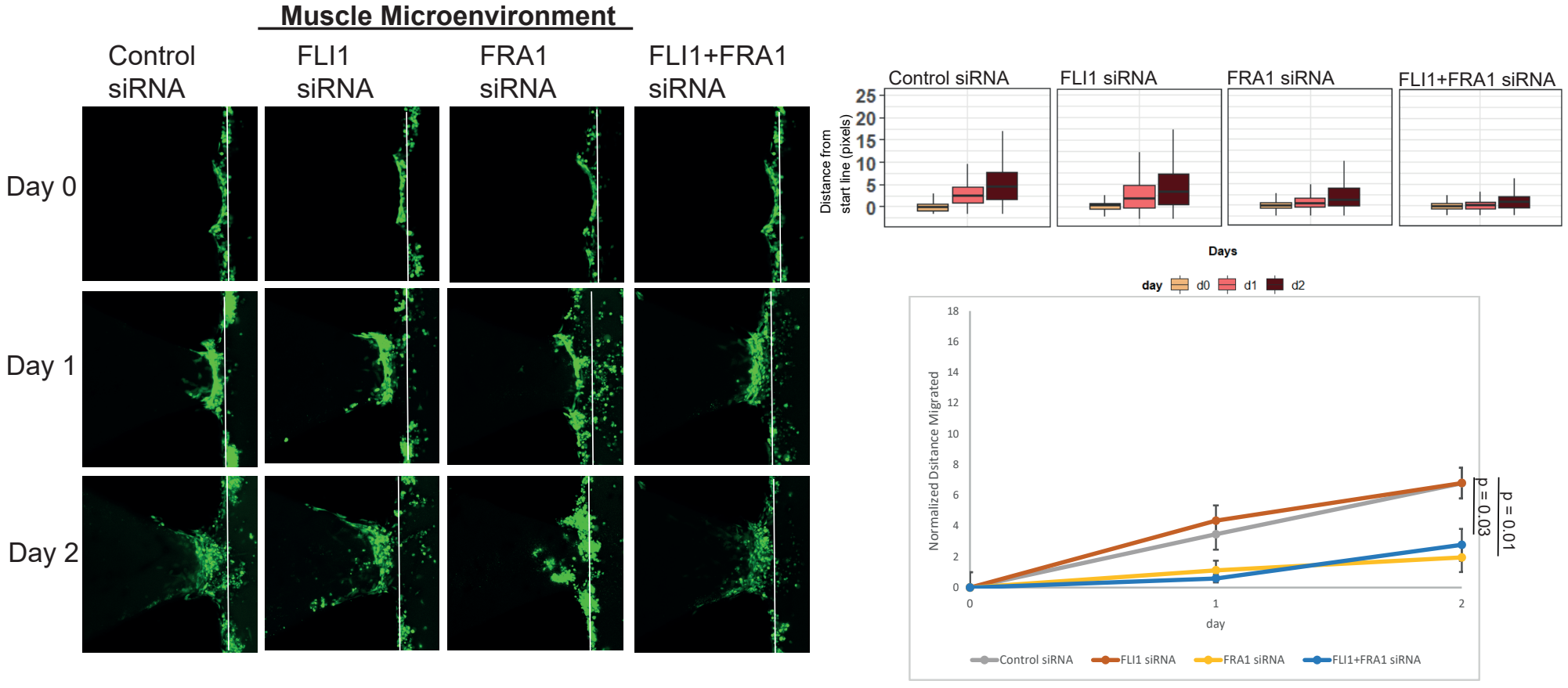




\section{SUPPLEMENTAL INFORMATION}

FLI1 and FRA1 transcription factors drive the transcriptional regulatory networks characterizing muscle invasive bladder cancer

Perihan Yagmur Guneri-Sozeri, Gulden Ozden Yilmaz, Asli Kisim, Aleyna Eray, Hamdiye Uzuner, Gökhan Karakülah, Devrim Pesen Okvur, Serif Senturk, Serap Erkek-Ozhan

Figure S1. Related to Figure 2. Distribution of the gene expression values in NMIBC and MIBC cell lines.

Figure S2. Related to Figure 3. Transcription factor motif enrichment analysis in MIBC cell lines.

Figure S3. Related to Figure 3. Transcription factor motif enrichment analysis in NMIBC cell lines.

Figure S4. Related to Figure 3. Expression level of transcription factors in primary MIBC and NMIBC tissue samples.

Figure S5. Related to Figure 4. Motif enrichment analysis at FRA1 and FLI1 ChIP-seq peaks.

Figure S6. Related to Figure 4. Expression level of EMT-related genes after FRA1 and FLI1 knockdown.

Figure S7. Related to Figure 4. Association of MAP4K4 expression with metastatic potential of MIBC.

Figure S8. Related to Figure 6. ChIP-seq signal of SWI/SNF complex components at MIBC enhancers regulating MAP4K4 and FLOT1.

Figure S9. Related to Figure 7. Knockdown efficiency of FLI1 and FRA1 in cells used in ICCHIP.

Figure S10. Related to Figure 7. Differentiation of $\mathrm{C} 2 \mathrm{C} 12$ cells and IC-CHIP assay in the presence and absence of FBS.

Figure S11. Related to Figure 7. Expression of key MIBC genes in T2 vs T3-T4 stage MIBC patients.

Table S1. Related to Figure 2. MIBC enhancers and their target genes.

Table S2. Related to Figure 2. NMIBC enhancers and their target genes.

Table S3. Related to Figure 2. Complete results of ClusterProfiler GO Term analysis for the target genes of MIBC enhancers.

Table S4. Related to Figure 2. List of transcription factors identified in target genes of NMIBC enhancers.

Table S5. Related to Figure 5. List of proteins identified to be interacting with FRA1 in T24 cell line according to ChIP-SICAP results. 
Table S6. Related to Figure 5. List of proteins identified to be interacting with FLI1 in T24 cell line according to ChIP-SICAP results.

Table S7. Related to Figure 4 and Figure S6. Primers used in RT-qPCR experiments. 


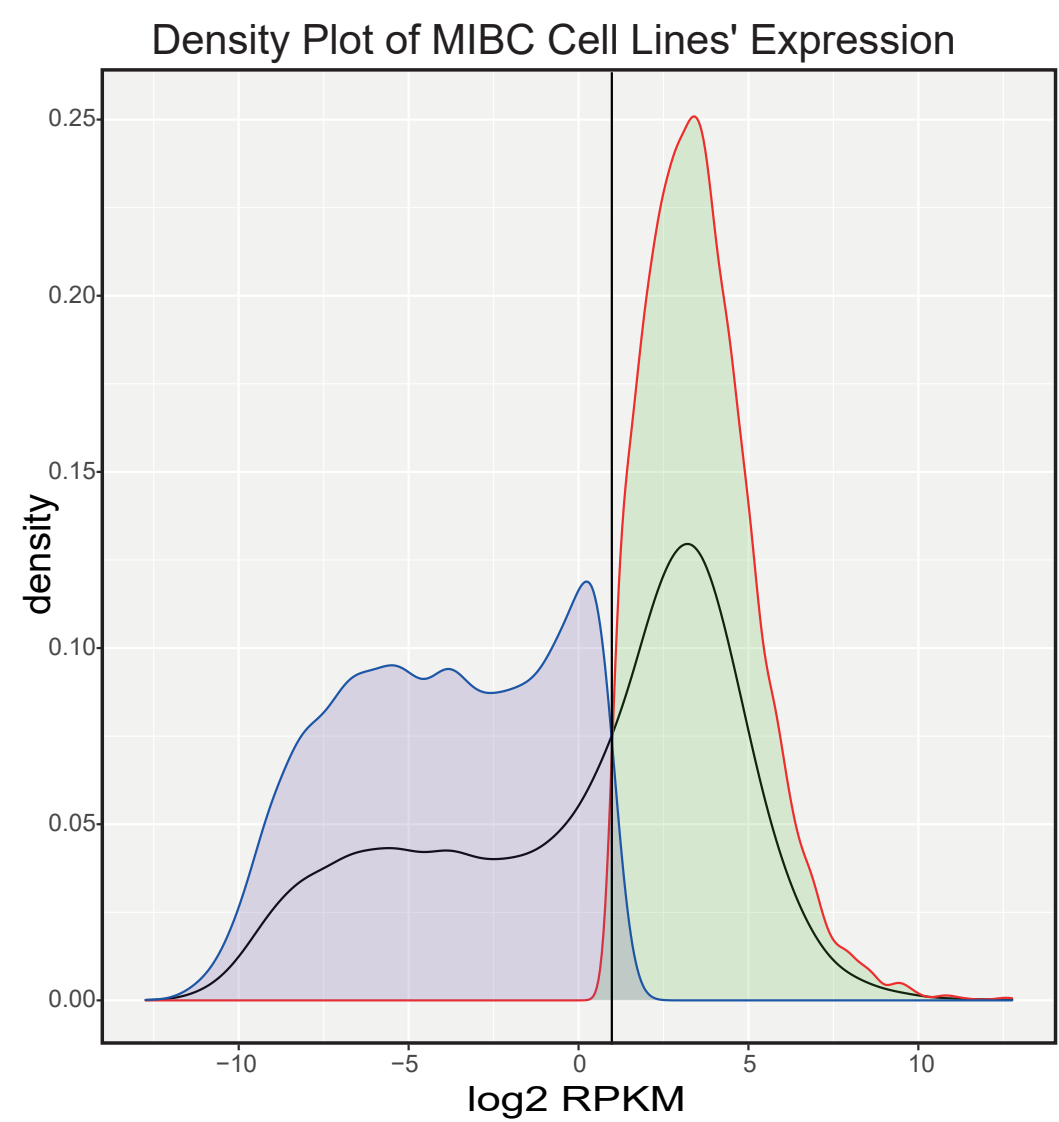

B

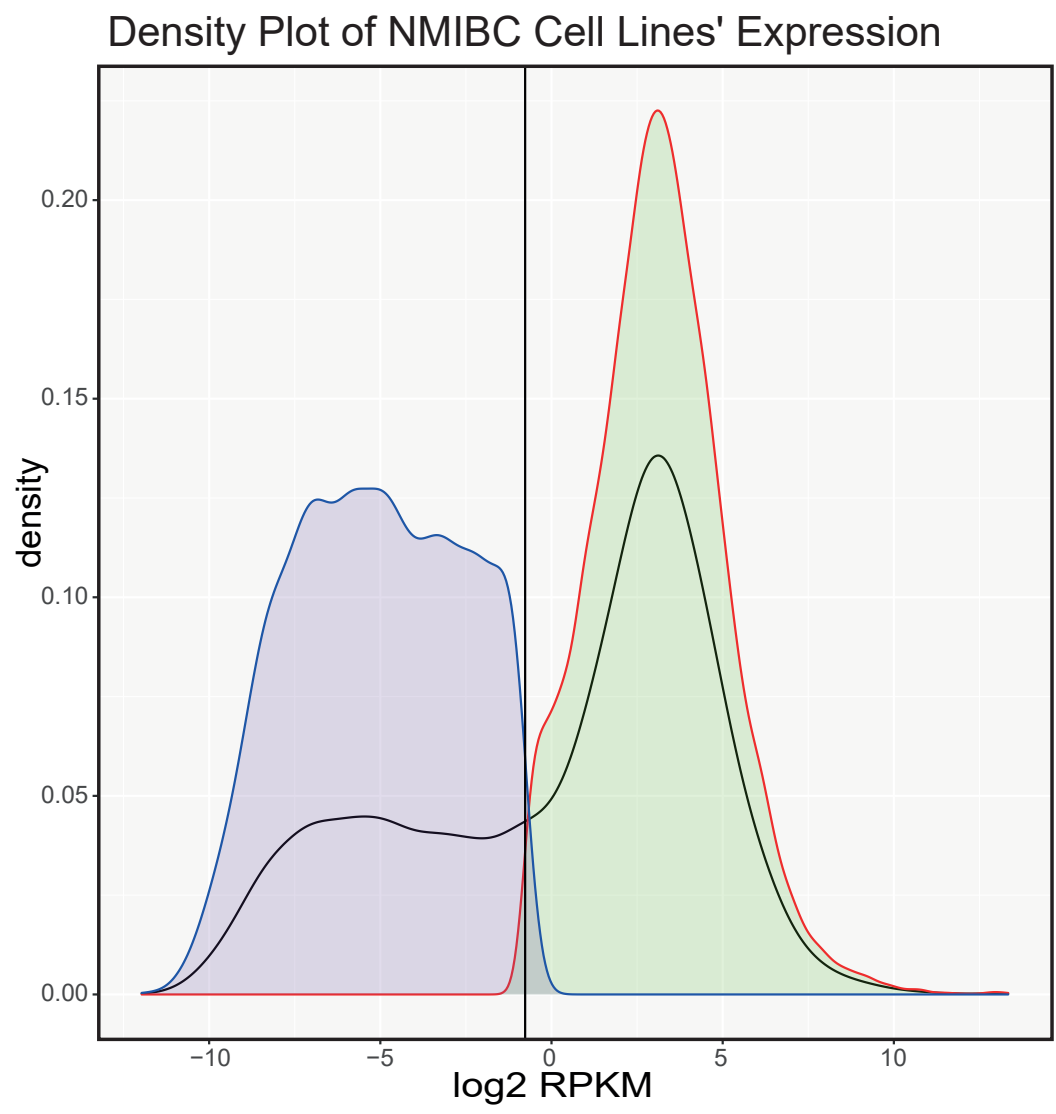

Figure S1. Distribution of the gene expression values in NMIBC and MIBC cell lines. Related to Figure 2. (A-B) Density plots displaying the average gene expression values in MIBC (A) and NMIBC (B) cell lines. Expressed genes were shown in green and not-expressed genes are shown in purple (using " $G=3$ " option and p-value $<0.05$ ). 


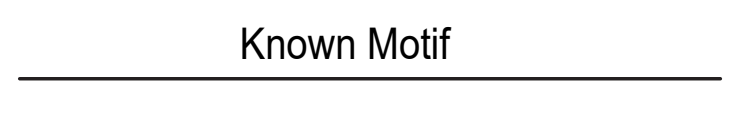

埕TGACETCAT돌술

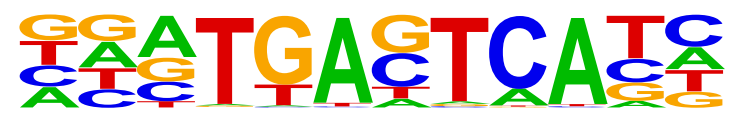
定合TGACTCAT ÂTGACTCATC TETGACTCAT

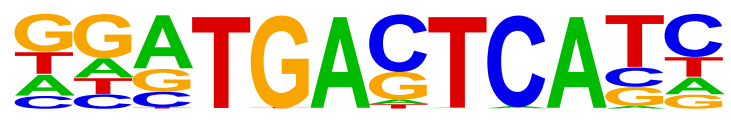

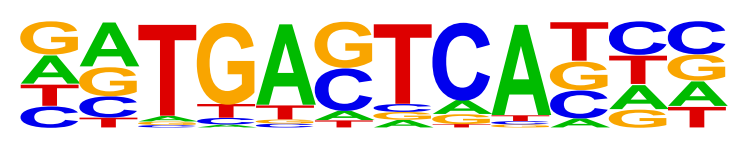

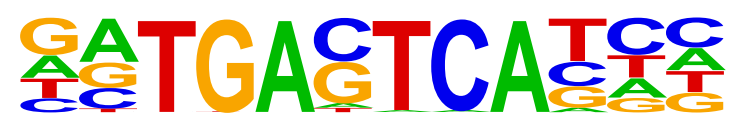
IEECTGAETCA

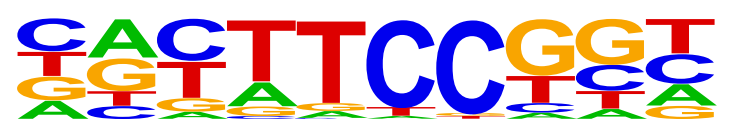

Transcription Factor

(Best Enrichment)

$\underline{P \text {-value }}$

ATF3

1e-198

FRA1

1e-191

JUNB

1e-187

AP-1

1e-184

BATF

1e-183

FRA2

1e-174

FOSL2

1e-160

Jun-AP1

1e-136

Bach2

1e-72

FLI1

1e-38

Figure S2. Transcription factor motif enrichment analysis in MIBC cell lines. Related to Figure 3. Image shows the top 10 transcription factor motifs enriched at MIBC enhancers. 
Known Motif

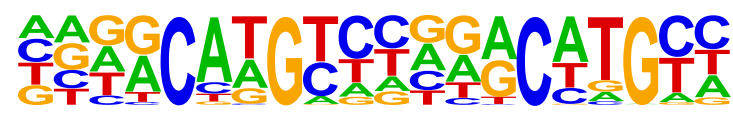

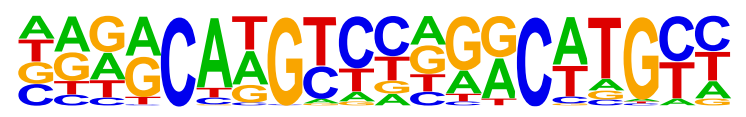

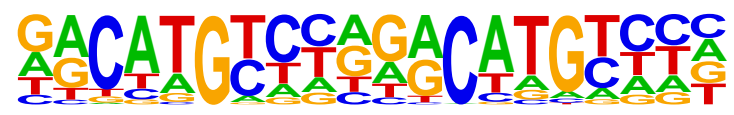

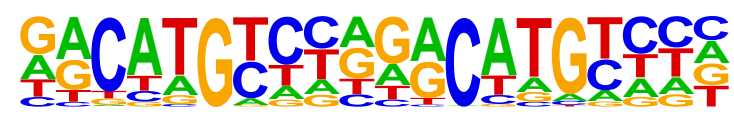

TGACCTTTCECCCCA

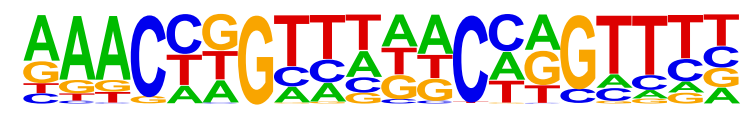

TAGGGCAAAGGTCA

舒AGGGTCAAGGTCA

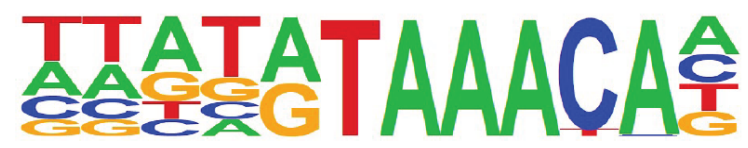

CACTCTTCCACGGAGC
Transcription Factor

(Best Enrichment)

P-value

p63

1e-12

p73

1e-7

p53

1e-5

p53

$1 e-5$

PPARG

$1 e-4$

GRHL2

$1 e-4$

RXR

$1 e-3$

PPARA

1e-3

FOXF1

1e-2

STAT3

1e-2

Figure S3. Transcription factor motif enrichment analysis in NMIBC cell lines. Related to Figure 3. Image shows the top 10 transcription factor motifs enriched at NMIBC enhancers. 
FRA1

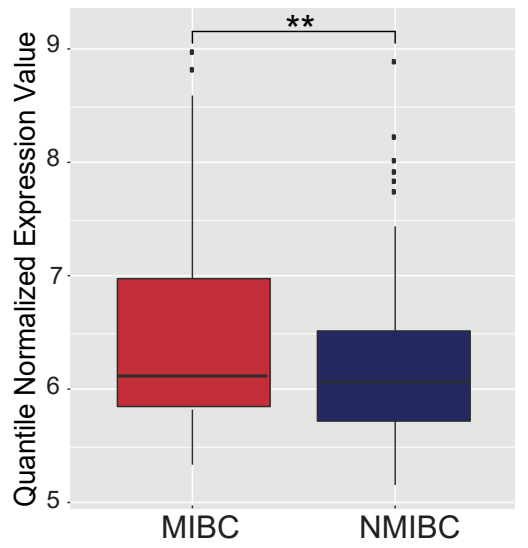

B

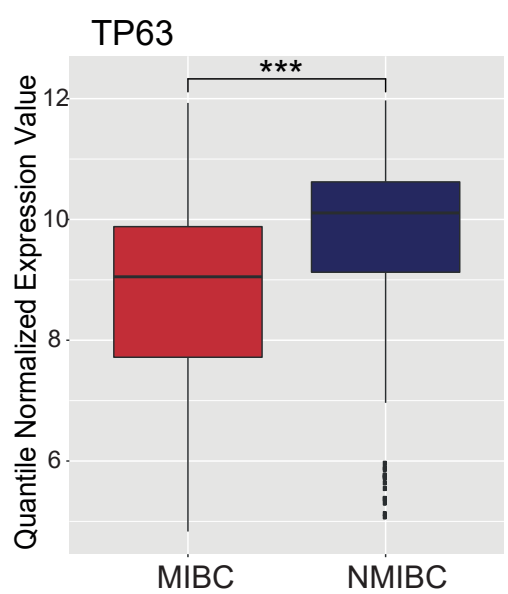

FLI1

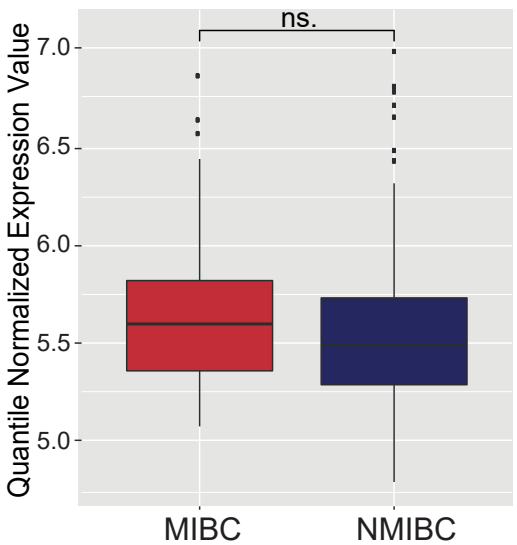

GRHL2

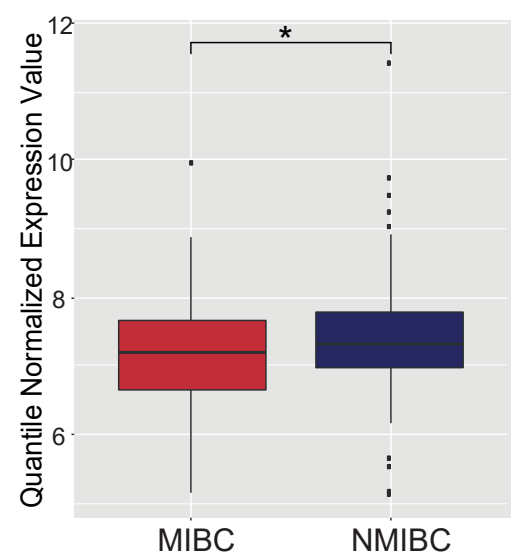

PPARG

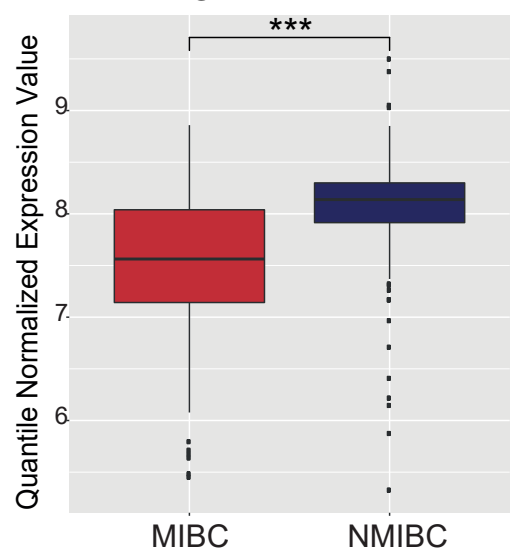

Figure S4. Expression level of transcription factors in primary MIBC and NMIBC tissue samples. Related to Figure 3. (A-B) Boxplots display the expression level of FRA1 and FLI1 (B) and the expression of TP63, GRHL2 and PPARG across the NMIBC $(n=213)$ and MIBC primary tissues $(n=93)$. ${ }^{*} p$ value $<0.05,{ }^{* *} p$ value $<0.01,{ }^{* * *} p$ value $<0.0001$, $n s=$ not significant 
A
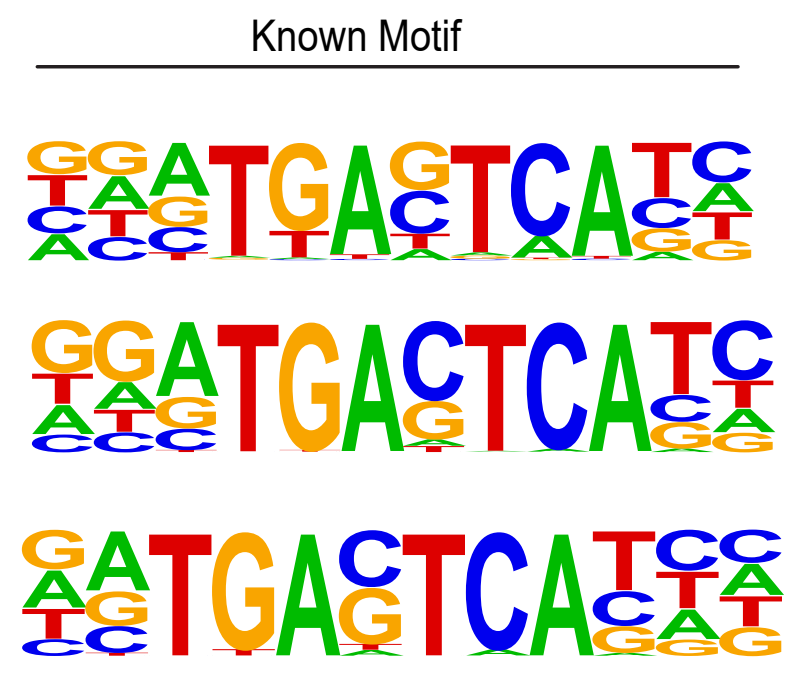

$\mathrm{B}$
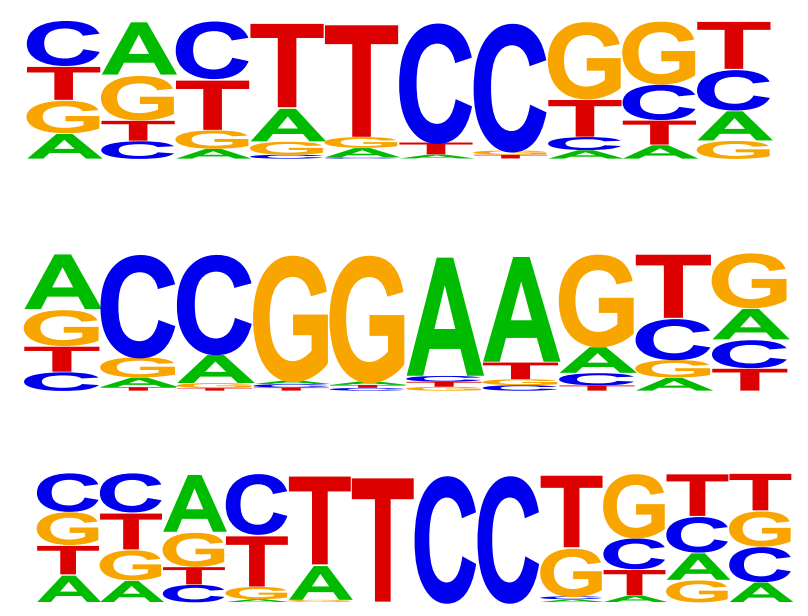

Transcription Factor

$\underline{\text { (Best Enrichment) }} \quad \underline{P \text {-value }}$

FRA1

$1 \mathrm{e}-13550$

FRA2

$1 e-13043$

ATF3

1e-12995

FLI1

$1 \mathrm{e}-1137$

ETV4

$1 \mathrm{e}-978$

ETV2

$1 e-971$

Figure S5. Motif enrichment analysis at FRA1 and FLI1 ChIP-seq peaks. Related to Figure 4. (A-B) Top three transcription factor motifs enriched for FRA1 (A) and FLI1 (B) ChIP-seq data. 
A

MYC

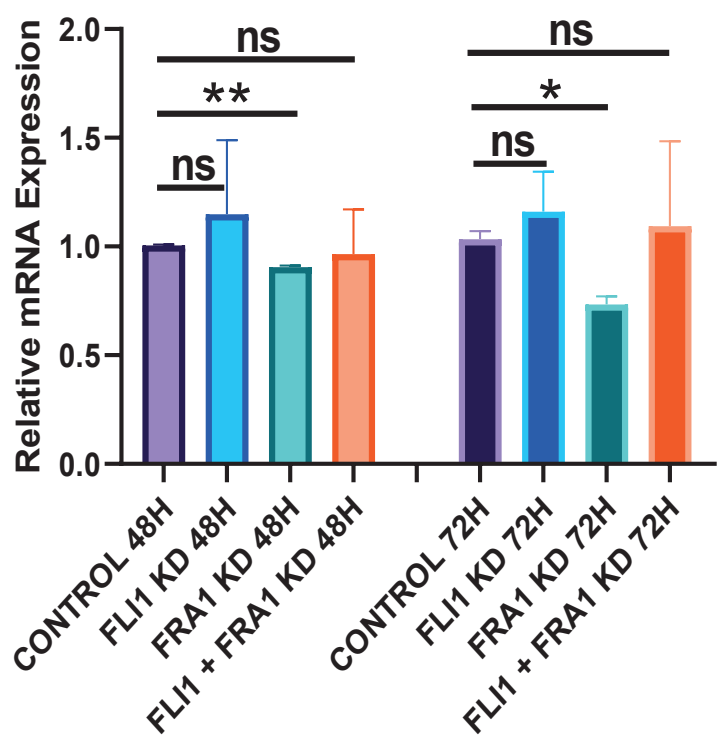

CD151

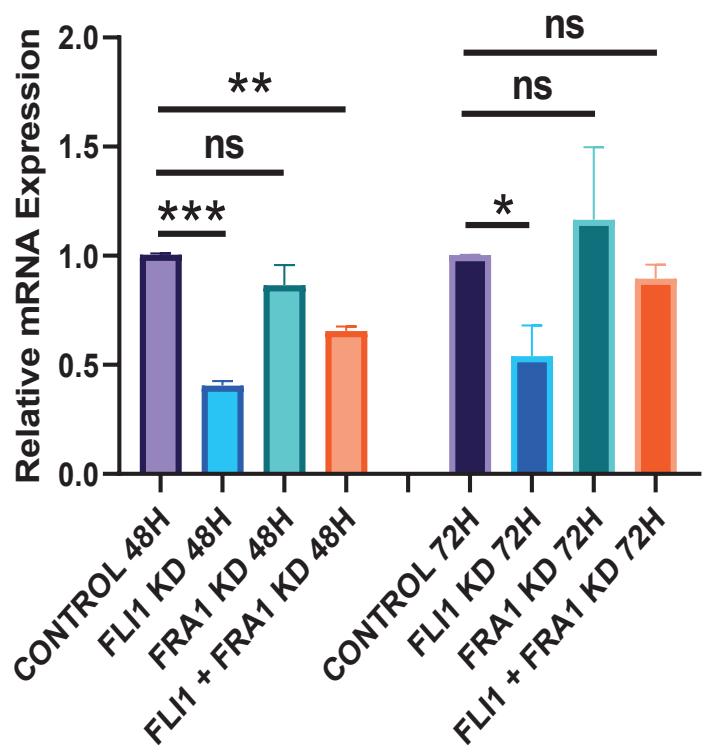

B

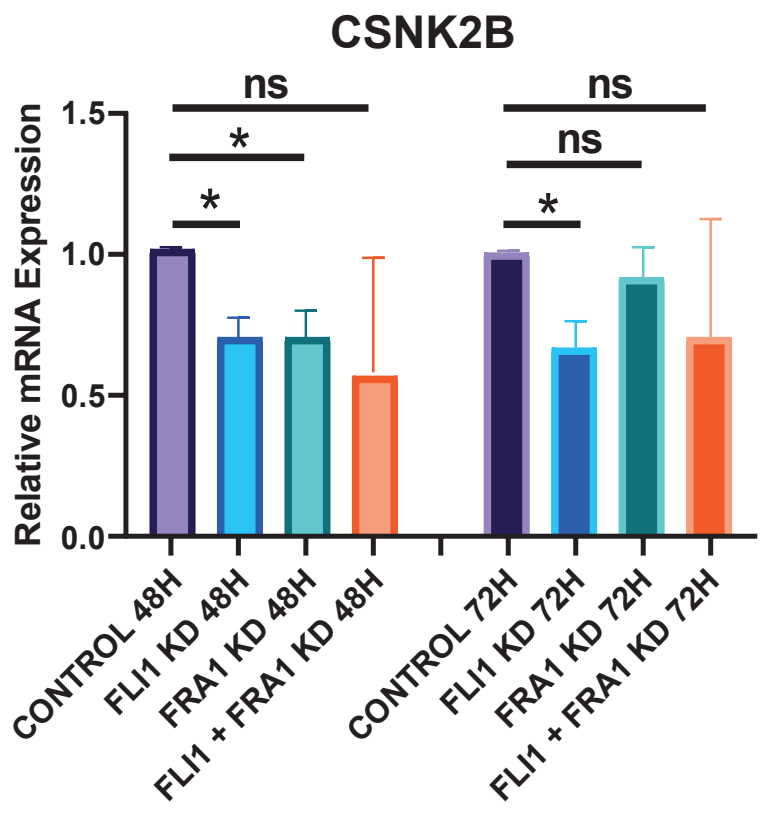

\section{TGFB2}

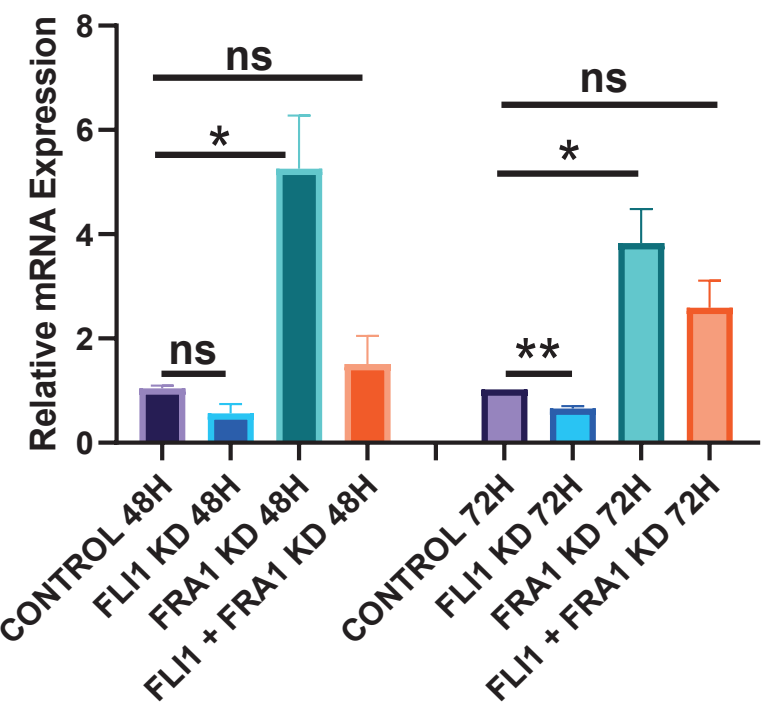

Figure S6. Expression level of EMT-related genes after FRA1 and FLI1 knockdown. Related to Figure 4. (A-D) Barplots display the relative mRNA levels of MYC (A), CSNK2B (B), CD151 (C), and TGFB2 (D). Error bars show the standard deviation of two biological replicates. Each biological replicate is analyzed in three technical replicates. ${ }^{*} p$ value $<0.05,{ }^{* *} p$ value $<$ $0.01,{ }^{* * *} p$ value $<0.001, \mathrm{~ns}=$ not significant. Snapshots below the barplots showing H3K27ac, FRA1 and FLI1 signals at the enhancer regions regulating the respective genes. 
A
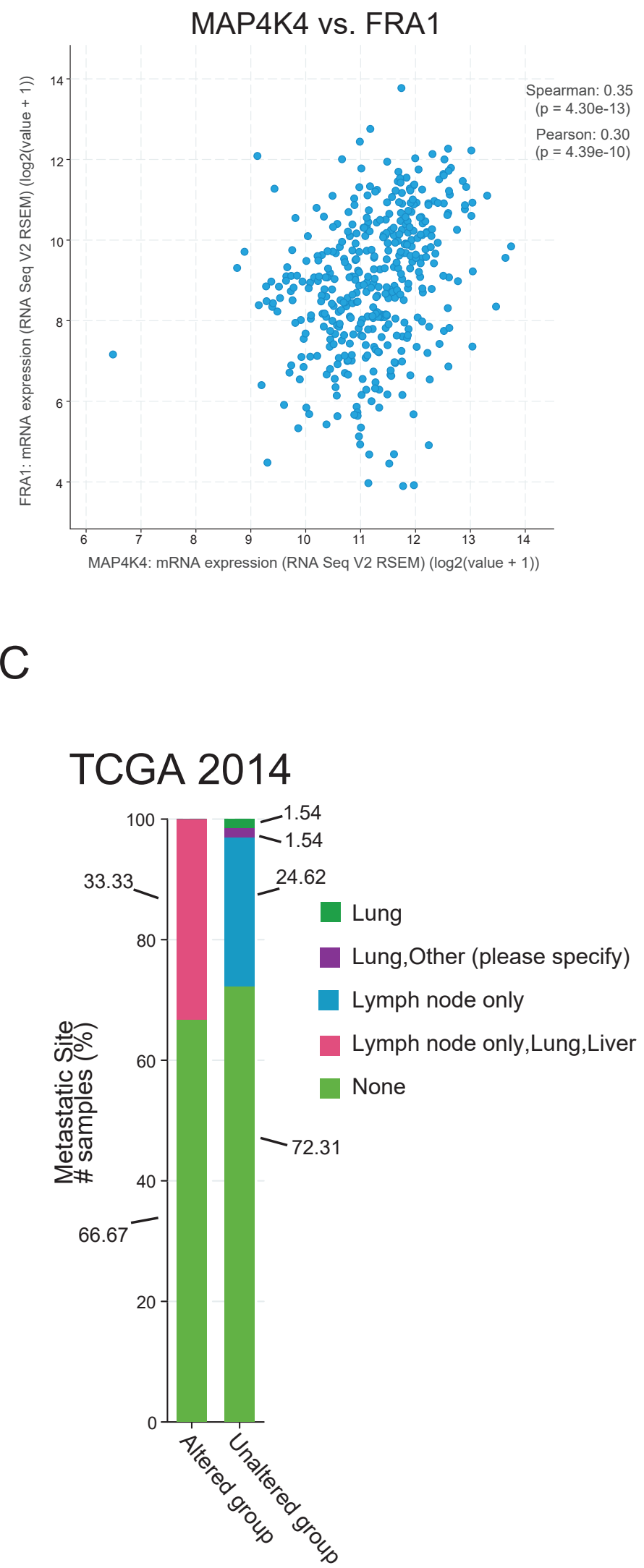

B
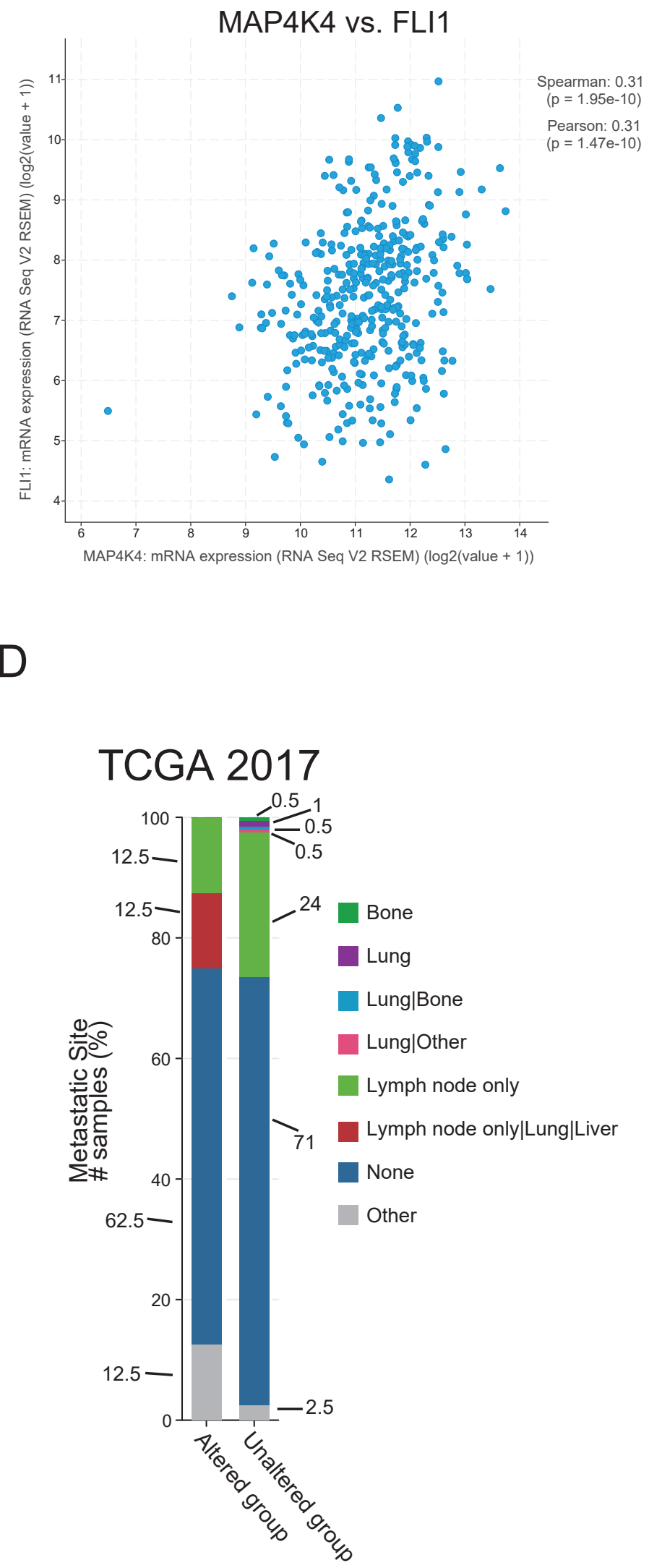

Figure S7. Association of MAP4K4 expression with metastatic potential of MIBC. Related to Figure 4. (A-B) Scatter plots display the correlation between the expression of FRA1 (A) and FLI1 (B) with MAP4K4 expression in primary tissue. (C-D) The samples with high MAP4K4 expression is determined in cbioportal database (83) (see Methods). Barplots show the distribution of metastatic sites in the patients with high expression and not high MAP4K4 expression in two different cohorts, TCGA $2014(C)(p$ value $=1.586 \mathrm{e}-4, q$ value $=5.868 \mathrm{e}-3)$ and TCGA $2017(\mathrm{D})(\mathrm{p}$ value $=1.878 \mathrm{e}-4, \mathrm{q}$ value $=4.508 \mathrm{e}-3)$. 
bioRxiv preprint doi: https://doi.org/10.1101/2021.11.22.468946; this version posted November 23, 2021. The copyright holder for this preprint (which was not certified by peer review) is the author/funder. All rights reserved. No reuse allowed without permission.

A

\begin{tabular}{|l|l|l|l|l|l|}
\hline Complex Name & Protein Name & Cell Line & Cancer Type & GEO ID & Available Data Type \\
\hline SWI/SNF Complex & SMARCA4 & $501 \mathrm{Mel}$ & Melanoma & GSM1517753 & wig file \\
\hline SWI/SNF Complex & SMARCA4 & TTC-549 & Liver rhabdoid tumor derived cell line & GSM1835892 & wig file \\
\hline SWI/SNF Complex & SMARCE1 & MCF7 & Breast adenocarcinoma & GSM2827281 & wig and peak file \\
\hline SWI/SNF Complex & SMARCE1 & MCF7 & Breast adenocarcinoma & GSM2827282 & wig and peak file \\
\hline SWI/SNF Complex & SMARCC1 & TTC-549 & Liver rhabdoid tumor derived cell line & GSM1835891 & wig file \\
\hline SWI/SNF Complex & SMARCC1 & BIN 67 & Small cell carcinoma of the hypercalcemic type derived & GSM3307888 & bigwig file \\
\hline SWI/SNF Complex & SMARCB1 & HeLa-S3 & Epithelial adenocarcinoma of uterus & GSM935635 & bigwig \\
\hline
\end{tabular}

$\mathrm{B}$

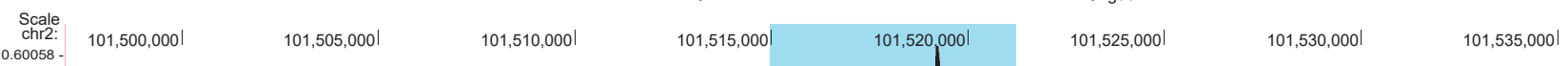

SMARCA4

SMARCA4

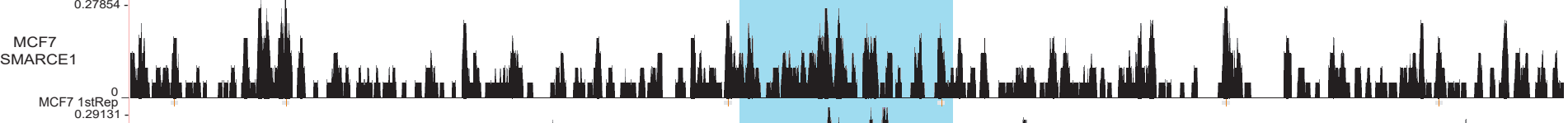

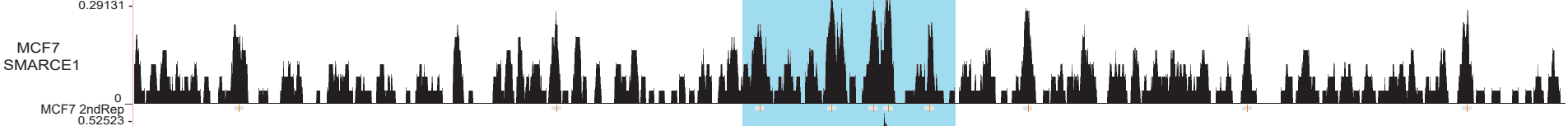

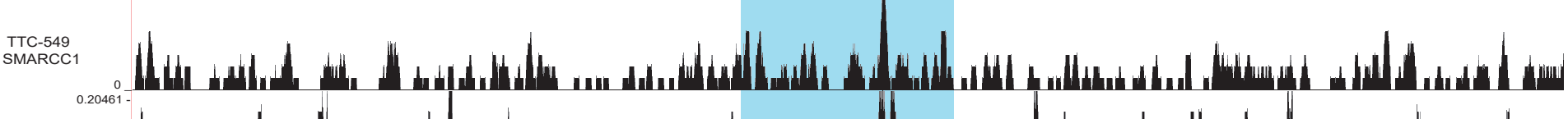

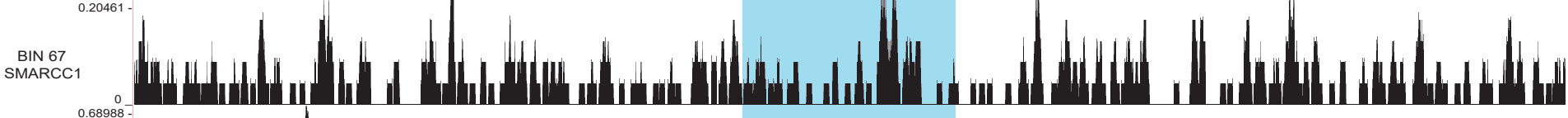
HeLa-S3
SMARCB1

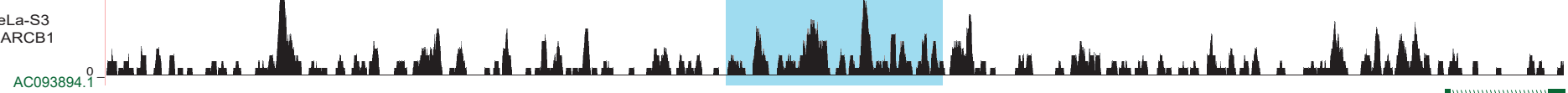

C

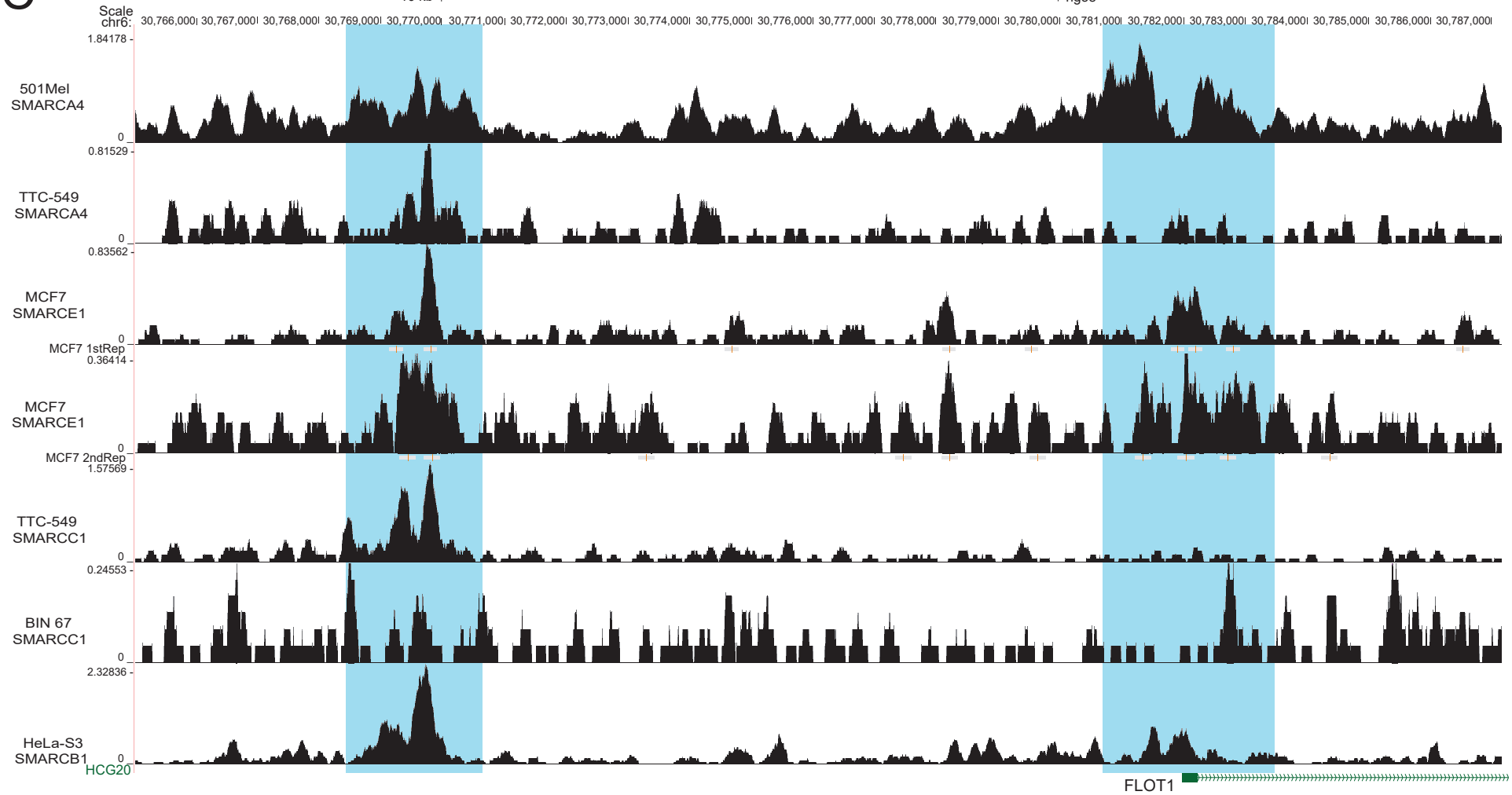

Figure S8. ChIP-seq signal of SWI/SNF complex components at MIBC enhancers regulating MAP4K4 and FLOT1. Related to Figure 6. (A) Summary of the used datasets. (B-C) Snapshot visualizations from UCSC Genome Browser (84), showing the localization of the SWI/SNF complex components according to data from (A) at enhancers regulating MAP4K4 (B) and FLOT1 (C). Blue highlights depict the respective enhancer regions. For FLOT1 gene, two enhancer regions involved in the regulation of this gene are shown. 
A

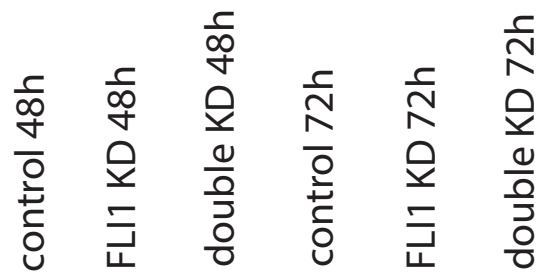

FLI1

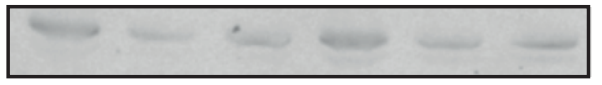

b-actin

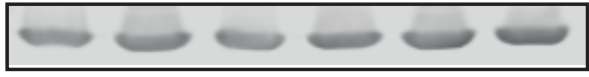

B

FRA1

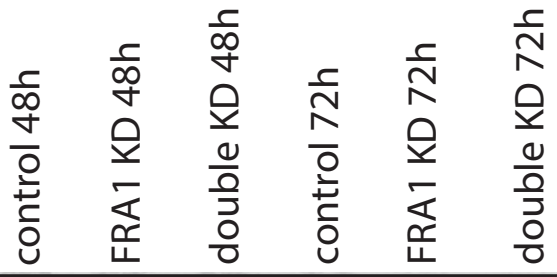

b-actin

Figure S9. Knockdown efficiency of FLI1 and FRA1 in cells used in IC-CHIP (A-B). Related to Figure 7. Western blot images show the FLI1 and FRA1 levels after FLI1 (A) and FRA1 knock-down. 


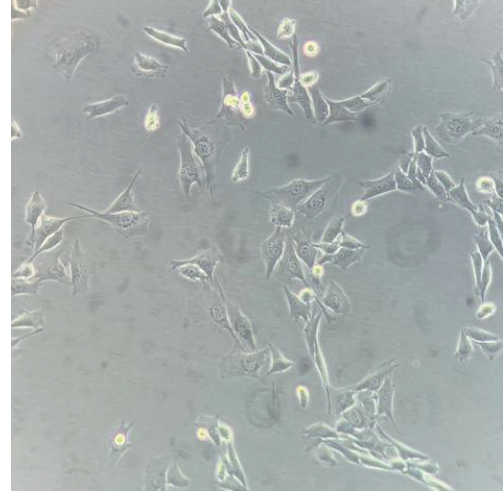

Day 1: Pre-Differentiation

DMEM with $10 \%$ FBS

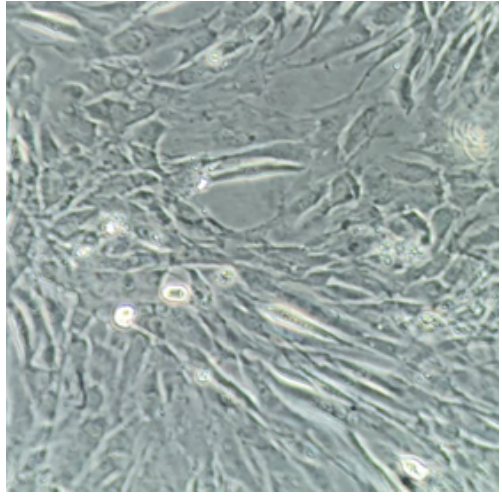

Day 3: Differentiation

DMEM with 10\% Horse Serum

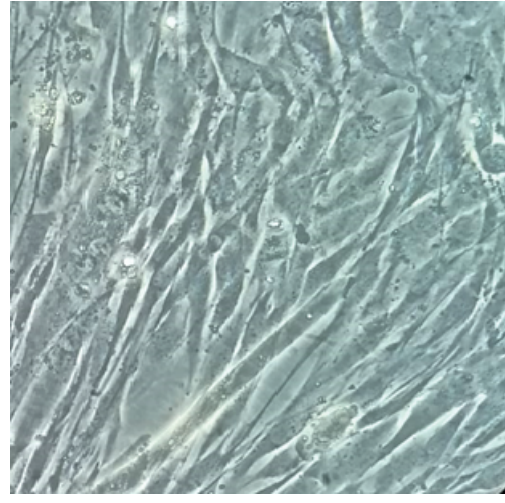

Day 5: Post-Differentiation

DMEM with $10 \%$ Horse Serum

B

FBS free medium
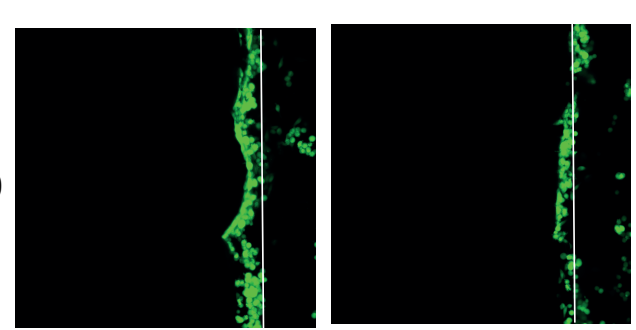

Day 1
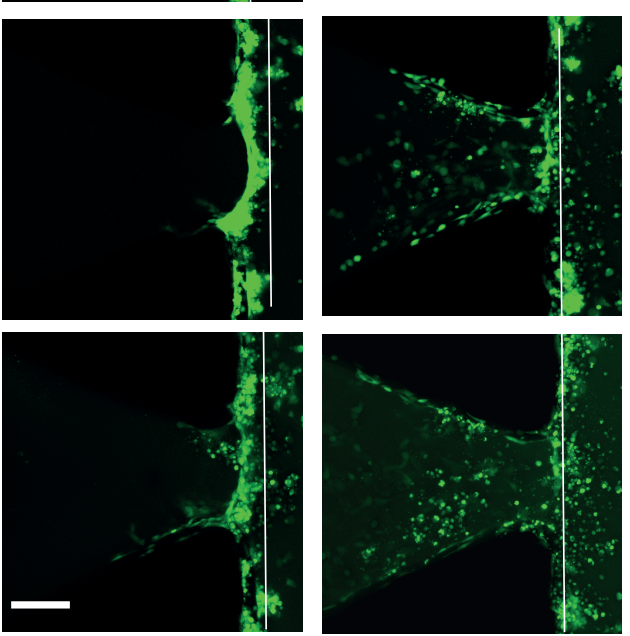

FBS free medium
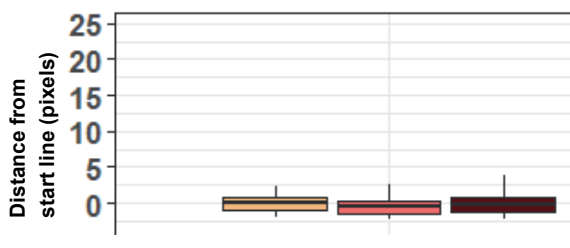

Days

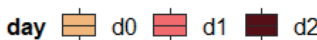

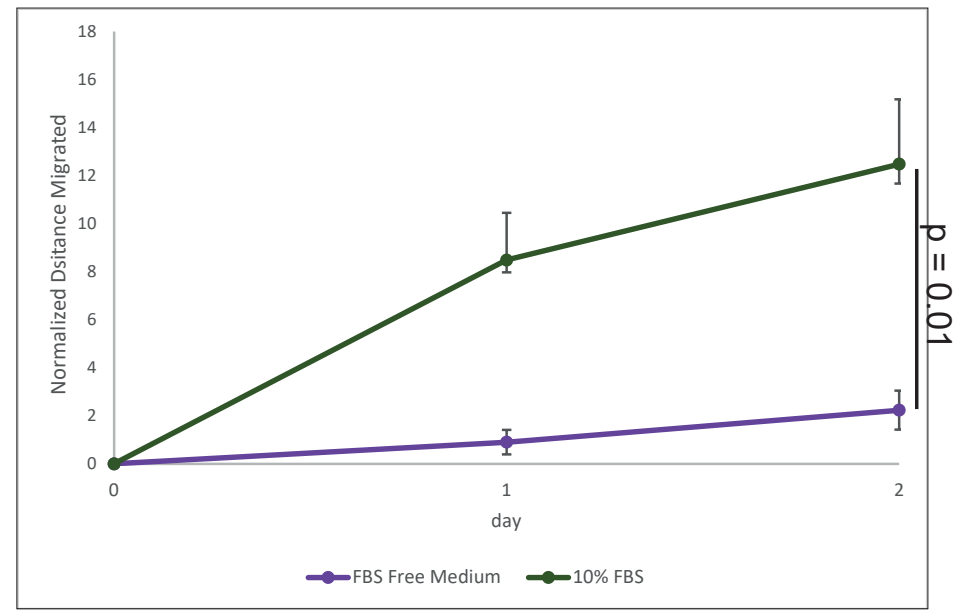

Figure S10. Differentiation of C2C12 cells and IC-CHIP assay in the presence and absence of FBS. Related to Figure 7. (A) The images show the differentiation of C2C12 myoblast cells to muscle for 4 days in the presence of $10 \%$ horse serum. (B) Comparison of the invasive capacity of T24 cells in the presence of $0 \%$ FBS and $10 \%$ FBS. Left panels show the representative Z-stack projection images for different conditions. Scale bar: 100 $\mu \mathrm{m}$. Boxplots display the distribution of the distance from the start line (right upper panel). Line graphs show the mean distance values with the error bars $(n=6)$ from day 0 to day 2 . The data is normalized to day 0 (right lower panel). Student's t-test (two-tailed) was used for the statistics. 
A

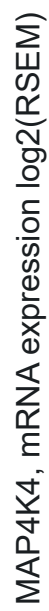

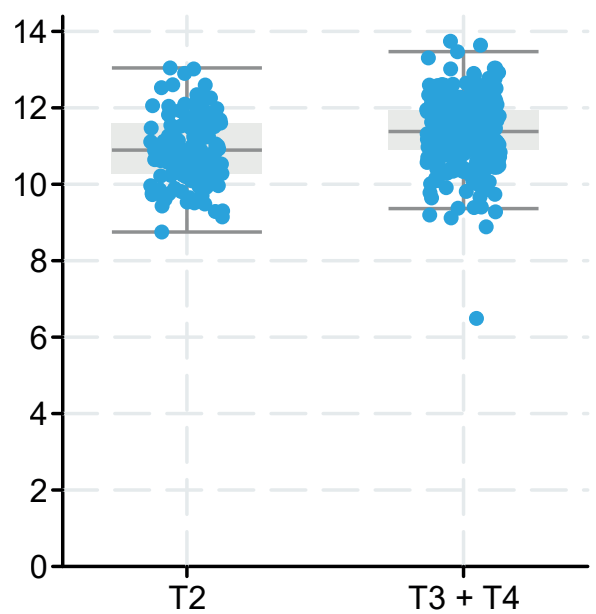

p-Value: $3.107 e-6$

q-Value: $1.073 e-4$

Group (Stage of the tumor)

B

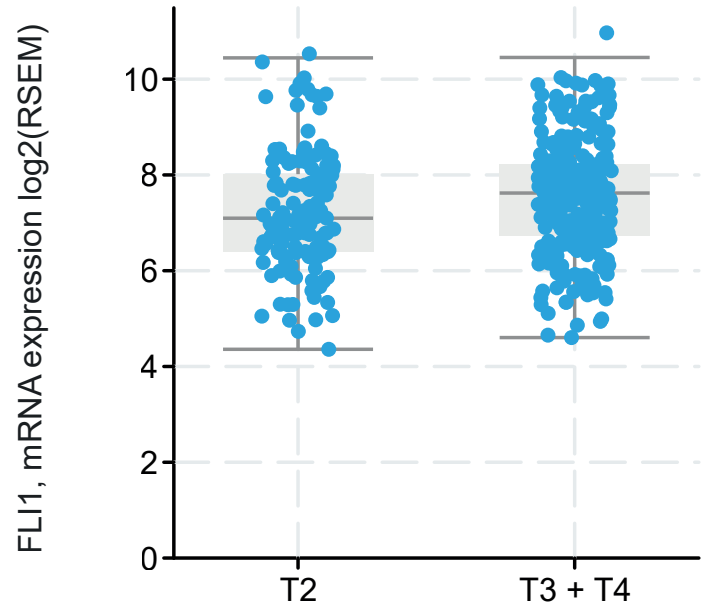

p-Value: 0.0205

q-Value: 0.0869

Group (Stage of the tumor)

C

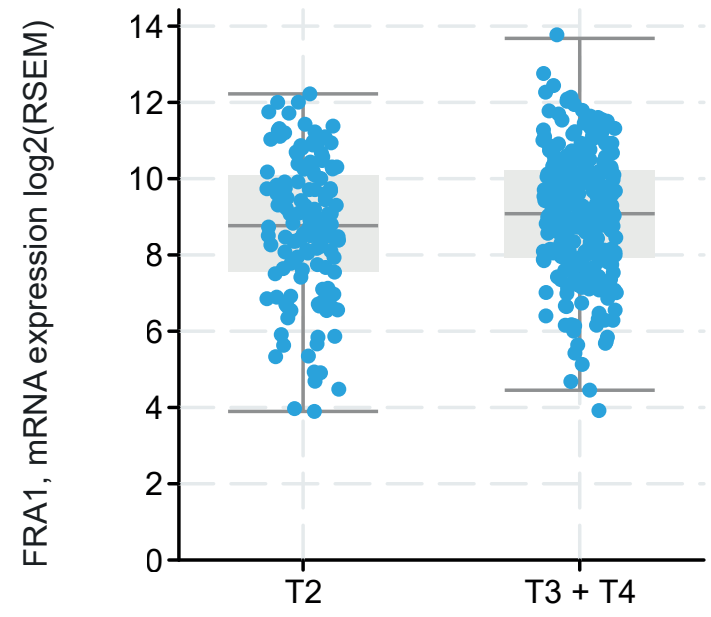

p-Value: 0.0725

q-Value: 0.203

Group (Stage of the tumor)

Figure S11. Expression of key MIBC genes in T2 vs T3-T4 stage MIBC patients. (A-C) Related to Figure 7. Boxplots show the expression of MAP4K4 (A), FLI1 (B) and FRA1 (C) in T2 stage and T3-T4 stage MIBC patients. 